\author{
Federal Reserve Bank of New York \\ Staff Reports
}

\title{
Regional Heterogeneity and \\ the Refinancing Channel of Monetary Policy
}

\author{
Martin Beraja \\ Andreas Fuster \\ Erik Hurst \\ Joseph Vavra
}

Staff Report No. 731

June 2015

Revised March 2018

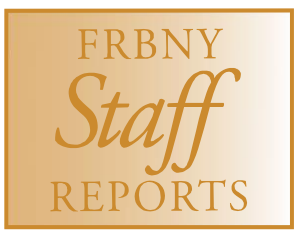

This paper presents preliminary findings and is being distributed to economists and other interested readers solely to stimulate discussion and elicit comments. The views expressed in this paper are those of the authors and do not necessarily reflect the position of the Federal Reserve Bank of New York or the Federal Reserve System. Any errors or omissions are the responsibility of the authors. 


\author{
Regional Heterogeneity and the Refinancing Channel of Monetary Policy \\ Martin Beraja, Andreas Fuster, Erik Hurst, and Joseph Vavra \\ Federal Reserve Bank of New York Staff Reports, no. 731 \\ June 2015; revised March 2018 \\ JEL classification: E21, E52, G21
}

\begin{abstract}
We argue that the time-varying regional distribution of housing equity influences the aggregate consequences of monetary policy through its effects on mortgage refinancing. Using detailed loan-level data, we show that regional differences in housing equity affect refinancing and spending responses to interest rate cuts but that these effects vary over time with changes in the regional distribution of house price growth. We then build a heterogeneous household model of refinancing with both mortgage borrowers and lenders and use it to explore the aggregate implications for monetary policy arising from our regional evidence. We find that the 2008 equity distribution made spending in depressed regions less responsive to interest rate cuts, thus dampening aggregate stimulus and increasing regional consumption inequality, whereas the opposite occurred in some earlier recessions. Taken together, our results strongly suggest that monetary policy makers should track the regional distribution of equity over time.
\end{abstract}

Key words: monetary policy, regional inequality, quantitative easing, mortgage refinancing

Fuster: Federal Reserve Bank of New York (email: andreas.fuster@ ny.frb.org). Beraja: MIT and NBER (email: martinberaja @ gmail.com). Hurst, Vavra: University of Chicago Booth School of Business and NBER (emails: erik.hurst@ chicagobooth.edu, joseph.vavra@ chicagobooth.edu). This paper, previously distributed under the title "Regional Heterogeneity and Monetary Policy," was originally prepared for a June 2015 conference on monetary policy and inequality at the Hutchins Center on Fiscal and Monetary Policy at the Brookings Institution. The authors thank Caitlin Gorback, Karen Shen, and Eilidh Geddes for excellent research assistance. For helpful comments, the authors thank their discussants John Campbell, Wouter Den Haan, Daniel Greenwald, Amit Seru, Junyi Zhu, and Mark Zandi, as well as Adrien Auclert, Arlene Wong, and seminar participants at Chicago Booth, University of Minnesota, NYU, MIT Sloan, Berkeley Haas, IIES Stockholm, University of Zurich, Central Bank of Ireland, NBER Summer Institute, the ECB Annual Research Conference, ASSA Chicago, SED-Edinburgh, SITE Stanford, Hutchins Center at Brookings, the Frontiers in Central Banking conference at the Bundesbank, and the CEPR-University of St. Gallen workshop on Household Finance and Economic Stability. The views expressed in this paper are those of the authors and do not necessarily reflect the position of the Federal Reserve Bank of New York or the Federal Reserve System. 


\section{Introduction}

Collateralized borrowing in the housing market can potentially play an important role in the monetary transmission mechanism, as interest rate cuts encourage households to refinance their mortgage and extract home equity to fund current consumption. ${ }^{1}$ Since housing markets are locally segmented, regional house price shocks are a critical determinant of home equity and the strength of this refinancing channel of monetary policy.

In this paper, we argue that the time-varying regional distribution of home equity plays a crucial role in determining both the aggregate effects of monetary stimulus and whether this stimulus flows to the regions which need it most. Our analysis is motivated by striking differences across recessions in the cross-region distribution of house price growth. During the Great Recession, house prices fell substantially on average, but declines varied greatly across space and were largest where economic activity also fell most (e.g., Nevada). In contrast, house prices grew on average throughout the 2001 recession with little regional variation. The resulting differences in the regional equity distribution across these recessions affect the refinancing channel of monetary policy for two reasons. First, lenders generally require a minimum level of equity in order to allow borrowers to refinance, even if they are not extracting equity. Second, the level of equity potentially extracted during refinancing clearly depends on the existing level of equity in the house prior to refinancing.

Our paper begins by using detailed micro-data to show that interest rate declines during the Great Recession mostly stimulated regions with the smallest declines in house prices (which also had the smallest increases in unemployment). In contrast, refinancing was strongest in high unemployment regions in the 2001 recession, when regional house price growth was mostly uncorrelated with unemployment. Then, we build a heterogeneous household model of refinancing and use it to explore aggregate implications of this regional evidence for monetary policy. Our model implies that interest rate cuts in 2008 indeed had the smallest effects on depressed regions. More importantly, the regional distribution of housing equity in 2008 substantially dampened the aggregate effects of monetary policy. Since the distribution of equity both varies across time and changes the consequences of monetary policy, we conclude that it is important for policy makers to track this variation. Furthermore, we show how certain mortgage market policy interventions can successfully complement monetary policy if the refinancing channel is again hindered in the future.

In more detail, the first half of our paper provides empirical evidence that regional variation in housing equity matters for the refinancing channel of monetary policy. We start by studying the response of different regions to the large interest rate declines immediately following the first round of the Federal Reserve's large-scale asset purchase program—commonly called quantitative easing (QE1). Based on loan-level data, we document three facts about the regional response to QE1. First, there was a boom in household mortgage refinancing right after the QE1 announcement. Second, refinancing activity and the amount of equity extracted increased more in metropolitan statistical areas (MSAs) that had lower unemployment and where homeowners had more housing equity on the eve of QE1. Specifically, very little refinancing occurred in places like Las Vegas, where most homeowners were underwater when QE1 was implemented. Third, MSAs with the most refinancing right after QE1 also

\footnotetext{
${ }^{1}$ See e.g. https://www.federalreserve.gov/boarddocs/hh/2004/february/testimony.htm and https://www. newyorkfed.org/newsevents/speeches/2012/dud120106.html for recent policy discussion of this channel.
} 
experienced the largest resulting increases in consumption, as measured by car purchases.

The effects of equity on refinancing are robust to a variety of controls and are economically meaningful. The increase in refinancing in response to QE1 more than doubles when moving from the bottom to the top quartile of MSAs by home equity. The additional equity extracted in these high equity MSAs is comparable to total unemployment benefits paid out in low equity MSAs in 2009, and our estimates imply that QE1 led to almost 250,000 additional car purchases in these high equity MSAs. Overall, these facts show that, during the Great Recession, the refinancing channel of monetary policy was weakest in the regions with the worst housing and labor market conditions.

Our second set of empirical results moves beyond QE1 to provide evidence that the consequences of monetary policy vary over time. First, we show there is large variation in the cross-region distribution of house price growth, and thus home equity, across different recessions over the last forty years. While we have long time-series for local house prices, it is more difficult to measure local refinancing activity in historical data. However, we are able to do so for the 2001 recession. Importantly, house price patterns were very different in 2001 than in 2008. In particular, aggregate house prices grew throughout the 2001 recession, and regional house price growth varied little across regions and was mostly uncorrelated with regional unemployment. Furthermore, we show that refinancing was higher in the 2001 recession than in the 2008 recession despite similar declines in interest rates. In addition, refinancing increased most in high unemployment MSAs in 2001 whereas the opposite was true in 2008. Finally, using aggregate (rather than regional) refinancing data going back to the early 90 s, we present evidence that the aggregate refinancing response to interest rate changes varies systematically with features of the regional house price growth distribution.

In the second half of the paper, we ask: what does this regional evidence imply for the aggregate consequences of monetary policy? Answering this question without a theoretical model is challenging. First, many features of the regional equity distribution move over time. With only a small number of recessions, it is essentially impossible to determine directly from the data which particular features of this distribution determine the strength of the refinancing channel of monetary policy. Second, echoing ideas in Beraja, Hurst, and Ospina (2016), drawing conclusions about aggregate spending from regional evidence requires accounting for offsetting behavior by lenders which cannot be measured in our data. An analysis of aggregation and counterfactuals then requires a formal model.

Thus, we build an equilibrium, incomplete-markets, heterogenous agents model with both mortgage borrowers and lenders. The goal of the model is to clarify the channels through which the regional distribution of equity matters for aggregate policy making and to explore whether the empirical effects we document at the regional level are indeed of any quantitative consequence for aggregates. While the exact magnitudes vary somewhat with different model assumptions and calibrations, we always find that regional variation has quantitatively important aggregate implications for monetary policy.

The key model feature driving our results is the inclusion of mortgage borrowers who face house price and income risk and can refinance mortgages and extract housing equity by paying a fixed cost. This implies refinancing decisions which follow threshold rules around some inaction region, in the spirit of Arrow, Harris, and Marschak (1951), Barro (1972), or Sheshinski and Weiss (1977). Households must satisfy a collateral requirement to refinance, so when interest rates fall, those with substantial equity can reduce their interest rate while also extracting equity whereas those currently underwater would need to put up additional cash. Hence, when interest rates fall, many households 
with positive equity refinance and further increase consumption by extracting equity, whereas almost no households with negative equity do. This leads to consumption responses to interest rate cuts that are highly convex in equity because households that are mildly underwater exhibit the same zero response as those substantially underwater, whereas households with substantial positive equity exhibit much stronger consumption changes than those with mildly positive equity. This convexity then implies that changing the distribution of equity affects the economy's response to rate declines. Thus, while the model includes many quantitatively realistic features and is rich enough to capture key aspects of the data shown in the first part of the paper, it delivers transparent intuition for why the refinancing channel depends crucially on the distribution of equity.

Our first quantitative results focus on the consequences of interest rate cuts in a benchmark economy that matches the joint distribution of housing equity and income observed in 2008. To discipline this exercise, we pick baseline parameters so our model matches the regional effects of QE1 documented in the first part of the paper and then compute the aggregate effects of this policy. We find that a decline in interest rates of the magnitude observed after QE1 modestly raises aggregate spending. This implies that the spending offset coming from lenders in equilibrium is not one-for-one, which occurs because our model features an important role for cash-out activity in determining spending. Households accumulate equity over time and periodically pay a refinancing cost to access this equity. Furthermore, since borrowers are more liquidity constrained than lenders, equity extraction increases spending on net. When interest rates decline, refinancing and equity extraction are accelerated and aggregate spending rises. However, under 2008 economic conditions, this aggregate spending effect is quantitatively small. As in our empirical analysis, we also find that monetary stimulus mainly flows to regions that are doing relatively well and thus amplifies cross-region consumption inequality.

In contrast, when we simulate the response to the same change in interest rates under economic conditions in 2001, we find very different effects: monetary policy generates much larger aggregate spending responses, and it actually mildly reduces cross-region inequality. These conclusions depend importantly on the fact that in 2001, aggregate house price growth is positive and local house price growth is essentially uncorrelated with local economic conditions.

Then, we ask: what can policy makers do in situations like 2008, when monetary policy's effectiveness through the refinancing channel is hindered? We show that targeted debt reduction and relaxation of collateral constraints for refinancing can amplify the stimulative effects of monetary policy and also reduce the trade-off with inequality. Policies along these lines were implemented during the Great Recession (though only after the large drop in interest rates we study) through the Home Affordable Modification and Refinance Programs (HAMP and HARP), and our results show that such mortgage market interventions can successfully complement monetary policy.

More generally, our model has interesting implications for the interaction between mortgage market design and the strength of the refinancing channel. It is often assumed that monetary policy should be more effective with adjustable-rate mortgages (ARMs) than with fixed-rate mortgages (FRMs) since households with ARMs automatically receive payment reductions when rates fall. Our model shows that this intuition is incomplete: while it is true that ARMs generate spending that is more sensitive to interest rates during times of low equity, the reverse is true when equity is high and refinancing constraints do not bind. This is because when FRM borrowers actively refinance, they can extract equity and front-load their increased spending, while passive rate resets under ARMs do not result in 
equity extraction. This means that whether ARMs amplify or dampen the effectiveness of monetary policy cannot be answered without knowing the distribution of equity in the economy.

Finally, it is useful to discuss the practical implications of our results for policy making. Central banks typically have no mandate to reduce spatial inequality or eliminate regional business cycles, and it is not clear that monetary policy has the tools necessary to address such concerns even if they wanted to. However, monetary policy makers do care about aggregates. Our results highlight that the aggregate impact of monetary policy depends importantly on the regional distribution of housing equity. Furthermore, even if central banks focus only on aggregate stabilization, their actions will nevertheless have consequences which vary across space. Such regional effects may in turn be important for the design of national fiscal policy, which is often the policy instrument of choice for stabilizing regional business cycles. State and other local authorities also have an obvious interest in forecasting the local consequences of monetary policy. Thus, even if central banks themselves only use regional information to more precisely estimate aggregate effects of their actions, there are still many additional reasons to understand the local implications of monetary policy.

We note that while our empirical analysis focuses mostly on QE1 since it provides a relatively well-identified shock to mortgage rates, our conclusions also apply to conventional monetary policy. Because conventional expansionary monetary policy also lowers mortgage rates, it will have similar time-varying interactions with the equity distribution. ${ }^{2}$

We study the distribution of equity and inequality across regions rather than across households within regions for similar practical reasons. Changes in the individual equity distribution in our data are mostly driven by regional house price movements, and regional house price data is more readily available at high frequencies than data on individual equity so regional distributions are a more practical input for policy making. ${ }^{3}$ In addition, inequality within regions is largely determined by income and wealth heterogeneity rather than by the refinancing channel of monetary policy.

\section{Related Literature}

Our work is related to much existing research. We depart from the New Keynesian literature which typically assumes frictionless household capital markets with one-period borrowing. In reality, the bulk of household borrowing occurs through the mortgage market, which features collateral requirements and long-term fixed nominal payments that can only be refinanced at some cost. Together, these features give rise to what we call the "refinancing channel" of monetary policy, which we show depends on the time-varying distribution of housing equity in the economy. We thus contribute to the growing literature arguing that the economy exhibits time-varying responses to aggregate shocks which depend on the microeconomic distribution of agents. ${ }^{4}$ Most closely related of these papers is Berger et al. (2015) who argue that increases in household leverage during the housing boom contributed to the large decline in spending when house prices subsequently crashed. Interestingly, we show here

\footnotetext{
${ }^{2}$ See, e.g., Gertler and Karadi (2015) or Wong (2016). There is time-variation in the pass-through from short rates to long-term bond yields (e.g., Hanson, Lucca, and Wright, 2017) and from long-term yields to mortgage rates (e.g., Fuster, Lo, and Willen, 2017), but we find no systematic relationship of this pass-through with house price growth, a proxy for equity.

${ }^{3}$ Equity also varies due to leverage differences at origination, differential equity extraction and amortization, and due to sub-region house price shocks which is why we use equity rather than house price growth in our analysis when available.

${ }^{4}$ See, e.g., Caballero and Engel (1999), Vavra (2014), Berger and Vavra (2015), and Winberry (2016).
} 
that these same leverage patterns hampered monetary policy's ability to stimulate the economy.

We are not the first to model monetary policy transmission through the mortgage market. Rubio (2011), Garriga, Kydland, and Sustek (2013) and Greenwald (2016) also model this channel but using a representative borrower. This means their models have no role for the distribution of housing equity which is at the heart of our paper. Our focus on realistic modeling of household borrowing and how it interacts with heterogeneity in the economy parallels many of the themes in Auclert (2015), who argues that the covariance of the marginal propensity to consume with interest rate exposure across agents matters for aggregate consumption responses to rate changes. His analysis abstracts from refinancing, which we show interacts with the time-varying distribution of housing equity. Wong (2016) uses a model closer to our own, but in partial equilibrium and she focuses on how aging affects monetary policy. Since the age distribution changes slowly across time, age effects are more relevant for crosscountry comparisons and long-run trends than for shorter-run changes in the refinancing channel of monetary policy. Guren, Krishnamurthy, and McQuade (2017) and Hedlund et al. (2017) build general equilibrium models with heterogeneity but use them to study alternative mortgage designs and housing market liquidity, respectively.

On the empirical front, Fuster and Willen (2010) measure effects of QE1 on the primary US mortgage market. They emphasize differential effects on borrowers with different creditworthiness, while we emphasize regional disparities. Di Maggio, Kermani, and Palmer (2016) study refinancing responses to quantitative easing and replicate our facts at the state-level, but their focus is on the timevarying composition of Fed asset purchases and their effects on conforming and non-conforming loans. Our empirical patterns in the QE1 episode are similar to those documented by Caplin, Freeman, and Tracy (1997) for the 1990 recession based on mortgage data from a single bank. We use more representative data over a longer time period and present a model that allows us to analyze aggregate implications and counterfactuals. Our results on spending effects of mortgage payment reductions and cash-out activity are in line with related findings by Bhutta and Keys (2016), Di Maggio et al. (2017), Agarwal et al. (2017), and Abel and Fuster (2018). There is also a growing literature using aggregate VARs to document that responses to monetary policy vary with regional housing markets (Fratantoni and Schuh, 2003) and household debt (Alpanda and Zubairy, 2017).

Finally, a large literature studies a "credit channel" of monetary policy, where changes in collateral values amplify output responses to rate changes. ${ }^{5}$ This channel is complementary but distinct from ours, as it arises from monetary policy changing collateral values which, in turn, affect economic activity. In contrast, we take the distribution of collateral at a point in time as given and show that it affects the transmission from interest rates to spending. We think both channels are important and exploring their interaction is an interesting area for future work.

\section{Data}

We briefly describe our primary mortgage-related data here. The Online Appendix provides additional details as well as discussion of other data used in our analysis.

Our main local refinancing measures come from Equifax's Credit Risk Insight Servicing McDash

\footnotetext{
${ }^{5}$ For example, Iacoviello (2005) shows that adding collateral constraints on housing to a financial accelerator model like that in Bernanke, Gertler, and Gilchrist (1999) amplifies the effects of rate changes.
} 
(CRISM) data set. This data set merges McDash mortgage servicing records (from Black Knight Financial Services) with credit bureau data (from Equifax) and is available beginning in 2005. The structure of the data set makes it possible to link multiple loans by the same borrower together, something that is not possible with mortgage servicing data alone. This allows us to measure refinancing activity much more accurately than what can be achieved with previous data. Since we know both the outstanding amount of the old loan (as well as any second liens) and the new loan, we can measure the dollar amount of equity removed (or "cashed out") from the home during refinancing. CRISM covers roughly two-thirds of the US mortgage market during the period we study.

We also use CRISM data to measure borrowers' home equity. We define home equity as one minus the household's combined loan-to-value (CLTV) ratio, which we estimate for each household by adding balances of first mortgages and any second liens and dividing by estimated property values. We estimate property values using appraisal values at loan origination, which we then update using location-specific house price indices from CoreLogic. Our preferred summary statistic for local equity conditions is the equity of the median borrower in a location. ${ }^{6}$ This statistic $E_{j, t}^{\text {med }}$ varies across MSAs $j$ and time $t$. We particularly emphasize $E_{j, \text { Nov2008 }}^{\text {med }}$ median equity in November 2008, just prior to QE1.

We supplement our analysis of refinancing activity using data from the Home Mortgage Disclosure Act (HMDA). For each mortgage application, HMDA data reports a variety of loan characteristics including loan purpose (purchase or refinance) and property location. HMDA data has broader coverage over a longer time period than CRISM data, which allows us to extend our analysis to the 2001 recession. However, it does not contain information on outstanding loans, which is necessary for measuring both the equity distribution and equity removed during refinancing. In the Appendix, we show that regional refinancing patterns after QE1 are nearly identical in HMDA and CRISM data.

\section{The Refinancing Channel Across Regions: Evidence from QE1}

This section documents several facts relating regional heterogeneity in housing equity to the refinancing channel. We use an event-study of the interest rate decline following QE1 to show: (1) mortgage originations increased substantially after QE1, mostly driven by households refinancing existing mortgages rather than by an increase in new purchases; (2) refinancing activity and equity extraction were higher in MSAs where homeowners had more equity (which were also locations where unemployment was lower) prior to QE1; and (3) car purchases increased the most after QE1 for individuals who removed equity when refinancing and in MSAs with the largest refinancing response.

\subsection{Aggregate Trends in Mortgage Activity Around QE1}

Figure 1 shows the monthly Mortgage Bankers Association Refinance Index from 2000 to 2012 (solid line) as well as the difference between the 30-year fixed-rate mortgage (FRM) rate in month $t$ and the average of the 30-year mortgage rate over the prior five years (dashed line). Negative values mean mortgage rates in a given month are low relative to previous years, giving many borrowers an incentive to refinance. Several points stand out in Figure 1. First, there is a strong negative relationship between

\footnotetext{
${ }^{6}$ We compute medians weighting borrowers by outstanding mortgage balances. Repeating our analysis using the fraction of borrowers with CLTV above 0.8 or above 1 yields very similar results.
} 
Figure 1: Mortgage Refinancing Activity in the US over 2000-2012

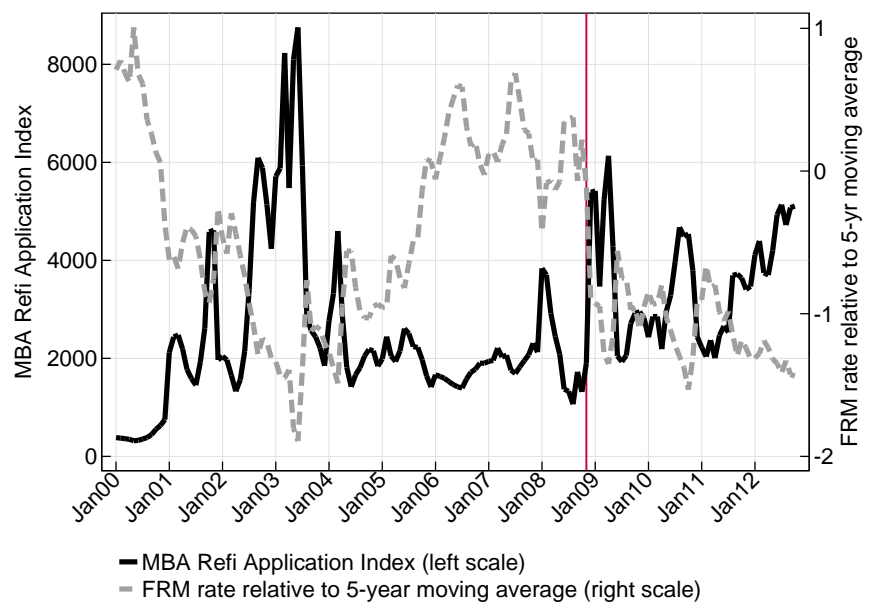

Figure shows monthly average of Mortgage Bankers Association (MBA) Refinancing Index (seasonally adjusted; March $1990=100$ ) and the 30-year fixed-rate mortgage rate (relative to 5-year moving average), also from MBA.

refinancing and mortgage rates: the correlation between the two series is -0.77 . Second, mortgage rates fell and refinancing activity expanded sharply when QE1 was announced in November 2008, marked as a vertical line in the figure. The Appendix shows that similar patterns hold in HMDA data and that the increase in mortgage originations after QE1 was almost entirely refinancing rather than new purchase mortgages. For this reason, we focus our analysis on refinancing.

We focus on QE1 because it was largely unexpected and was followed by such a sharp drop in mortgage rates, and because our CRISM data begins in 2005. While high-frequency event studies show that both mortgage rates and applications reacted strongly to QE announcements (Fuster, Lo, and Willen, 2017), it is of course likely that other factors also contributed to the low rates following QE1. This is not a problem for us since we are more generally interested in the transmission of interest rate drops to refinancing and household consumption, and monetary policy is one key driver of such interest rate drops. Thus, our focus is also not QE-specific: the refinancing channel of monetary policy can potentially operate whenever monetary policy moves mortgage rates. While the refinancing boom after QE1 was larger than at any time since mid-2003, it was stronger still in 2001-2003 when falling rates were coupled with broad-based house price appreciation in most locations. Therefore, we will often contrast the effects of the refinancing channel in 2008-2009 with the effects in 2001-2003.

It also bears noting that the beginning of QE1 is separated in time from other housing market policies implemented in response to the Great Recession. Specifically, the Home Affordable Modification and Refinance Programs (HAMP and HARP) were announced in March 2009, with the goal of alleviating the collateral friction we study (as we return to in Section 7) but for various reasons (such as limited participation by servicers) had a very slow start. In particular, HARP only started having large effects on refinancing volumes in 2012 (Agarwal et al., 2017), well after our study window. ${ }^{7}$ Furthermore, any debt reduction policies around the time of our sample would likely reduce our effects

\footnotetext{
${ }^{7}$ Agarwal et al. (2017) show that refinancing spurs spending and that this channel was strengthened by the HARP's reduction of collateral frictions, in line with the mechanism we emphasize. Another major policy intervention was that Fannie Mae and Freddie Mac were placed in federal conservatorships in September 2008, but this did not by itself lead to a drop in mortgage rates or a refinancing boom; it did however assure that credit supply continued relatively uninterrupted, at least for conforming mortgages (Frame et al., 2015).
} 
of interest since they would have larger effects in low equity MSAs.

To get a sense of the potential effects of refinancing on borrowers' disposable resources during the Great Recession, we note that in the CRISM data over the first half of 2009, the median rate on the old loan was $6.125 \%$, while the median rate on the new (refinance) loan was $4.875 \%$. The average balance of the first-lien mortgage being refinanced was $\$ 206,000$, so that, leaving the balance unchanged and assuming a 30-year FRM, the monthly payment would decrease by at least $\$ 160 .{ }^{8}$ If we discount this at $5 \%$ per year over 7 years (roughly the average lifespan of a mortgage) then the present value of pre-tax savings is $\$ 11,400$ for monthly payments and $\$ 15,000$ for interest payments. The latter is larger since the lower rate leads to faster amortization. In addition to lowering the interest rate, many borrowers also increase the balance of their loan by withdrawing some of their equity. Over 2009:H1, the mean and median equity withdrawal in our data are $\$ 25,000$ and $\$ 7,400$, respectively.

\subsection{Regional Variation in Equity Distributions Prior to QE1}

Throughout the paper, we use metropolitan statistical areas (MSAs) as our measure of "regions." We begin by showing that equity distributions evolved very differently across MSAs between 2007 and 2008. Figure 2 shows the distribution of household housing equity in two different time periods for five MSAs: Chicago, Las Vegas, Miami, Philadelphia, and Seattle. These are examples of MSAs that had house price declines from 2007 to 2008 that were large (Miami and Las Vegas), medium (Chicago), and small (Philadelphia and Seattle). ${ }^{9}$ Panel (a) shows the housing equity distribution for these MSAs in January 2007, just prior to the nationwide house price decline. For all five MSAs, housing equity distributions are quite similar. As noted above, we often summarize the distribution in each MSA $j$ at a point in time using the equity of the median borrower $E_{j, t}^{\text {med }}$. In January 2007, $E_{j, t}^{\text {med }}$ in most of these MSAs is between 0.3 and 0.4. The equity of the median borrower in Las Vegas is a bit lower (roughly 0.23) since house prices there starting falling before 2007.

Figure 2: Distributions of Borrowers' Equity in their Homes across 5 MSAs

(a): January 2007

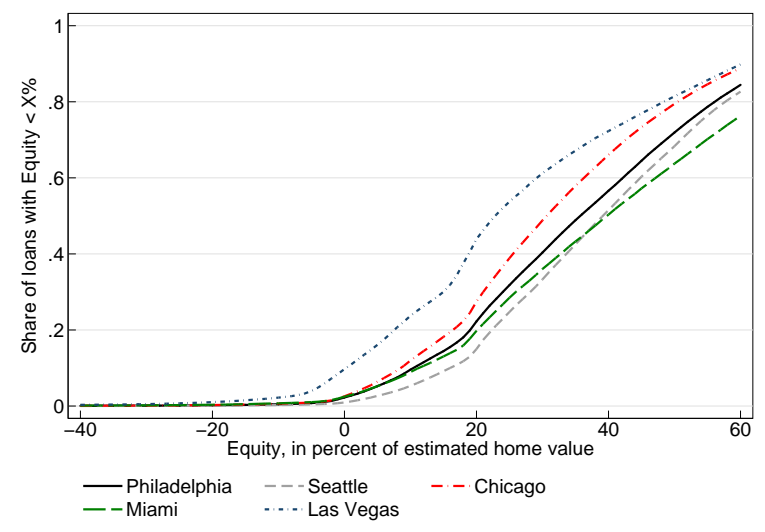

(b): November 2008

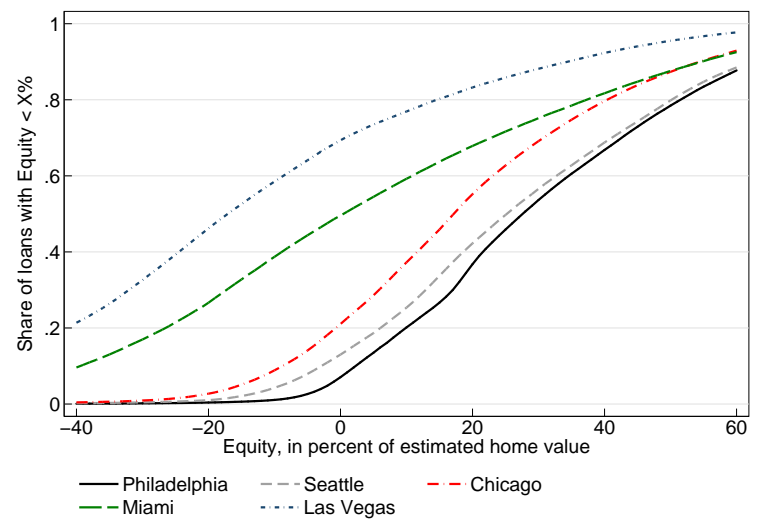

Figure shows the cumulative distribution of borrower equity in five illustrative MSAs in January 2007 and November 2008. Equity is measured for each household using CRISM data as the estimated current house value minus total current mortgage debt, divided by estimated current house value (i.e., equity $=1-\mathrm{CLTV}$ ). Distributions are weighted by mortgage balance.

\footnotetext{
${ }^{8}$ In reality the decrease would typically be larger since the old monthly payment is based on the higher original balance.

${ }^{9}$ Appendix Table A-1 shows descriptive statistics for all 381 MSAs in our analysis.
} 
Panel (b) shows that by November 2008, when QE was announced, there was large variation in equity distributions across MSAs. Between early 2007 and late 2008, the equity distribution in places like Las Vegas and Miami shifted dramatically relative to places like Philadelphia and Seattle. By November 2008, $E_{j, t}^{\text {med }}$ was around -0.17 in Las Vegas and zero in Miami. Conversely, $E_{j, t}^{\text {med }}$ in Philadelphia and Seattle was around 0.25-0.3, so the median borrower in these MSAs still had substantial equity. The equity of the median borrower correlates strongly with other moments of the equity distribution. For example, 50 percent of borrowers in Miami and 70 percent of borrowers in Las Vegas had negative equity in November 2008, while only 6 to 10 percent had negative equity in Philadelphia and Seattle.

The Appendix explores many additional results that reinforce the patterns in Figure 2. Specifically, we show the distribution of $E_{j, t}^{m e d}$ across all 381 MSAs in January 2007 and November 2008 to highlight that the cross-region heterogeneity in Figure 2 is representative. We also show similar patterns for the distribution of individual equity rather than $E_{j, t}^{\text {med }}$ to illustrate that focusing on median equity is not essential for our conclusions. Additionally, we show the relationship between equity, unemployment changes, and house price growth from January 2007 to November 2008. Over this period, differential house price declines across MSAs were the main driver of differences in $E_{j, t}^{\text {med }}$. On average, a 10 percent decline in house prices from January 2007 to November 2008 is associated with an 8.3 percentage point lower $E_{j, \text { Nov2008 }}^{\text {med }}$ We cannot measure local equity before 2005 , but this relationship between house price growth and equity will allow us to use regional variation in house price growth to proxy for regional variation in housing equity in earlier periods.

Finally, we document that MSAs with the largest increases in local unemployment rates also had the lowest $E_{j, \text { Nov2008. }}^{\text {med }}$ This is unsurprising since house price declines were associated with weakening labor markets during this period (Charles, Hurst, and Notowidigdo, 2013; Mian and Sufi, 2014), but it is important for interpreting the cross-region effects of monetary policy, since we will now show that refinancing activity responded least to QE1 in the locations with the least home equity.

\subsection{Regional Variation in Mortgage Activity Around QE1}

We now show that in the months after QE1 was announced, refinancing activity was much higher in regions with more home equity and lower unemployment. To facilitate the exposition of our results, we divide all MSAs into quartiles based on $E_{j, \text { Nov2008 }}^{\text {med }}{ }^{10}$ Figure 3 shows refinancing activity over time for MSAs in the top and bottom quartiles of $E_{j, \text { Nov2008. }}^{\text {med }}$ The bottom quartile of $E_{j, \text { Nov2008 }}^{\text {med }}$ includes MSAs like Las Vegas where the median mortgage borrower was underwater. The top $E_{j, \text { Nov2008 }}^{\text {med }}$ quartile includes MSAs like Seattle where most borrowers had sufficient equity to refinance.

Panel (a) shows monthly refinancing propensities from January 2008 through December 2009. Refinancing propensities are higher throughout in the high equity quartile, but they evolve similarly between high and low equity MSAs up to November 2008. After QE1, refinancing activity jumpedbut it jumped much more in the high equity MSAs relative to the low equity MSAs. ${ }^{11}$

\footnotetext{
${ }^{10}$ Quartiles are population-weighted using 2008 numbers from the Census. This ensures that there are the same number of people within each quartile. Appendix A.1 lists the specific MSAs within each of the $E_{j, \text { Nov2008 }}^{\text {med }}$ quartiles.

11 The jump happens in January/February (rather than December) because CRISM measures originations, not applications, and there is a delay of 1-3 months between when a mortgage application is initially made and when the actual mortgage origination takes place due to the underwriting process. As Fuster, Lo, and Willen (2017) document, loan processing times increased following the QE1 announcement, but based on HMDA data with exact application and origination dates, we find little differential increase between high- and low equity MSAs. In Appendix Figure A-5, we use the HMDA data to show
} 
Figure 3: Mortgage Refinance Activity 2008-2009 in Top and Bottom Quartile of MSAs Defined by Median Borrower Equity in November 2008

(a): Refinance Propensities

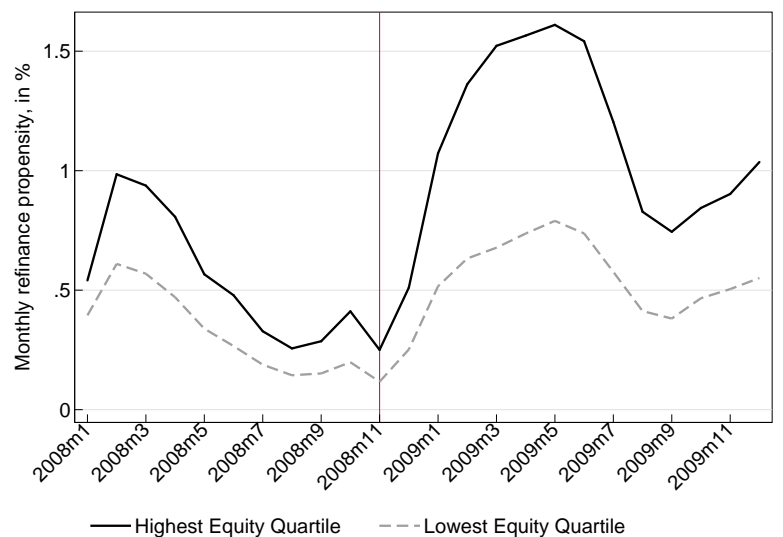

(b): Cumulative Difference

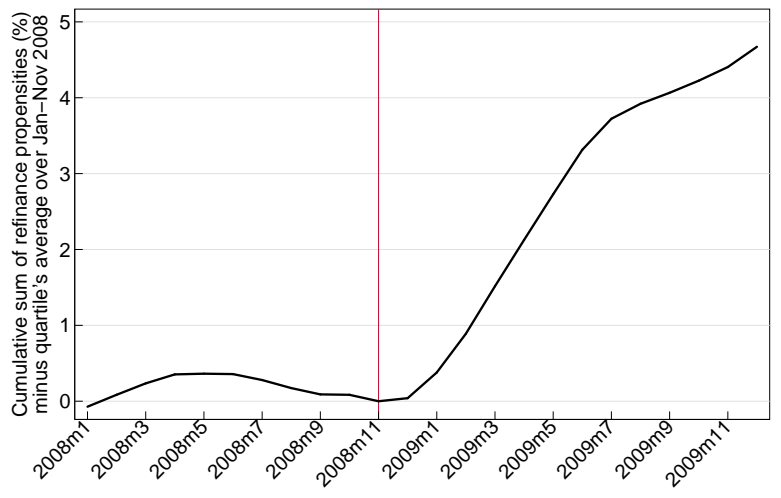

—Difference between High Equity and Low Equity Quartiles

Panel (a) shows monthly refinance propensities in CRISM, defined as the dollar amount of refinance mortgage originations divided by outstanding mortgage amounts in the prior month. Calculations are done over MSA quartile groups for the highest and lowest $E_{\text {Nov2008 }}^{\text {med }}$ quartiles. Panel (b) shows the cumulative difference between the two groups, after subtracting each group's average refinancing propensity from January to November 2008. Vertical lines show the month of the QE1 announcement (November 2008).

Panel (b) shows the cumulative difference between the two groups, after subtracting each group's average refinancing propensity from January to November 2008 to remove the initial level difference. Prior to QE1, the cumulative difference is essentially flat at zero, reflecting the parallel pre-trend in panel (a). After QE1, a sharp difference emerges, eventually leading to a cumulative refinancing propensity about 5 percentage points larger in the high equity MSA group than in the low equity MSA group. This is a substantial difference, since the cumulative refinancing propensity in the low equity group is only 7 percent over the entire year 2009.

While Figure 3 shows a clear difference in refinancing responses to QE1 in high and low equity MSAs, one might be concerned that this difference is driven by other factors that vary across these MSAs. We thus complement these figures with difference-in-difference style regressions which allow us to control for additional local factors and assess statistical significance. Specifically, we estimate:

$$
R e f i_{j, t}=\alpha_{j}+\alpha_{t}+\beta\left(E_{j, \text { Nov } 2008}^{\text {med }} \times \text { post } Q E\right)+\Gamma\left(X_{j, \text { Nov2008 }} \times \text { post } Q E\right)+\varepsilon_{j, t},
$$

where $\operatorname{Ref} i_{j, t}$ is the monthly refinancing propensity in each MSA over the six months prior to QE1 and the six months after QE1, $\alpha_{j}$ and $\alpha_{t}$ are MSA and time fixed effects, and postQE is an indicator variable that equals one for the six months after QE1. We use February 2009 as the start of the postQE-announcement period since there is a lag between the time one applies for a mortgage and when it is originated, as discussed in footnote $11 . X_{j, N o v 2008}$ is a vector of local controls including changes in the unemployment rate between January 2007 and November 2008, changes in local income between January 2007 and November 2008, average borrower FICO score, average outstanding interest rate on mortgages, average loan age, average mortgage balance, and local ARM, jumbo, GSE and privately securitized shares of loans. All the latter variables are measured in November 2008. We also include that applications jumped immediately after the announcement of QE1, and more so in high equity MSAs. 
local age, education, and homeownership controls measured using the 2008 American Community Survey. Regressions are run including one control at a time as well as jointly including all controls.

To conserve space, we show the full estimates of these conditional regressions in the Appendix. The results reinforce the patterns found in Figure 3, but some results are worth highlighting. First, $\beta$ is always positive and highly statistically significant, indicating that the patterns in Figure 3 are robust to many detailed local controls. Importantly, all controls are interacted with postQE so that the responsiveness of refinancing to interest rates can vary with these observable characteristics, and all regressions include MSA fixed effects which absorb any permanent differences in refinancing across MSAs due to unobservables. Adding the average FICO score of mortgage borrowers (interacted with post $Q E$ ) to the regression reduces the coefficient on equity by almost half, but average FICO scores are themselves endogenous to changes in local equity (since underwater borrowers are more likely to default); therefore, we view the fact that equity remains strongly significant as underscoring its importance in explaining differences in refinancing. Adding all additional controls at once further reduces $\beta$. Again, this is to be expected since a linear combination of these variables is very highly correlated with median equity. Nevertheless, equity remains individually significant.

One might also be concerned that our results could reflect relatively tighter credit supply in low equity locations in the period after QE1. However, consistent with results in Hurst et al. (2016), the Appendix shows there is little variation in mortgage rates across MSAs and that rates fell as much in low equity locations as in high equity locations after QE1. This suggests that lower refinancing rates in low equity locations are not driven by higher borrowing costs. This likely reflects the fact that during this time period, the mortgage market consists almost entirely of loans whose default risk is insured by GSEs, which do not vary their pricing with regional default risk (again see Hurst et al., 2016).

While we focus on effects of CLTV constraints, borrowers must also satisfy payment-to-income (PTI) constraints to refinance. During the QE1 episode, house price declines are highly correlated with increases in unemployment, so it is possible our results might be driven by PTI rather than CLTV constraints. Although it is indeed the case that, conditional on local equity levels, MSAs with larger increases in unemployment saw moderately smaller increases in refinancing, equity effects remain independently very large. Controlling directly for income also has little effect on our coefficient of interest. The Appendix further shows that the distribution of PTI for newly originated loans in 2009 is very similar in high and low equity MSAs and exhibits no bunching around institutional constraints, in contrast to substantial bunching and spatial variation in the distribution of CLTVs. This strongly suggests that our results are primarily driven by spatial variation in equity rather than PTI constraints.

Collectively, the results from Figure 3 and the various robustness results provided in the Appendix show there were large regional differences in refinancing activity in response to QE1. Regions with the least equity were the least responsive to QE1 in terms of subsequent mortgage refinancing activity.

\subsection{Regional Variation in Equity Extraction and Spending Around QE1}

To what extent do these spatial differences in refinancing activity lead to differences in spending? Unfortunately, local spending data is extremely limited, but we provide evidence on this front in two ways. First, we explore the extent to which households removed equity from their home when refinancing. Prior research has shown that households typically spend a large amount of such "cash- 
outs" on current consumption and home improvements. ${ }^{12}$ Second, we use R.L. Polk data on new car purchases at the MSA level as one measure of local spending, as in Mian, Rao, and Sufi (2013).

\section{Figure 4: Cash-Out Refinancing in Top and Bottom Quartile of MSAs by Median Borrower Equity in November 2008}

(a): Cash-out Volumes, in \$

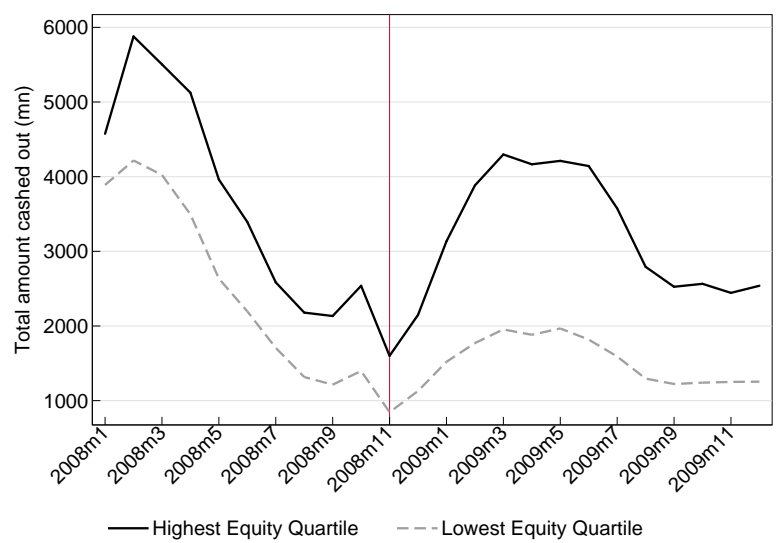

(b): Cumulative Difference

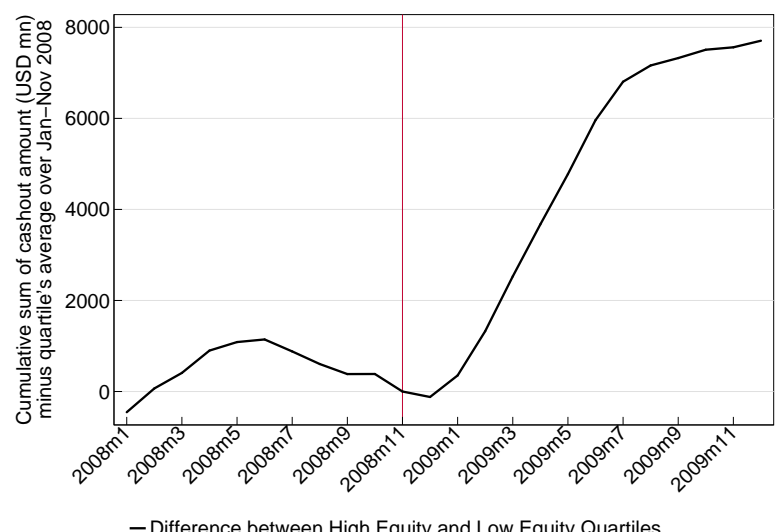

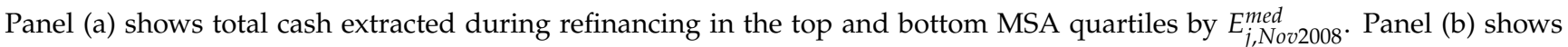
the cumulative difference between the two groups, after subtracting each group's average cash-out amounts from January to November 2008. Since CRISM data does not cover the whole mortgage market, we scale up dollar amounts in CRISM for this figure; see Appendix A.2.3 for details. Vertical lines show the month of the QE1 announcement (November 2008).

Figure 4 shows the amount of equity removed during refinancing for the top and bottom quartile MSAs by $E_{j, N o v 2008}^{\text {med }}$. Panel (a) shows dollar amounts per month, while panel (b) shows the cumulative difference between the two groups, after subtracting each group's average cash-out amounts from January to November 2008. The total amount of equity removed during the refinancing process sums over households who removed no equity, those who put equity into their home, and those who extracted equity. On net, borrowers remove equity during the refinancing process in both high and low equity locations. At all points in time, there is more equity removal in high equity locations, but trends evolve similarly prior to the QE1 announcement. After QE1, equity removal increases substantially in the high $E_{j, \text { Nov2008 }}^{\text {med }}$ locations relative to the low $E_{j, \text { Nov2008 }}^{\text {med }}$ locations.

Summing across all MSAs in the top equity quartile, about $\$ 23.8$ billion of equity was cashed out during refinancing in the six months after QE1 (January-June). Conversely, for the MSAs in the bottom equity quartile, only $\$ 10.9$ billion of equity was cashed out. However, some of this $\$ 12.9$ billion difference reflects the continuation of differential extraction levels prior to QE1. Panel (b) shows the cumulative difference in cash-out amounts over 2009 between the two MSA groups—after subtracting each group's pre-QE averages-amounted to around $\$ 8$ billion. ${ }^{13,14}$

\footnotetext{
${ }^{12}$ See Brady, Canner, and Maki (2000), Canner, Dynan, and Passmore (2002), Hurst and Stafford (2004) and Bhutta and Keys (2016).

${ }^{13}$ Regressing MSA-level cash-out amounts on group dummies interacted with a post-QE dummy (with standard errors clustered by MSA) we get an estimate of this cumulative difference of $\$ 7.95$ billion with a standard error of $\$ 3.11$ billion.

${ }^{14}$ Our equity extraction measure does not include HELOC draws. Unlike cash-out refis, HELOC balances can be adjusted without closing costs, and interest rates are usually variable. This mutes incentives to respond to long-term rate declines. Nevertheless, our $\$ 8$ billion could be overstated if high equity MSAs extract equity by refinancing while low equity MSAs do so through HELOCs. However, using quarterly FRBNY Consumer Credit Panel data, HELOC balances grew more in high equity than low equity MSAs over 2008-2009, and differentially increased in high equity locations by roughly $\$ 4$ billion after
} 
Is an $\$ 8$ billion difference in equity extraction across regions caused by QE1 a large number? Since this number comes from a cross-region calculation, which differences out any aggregate effects, it should not be interpreted as the effect of QE1 on aggregate equity extraction or compared to the overall size of the recession. In the second half of the paper we use a model to infer aggregate effects from our cross-region evidence, but for now it is more relevant to compare the $\$ 8$ billion cash-out difference to differences in the size of the recession across regions. Using BEA data, we find that $\$ 8$ billion is around $10 \%$ of the differential spending change from 2008 to 2009 between the two MSA groups. ${ }^{15}$ This effect is both large and similar in size to the effects in our model. It is also useful to compare these numbers to other stabilization programs. Unemployment benefit payments in 2009 totaled around \$16 billion in the lowest equity MSAs. Thus, $\$ 8$ billion is similar in magnitude. However, our results show it differentially went to the regions with the lowest instead of highest unemployment rates. ${ }^{16}$ Dividing $\$ 8$ billion by the number of households in the highest equity quartile implies that QE1 increased potential spending per household in those locations by roughly $\$ 280$. This is similar in size to tax stimulus payments received by households in the recession, and suggests that QE1 had cross-region effects similar to sending an extra tax rebate only to locations which were already doing relatively well.

The Appendix also shows results from a regression similar to equation (1) but with monthly equity removed (relative to outstanding balance) as the dependent variable. We refer to this variable as the cash-out share. Echoing the results in Figure 4, we find a positive relationship between $E_{j, N o v 2008}^{\text {med }}$ and the cash-out share after QE1 that is highly significant and robust to a variety of additional controls. We also show that high equity places extract more equity even after conditioning on the frequency of refinancing. That is, the patterns in Figure 4 are not driven just by the differential refinancing propensities shown in Figure 3. To show this, we add monthly refinancing propensities as separate controls in our regression. We find that both the coefficient on $E_{j, \text { Nov2008 }}^{\text {med }} \times$ postQE and on the monthly refinancing propensity are positive and strongly significant. Hence, low $E_{j, \text { Nov2008 }}^{\text {med }}$ MSAs both refinanced less and removed less equity, conditional on refinancing. This is intuitive, since these places indeed have less equity to remove when refinancing.

Since prior research has shown tight links between equity removal and spending, these results suggest that locations with different $E_{j, \text { Nov2008 }}^{\text {med }}$ had different spending responses to QE1. However, differences in the marginal propensity to consume could potentially lead consumption to respond more to QE1 in low equity regions despite smaller refinancing responses. In particular, it could be the case that instead of spending extracted home equity, households in high equity MSAs used it to pay down other (higher-interest) non-housing debt. However, as a robustness exercise in the Appendix, we use FRBNY Consumer Credit Panel data to show that average non-housing debt per person actually modestly increased in high equity MSAs relative to low equity MSAs after QE1. This suggests that borrowers in those MSAs used withdrawn equity for spending, rather than to pay down existing debt.

We now show this more directly using auto sales data from Polk. Panel (a) of Figure 5 shows total monthly auto sales in the top and bottom $E_{j, N o v 2008}^{\text {med }}$ groups. A few things stand out. First, the

QE1. So including HELOCs would increase the differential QE effects on equity extraction to roughly $\$ 12$ billion.

${ }^{15}$ Total GDP in low equity MSAs fell by \$113.5 billion more than total GDP in high equity MSAs between 2008 and 2009. Scaling these differences by the aggregate share of consumption in GDP of $68 \%$ delivers $.104=8 /\left(.68^{*} 113.5\right)$.

${ }^{16}$ Unemployment benefit payments are only reported at the state-level by the Department of Labor, but we apportion statelevel benefits payments to individual MSAs using each MSA's share of total state unemployment. This calculation implies the lowest equity MSAs received \$16.3 billion in unemployment benefits payments in 2009 and \$9.6 billion in 2008 . 
Figure 5: New Auto Sales in Top and Bottom Quartile of MSAs Defined by Median Borrower Equity in November 2008

(a): Monthly Auto Sales

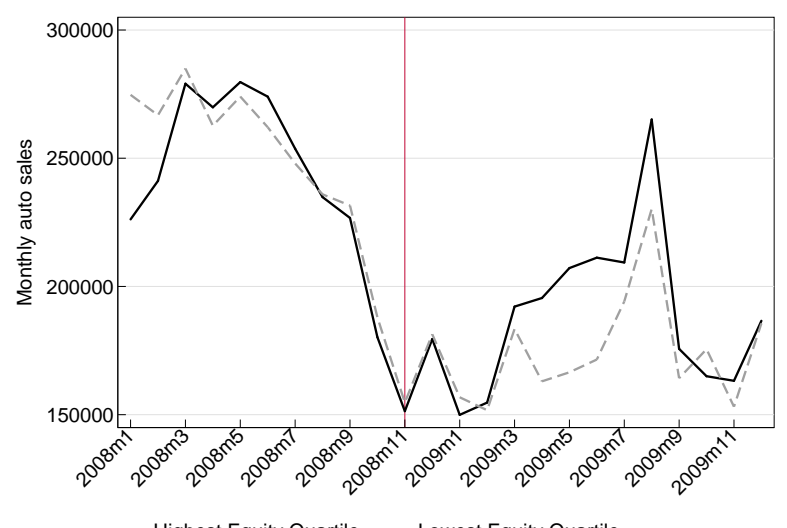

- Highest Equity Quartile - Lowest Equity Quartile (b): Cumulative Difference

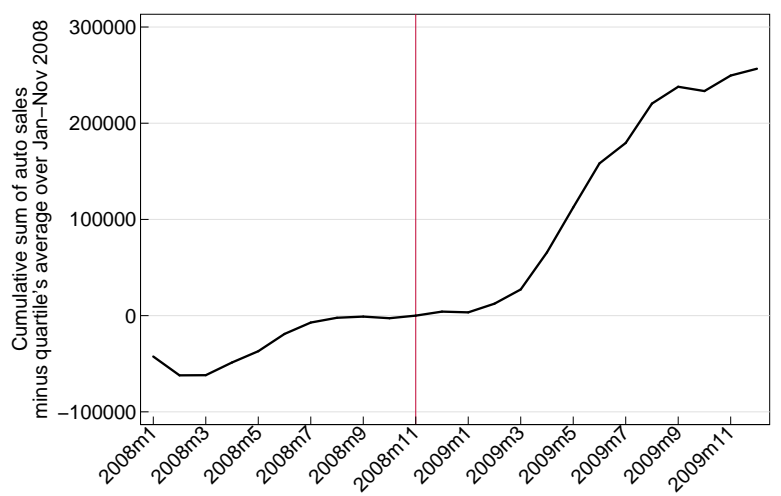

—Difference between High Equity and Low Equity Quartiles

Figure shows the total volume of new car purchases in the top and bottom MSA quartiles by $E_{j, \text { Nov2 } 2008}$ using R.L. Polk data. Panel (a) shows total monthly car purchase volumes, summed over MSAs in each quartile. Panel (b) shows cumulative differences between the two groups, after subtracting from each group's series the group's average car purchases from January to November 2008. MSA groups are the same as in Figure 3. The vertical line shows the month of QE1 announcement.

trend in auto sales was very similar in the high and low equity quartiles prior to QE1. In both groups, new auto sales fell rapidly throughout 2008. Second, these trends remained parallel through February 2009. This is not surprising since refinancing applications that took place in December 2008 would not result in new mortgage originations until January or February 2009. Third, and most important, after February 2009, auto sales diverge sharply between the two equity groups. On average, sales increased by 31 percent in March-May 2009 relative to November 2008 in the high equity MSAs while they only increased 15 percent in the low equity MSAs. This difference is economically and statistically significant, and the timing lines up perfectly with expected spending responses to QE1. ${ }^{17}$ Panel (b) shows that cumulative differences between the groups through 2009 amount to 250,000 cars, or roughly 1.5 months of sales. It is also worth noting that these differences all occur prior to the start of the Cashfor-Clunkers program in July 2009 and so are not driven by this program. ${ }^{18}$

\subsubsection{Household-level Analysis of Spending after Refinancing}

Of course, high and low equity MSAs differ in many ways, so that observed differences in spending following QE1 could be due to factors other than mortgage refinancing and equity withdrawal. Our spending regressions include both MSA fixed effects and long-run MSA trends to control for many

\footnotetext{
${ }^{17}$ The Appendix shows MSA-level regressions, similar to equation (1), but using the log of monthly new car sales as our dependent variable. $\beta$ is positive and statistically significant even if we allow for differential time trends across locations with different equity levels. Furthermore, to directly test the link between refinancing, equity extraction, and auto sales, we add both refinancing and cash-out propensities as independent variables and find they are both correlated with stronger auto sales over this period. Once we control for both equity and refinancing propensities, only the latter are significant, consistent with the hypothesis that equity only matters for spending through its effects on refinancing.

${ }^{18}$ The start of the program can be seen as a large spike in panel (a). Although irrelevant for our regressions with MSA fixed effects, clunker shares are actually mildly negative correlated with median equity which should imply larger responses to cash-for-clunkers in low equity regions. This correlation, together with the fact that the program pulled forward many purchases from the future, may explain why spending differences with equity disappear after July 2009.
} 
differences across MSAs, so any alternative explanation would need to interact at high frequencies with our QE1 event study. However, channels aside from refinancing might satisfy this requirement. For instance, mortgages defaults were higher in low $E_{j, 2008}^{m e d}$ MSAs, which would lower credit scores and make it more difficult to benefit from lower interest rates on car loans.

To provide direct evidence that spending effects indeed arise from refinancing, we move to CRISM data at the household level (rather than the MSA level) and study spending responses of borrowers who refinanced at some point in 2009. The credit record component of the data includes information on each borrower's monthly auto loan balances, and we follow the literature (e.g. Agarwal et al., 2017; Di Maggio, Kermani, and Palmer, 2016) in using large balance increases from one month to the next as a proxy for a car purchase. We then conduct an "event study" where we look at borrowers' propensity to purchase a car in the months around refinancing. Given our earlier analysis, we are particularly interested in how spending responses differ between cash-out and non-cash-out refinances.

\section{Figure 6: Borrower-Level Evidence on Response of Car Purchase Propensity to Refinancing}

(a): Monthly Averages around Refinancing

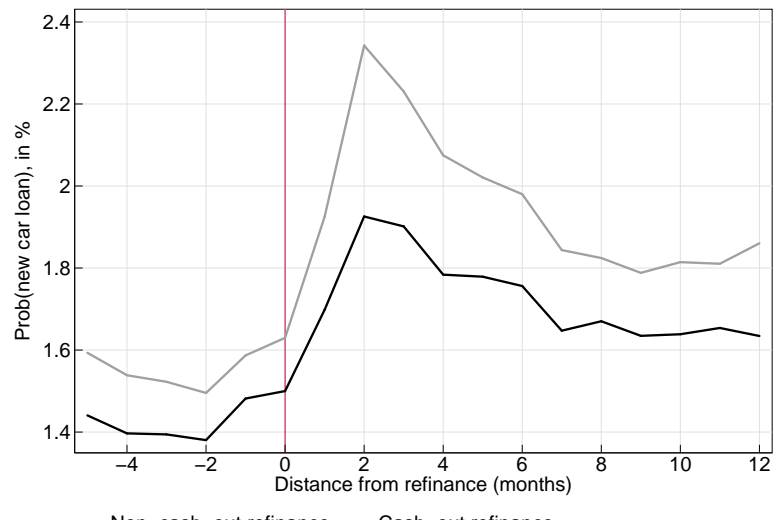

(b): Regression Coefficients

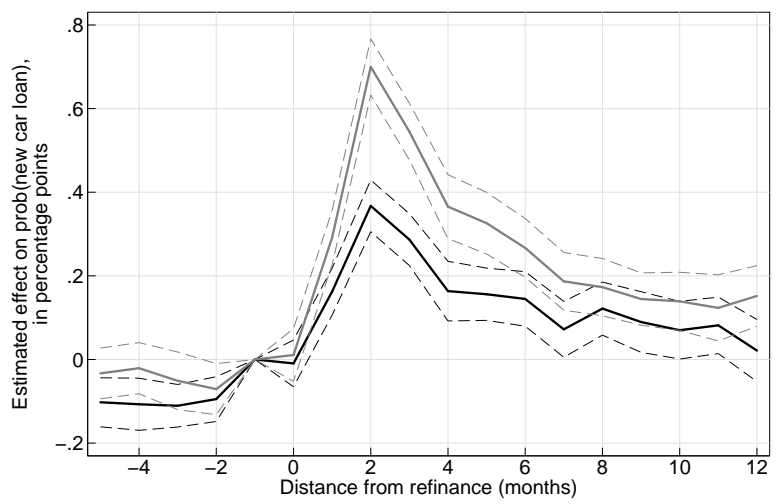

- Non-cash-out refinance - Cash-out refinance

Panel (a) shows average fractions of refinancing borrowers who obtain a new car loan in each month surrounding a mortgage refinancing (in month 0 ), distinguishing between cash-out and non-cash-out refinancing. We identify a borrower as obtaining a new car loan in month $t$ if their car loan balance increases by $\$ 2,000$ or more between month $t-1$ and month $t$. Panel (b) shows coefficients on month indicators (relative to the refinancing month, with -1 as the omitted month) from a regression of the new car loan indicator on calendar-month-by-MSA fixed effects as well as months-from-refinancing indicators interacted with whether the refinancing involves cash-out. Dashed lines are 95 percent confidence intervals based on robust standard errors clustered at the MSA level. See Appendix A.2.5 for additional details.

Panel (a) of Figure 6 simply shows average car purchase propensities for borrowers in the months before and after completing a cash-out or non-cash-out refinance. Supporting the view that refinancing spurs spending, purchase propensities spike for both groups following the refinance, and more so for borrowers who remove equity during the process. Panel (b) shows monthly coefficients (and 95 percent confidence intervals) from a regression of the car purchase indicator on calendar-month-by-MSA fixed effects, as well as indicators of the distance in months to the time of the refinance, with month -1 as the omitted month. The results show a strong increase in car purchase propensities in the months following refinancing, with a peak after two months that is almost twice as large for cash-out as for non-cash-out refinances. Effects remain positive for several months after refinancing, and there is little pre-trend prior to refinancing. While this link from refinancing to car spending is not necessarily causal 
(we do not have exogenous variation in refinancing propensity at the individual level), it nevertheless supports the view that refinancing in the wake of QE1 did stimulate consumer spending, and more so if the borrower also removed equity in the process. We further note that positive refinancing effects on spending are also found in work exploiting exogenous variation in access to refinancing (Agarwal et al., 2017; Abel and Fuster, 2018) or payment reductions from ARM resets (Di Maggio et al., 2017).

The results in this section suggest that QE1 raised aggregate spending by borrowers (in part by inducing them to remove equity) but that regional spending responses differed with equity at the onset of QE1. Collectively, our results show that the "refinancing channel" of monetary policy interacts with the regional distribution of housing equity and that the 2008 distribution reduced the effectiveness of monetary policy by preventing it from stimulating places which needed it most.

\section{The Time-Varying Refinancing Channel in the US}

In this section, we first show that there is substantial time-variation in the regional distribution of house price growth and its correlation with unemployment changes. We then focus on the 2001 recession, which exhibits house price patterns most distinct from 2008, and show that this recession also has very different refinancing patterns. Finally, we present longer-term evidence that the refinancing response to interest rate changes depends on the regional distribution of house price growth. Together these results provide evidence that the time-varying regional equity distribution produces time-varying effects of monetary policy through the refinancing channel.

Figure 7: Changes in Distribution of House Price Changes Across Time

(a) Average House Price Growth

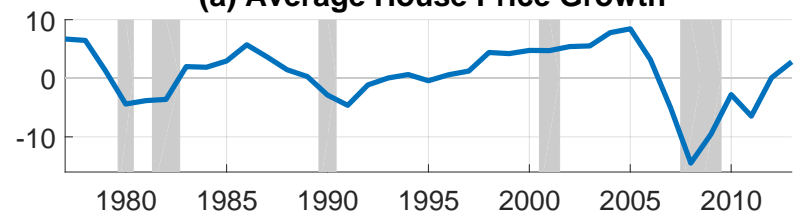

(b) Cross-State Standard Deviation of House Price Growth

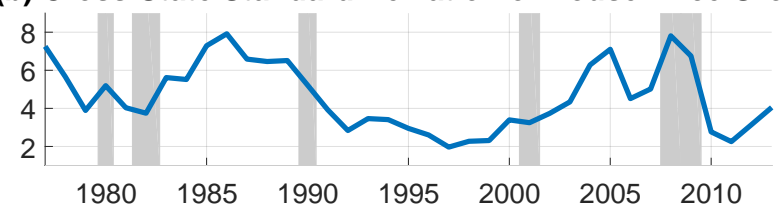

(c) Unemployment-House Price Growth Relationship

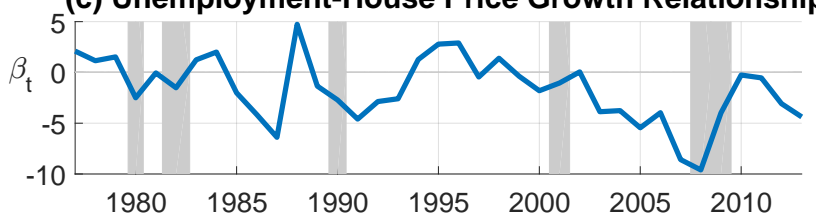

Figure shows time-series of the mean and standard deviation of state-level annual house price growth and of the cross-state relationship between house price growth and unemployment rate changes. Calculations are population weighted by state.

Since CRISM data begins in 2005, we cannot construct the housing equity data necessary to simply replicate our prior analysis in earlier recessions. However, as noted in Section 4.2, house price changes and housing equity are strongly correlated in this recession. Motivated by this relationship, we now show that the cross-region distribution of house price growth varies substantially across time. Panel 
(a) of Figure 7 shows average real house price growth in CoreLogic data from 1976-2013. ${ }^{19}$

While the large house price declines in the Great Recession stand out, there is substantial variation across time. During the 2001 recession, real house prices were growing rather than falling, and house price declines in the previous three recessions were mild. Panel (b) plots the standard deviation of house price growth across states in each year. Clearly, spatial variation in house price growth was unusually high in the late 80s and in the Great Recession and unusually low during the 2001 recession.

Finally, panel (c) explores relationships between state-level unemployment and house price growth, a moment that will be particularly important for determining monetary policy implications for crossregion inequality. In particular, we run a regression of one-year house price growth on state-level one-year changes in unemployment (in percentage points) interacted with annual dummies for each year from 1976-2013 and including year and state fixed effects so that the results are not driven by slow moving state-level trends or aggregate unemployment changes or house price growth:

$$
\Delta \log H P_{i, t}=\alpha+\beta_{t} \Delta U R_{i, t}+\gamma_{t}+\zeta_{i}+\epsilon_{i, t}
$$

$\beta_{t}$ then measures the comovement between house prices and unemployment in the cross-section each year. Panel (c) shows that in the Great Recession, unemployment and house price growth were unusually negatively correlated. Again, these patterns vary across time. In the 2001 and 80 s recessions there was basically no relationship between unemployment and house price growth.

In the following section we build a theoretical model consistent with these time-series patterns and show they imply important time-varying consequences of monetary policy. Supporting these conclusions, Figure 8 illustrates that the pass-through of monetary policy through the mortgage market was much stronger in the 2001 recession than in the 2008 recession and that regional effects were also very different. ${ }^{20}$ Panel (a) shows the time series of monthly refinancing propensities in HMDA for the lowest and highest unemployment quartile MSAs during the 2008 recession. MSAs are sorted into quartiles based on the total increase in unemployment from November 2007 to October 2009. The top (bottom) quartile experienced unemployment increases of 6.3 percent or more (3.8 percent or less) over this period. ${ }^{21}$ Given the high correlation between unemployment changes and house price changes, the unemployment results in panel (a) are very similar to those shown for equity quartiles in Figure 3.

Panel (b) shows time-series patterns for monthly refinancing by unemployment quartiles during the 2001 recession. The sorting is again done by total increases in unemployment over this period. The top (bottom) quartile the unemployment rate increased by 2.5 percent or more (1.6 percent or less). The refinancing patterns are very different from those shown in panel (a): during the entire period, refinancing volumes were higher in the MSAs with more rapidly rising unemployment. ${ }^{22}$ Overall

\footnotetext{
${ }^{19}$ State-level house prices are deflated using the CPI-U and are population weighted. We concentrate on the state-level rather than MSA-level distribution of house price growth, since MSA-level labor market data is only available starting in 1990, but patterns at the MSA (and zip code) level are similar for the mean and standard deviation.

${ }^{20}$ Since CRISM data starts in 2005 we must use HMDA data for this analysis.

${ }^{21}$ These periods match turning points in the overall seasonally adjusted US civilian unemployment rate. In the earlier episode, national unemployment increased from a low of 3.9 percent in December 2000 to a high of 6.3 percent in June 2003. In the latter episode, unemployment increased from 4.7 percent in November 2007 to 10.0 percent in October 2009.

${ }^{22}$ Chen, Michaux, and Roussanov (2013) similarly find that over 1993-2009, refinancing activity at a point in time was higher in states with worse economic conditions. Avery et al. (2011) document lower refinancing propensities in 2010 than in 2003 using credit records data. While these data do not allow one to measure borrower equity, state-level differences in propensities are consistent with lack of equity being an important impediment to refinancing in 2010.
} 
Figure 8: Refinancing Propensities for High and Low Unemployment Change Quartiles, 2008 Recession and 2001 Recession

(a): Refinance Propensities 2007-2009

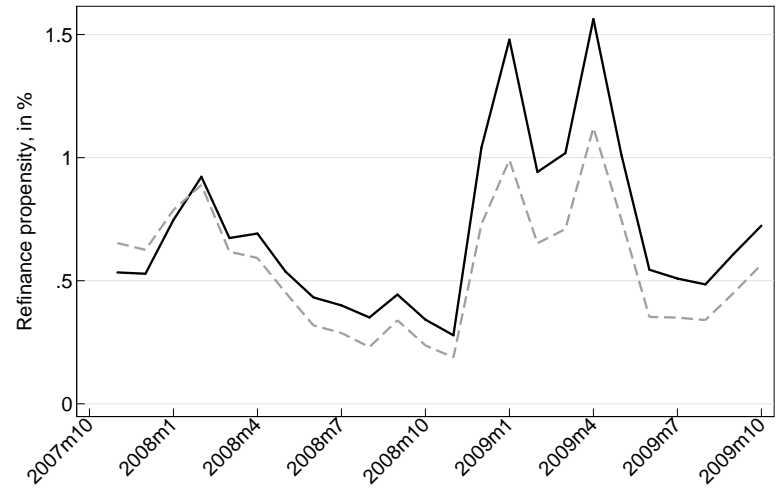

_Lowest Unempl. Quartile

- - Highest Unempl. Quartile (b): Refinance Propensities 2001-2003

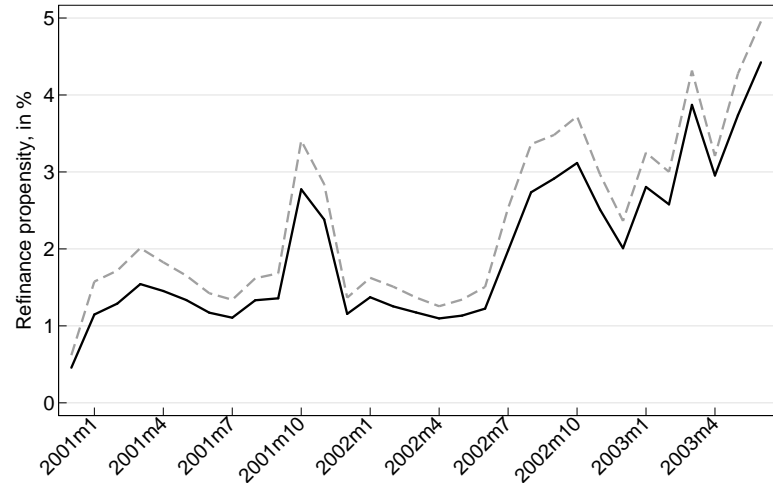

— Lowest Unempl. Quartile _ - - Highest Unempl. Quartile

Figure shows monthly refinancing propensities for the top and bottom quartiles of MSAs by unemployment changes. Specifically, for each MSA we compute the change in unemployment between November 2007 and October 2009 (panel a) and December 2000 to June 2003 (panel b). Each MSA is placed into population-weighted quartiles by this measure. Refinancing propensities are computed using HMDA data on origination volumes (by month of loan application) divided by the total number of mortgages in MSA quartiles from the American Community Survey in 2008 (panel a) or 2000 (panel b).

refinancing propensities were also dramatically higher in this earlier episode, when house prices were growing rather than shrinking (especially between mid-2002 and mid-2003). While there was no single monetary policy "event" during this period, as the federal funds rate instead declined gradually, it is evident from Figure 1 that overall mortgage rate declines relative to recent levels were similar in 2001-2003 and 2007-2009. Because the decline in mortgage rates was similar during both recessions, the fact that refinancing activity was much higher in 2001-2003 is consistent with much higher home equity during this period.

Of course, 2001 and 2008 are different in many ways besides their house price patterns. For instance, credit standards were likely tighter in 2008 due in part to the disappearance of non-agency securitization. Thus, we now provide some broader time-series evidence that the aggregate responsiveness of refinancing to interest rate changes depends systematically on housing market conditions. Formally, we separately estimate the following two regressions:

$$
\text { Refi }_{t}=\omega_{0}+\omega_{1} \text { Rate }_{t}+\omega_{2} \Delta H P_{t}+\omega_{3} \text { Rate }_{t} \times \Delta H P_{t}+\omega_{4} S D\left(\Delta H P_{t}\right)+\omega_{5} \text { Rate }_{t} \times S D\left(\Delta H P_{t}\right)+\epsilon_{t}
$$

and

$$
\Delta \text { Refi }_{t}=\omega_{0}+\omega_{1} \Delta \text { Rate }_{t}+\omega_{2} \Delta H P_{t}+\omega_{3} \Delta \text { Rate }_{t} \times \Delta H P_{t}+\omega_{4} S D\left(\Delta H P_{t}\right)+\omega_{5} \Delta \text { Rate }_{t} \times S D\left(\Delta H P_{t}\right)+\epsilon_{t}
$$

where $R e f i_{t}$ is the ratio of refinance mortgages with application month $t$ (from HMDA) to the stock of outstanding mortgages in month $t-1$ (from the Flow of Funds), and $\Delta R e f i_{t}$ is the one-year change in Refi (i.e., between months $t-12$ and $t$ ). For Rate $_{t}$ in spefication (3), we use a measure of the average incentive to refinance, defined as the difference between the market rate on new 30-year fixed-rate mortgages in month $t$ and the average rate on outstanding mortgages in month $t$. The more negative this difference, the more the average borrower gains from refinancing. $\Delta$ Rate $_{t}$ in equation (4) is either the 12-month change in the market rate on new 30-year FRMs, or the 12-month sum of monthly 
monetary policy surprises from Gertler and Karadi (2015). These rate measures are interacted with one-year rolling average real house price growth across states $(\triangle \mathrm{HP}$, as in Figure $7 \mathrm{a})$ and the standard deviation of house price growth across states $(\mathrm{SD}(\Delta \mathrm{HP})$, Figure $7 \mathrm{~b})$ to study how the transmission of monetary policy to refinancing varies with the regional house price distribution.

\section{Table 1: Aggregate Refinancing Propensities and Interest Rates}

\begin{tabular}{|c|c|c|c|c|c|c|}
\hline \multirow{3}{*}{$\begin{array}{l}\text { Dep. var.: } \\
\text { Int. rate measure: }\end{array}$} & (1) & (2) & (3) & (4) & (5) & (6) \\
\hline & \multirow{2}{*}{\multicolumn{2}{|c|}{$\frac{\operatorname{Refi}_{t}}{\text { Mtg. rate minus avg. outstanding }}$}} & \multicolumn{4}{|c|}{$\Delta \operatorname{Refi}_{t-12, t}$} \\
\hline & & & \multicolumn{2}{|c|}{$\Delta \mathrm{Mtg}$. rate $_{t-12, t}$} & \multicolumn{2}{|c|}{$\sum_{t-12}^{t}$ Mon. pol. shocks } \\
\hline Rate & $\begin{array}{c}-0.697^{* * *} \\
(0.181)\end{array}$ & $\begin{array}{c}-0.962^{* * *} \\
(0.139)\end{array}$ & $\begin{array}{l}-0.977^{* * *} \\
(0.126)\end{array}$ & $\begin{array}{c}-0.983^{* * *} \\
(0.128)\end{array}$ & $\begin{array}{c}-1.387^{* * *} \\
(0.478)\end{array}$ & $\begin{array}{l}-2.094^{* * *} \\
(0.532)\end{array}$ \\
\hline$\Delta \mathrm{HP}$ & & $\begin{array}{c}0.063^{* * *} \\
(0.012)\end{array}$ & & $\begin{array}{c}0.004 \\
(0.021)\end{array}$ & & $\begin{array}{c}0.007 \\
(0.029)\end{array}$ \\
\hline Rate $\times \Delta \mathrm{HP}$ & & $\begin{array}{c}-0.095^{* * *} \\
(0.030)\end{array}$ & & $\begin{array}{c}-0.070^{* *} \\
(0.032)\end{array}$ & & $\begin{array}{l}-0.248^{* *} \\
(0.120)\end{array}$ \\
\hline $\mathrm{SD}(\Delta \mathrm{HP})$ & & $\begin{array}{c}0.116^{* * *} \\
(0.036)\end{array}$ & & $\begin{array}{l}-0.076 \\
(0.060)\end{array}$ & & $\begin{array}{l}-0.106 \\
(0.084)\end{array}$ \\
\hline Rate $\times \mathrm{SD}(\Delta \mathrm{HP})$ & & $\begin{array}{c}-0.178^{* *} \\
(0.077)\end{array}$ & & $\begin{array}{l}-0.176^{*} \\
(0.092)\end{array}$ & & $\begin{array}{l}-0.944^{*} \\
(0.490)\end{array}$ \\
\hline Constant & $\begin{array}{c}1.003^{* * *} \\
(0.077)\end{array}$ & $\begin{array}{c}0.964^{* * *} \\
(0.060)\end{array}$ & $\begin{array}{c}-0.241^{* *} \\
(0.113)\end{array}$ & $\begin{array}{l}-0.180^{*} \\
(0.108)\end{array}$ & $\begin{array}{l}-0.192 \\
(0.148)\end{array}$ & $\begin{array}{l}-0.193 \\
(0.124)\end{array}$ \\
\hline Adj. R2 & 0.22 & 0.63 & 0.50 & 0.56 & 0.12 & 0.20 \\
\hline Obs. & 222 & 222 & 258 & 258 & 258 & 258 \\
\hline
\end{tabular}

Table shows results from regressions of monthly aggregate refinancing propensities on measures of (mortgage) interest rates. In columns (1) and (2), the interest rate measure is the mortgage rate on new 30-year FRMs (from Freddie Mac PMMS) minus the weighted average coupon on outstanding mortgages guaranteed by Fannie Mae, Freddie Mac, and Ginnie Mae (from eMBS, available since Jan 1994). In columns (3) and (4), the interest rate variable is the 12-month change in the rate on new 30-year FRMs (one standard deviation $=0.78$ ). In columns (5) and (6), the interest rate variable is the 12-month sum of monthly monetary policy surprises (the surprise in the three-month ahead futures rate) from Gertler and Karadi (2015) (one standard deviation =0.28). Sample period: columns (1)-(2): Jan 1994-June 2012; (3)-(6): Jan 1991-June 2012. June 2012 is when Gertler-Karadi series ends. Standard errors in parentheses are Newey-West (4 lags) in columns (1)-(2) and Hansen-Hodrick (12 lags) in columns (3)-(6). Significance: ${ }^{*} p<0.1,{ }^{* *} p<0.05,{ }^{* * *} p<0.01$.

Table 1 presents the results. Column (1) shows that, as expected, there is a strong relationship between refinance propensities at the aggregate level and the average borrower's incentive $\left(\omega_{1}<0\right)$. However, column (2) shows the strength of this relationship varies with prior house price growth: it is significantly stronger when house prices were growing on average $\left(\omega_{3}<0\right)$ and if there is more heterogeneity in house price growth across space $\left(\omega_{5}<0\right)$. These results are at the heart of the mechanism in this paper, as the theoretical model below will help clarify.

In columns (3) and (4), we repeat these regressions in one-year changes, using the change in 30-year FRM rates as the key right-hand side variable. As rates fall, we find refinancing strongly increases. Again, this refinancing response rises with the mean and dispersion of house price growth. Columns (5) and (6) shows result are similar when redoing the same regression using monetary policy shocks,. This specification alleviates concerns about reverse causality, although we would generally expect them to go in the opposite direction of what we find: for instance, one could imagine that as refinancing increases and aggregate demand strengthens, that would lead to an increase in interest rates. While 
these regressions are not as cleanly identified as our results using regional variation around QE1, we find it encouraging that these aggregate time series results are consistent with our model predictions. ${ }^{23}$

\section{A Model of Regional Heterogeneity and Monetary Policy}

In this section, we move to a theoretical analysis of the interaction between monetary policy and regional heterogeneity that can be used to interpret our empirical results. Our goal is to clarify how the regional equity distribution affects the transmission from interest rate cuts to both local and aggregate spending through the refinancing channel. Because the equity distribution is time-varying, we argue that this leads to situations where expansionary monetary policy provides the least stimulus to the places that need it most and thus faces a trade-off between stimulating aggregate spending and increasing cross-region consumption inequality. Our model includes many realistic features of mortgage markets, including equilibrium effects between borrowers and lenders but is intentionally stylized in many other dimensions, as the goal is to transparently illustrate how the refinancing channel of monetary policy interacts with the regional distribution of equity. Embedding our framework into a richer DSGE structure might produce more realistic numerical results but would complicate the analysis in a way that obscures the interaction between interest rates and local equity. As discussed in Section 8.6, complicating the analysis in this way would likely amplify many of our conclusions.

The starting point is a standard consumption-savings model with income shocks and borrowing constraints as in Huggett (1993). To this standard framework, we add housing and mortgages. Houses are subject to stochastic regional house price shocks, and agents can borrow against the value of their homes using fixed-rate mortgages that can be refinanced by paying a fixed cost. We account for equilibrium interactions between borrowers and lenders by assuming that mortgage payments are received by lenders in the economy who potentially adjust consumption when borrowers refinance.

\subsection{Model Description}

Environment. The economy is populated by a continuum of infinitely-lived households, indexed by $i$ and located in region $j=1,2, \ldots, J$, and a representative lender.

Idiosyncratic Earnings. In each period $t$, household's nominal earnings are given by $y_{t}^{i j}$, which follows a random walk with drift,

$$
\log \left(y_{t}^{i j}\right)=\mu_{y}^{j}+\log \left(y_{t-1}^{i j}\right)+\varepsilon_{t}^{i j}
$$

with region-specific income drift $\mu_{y}^{j}$ and mean zero income shock $\varepsilon_{t}^{i j}$, which is i.i.d. over time but possibly correlated both across and within regions.

Assets and Liabilities. Households have access to a risk-free nominal asset $a_{t}^{i j}$ paying nominal interest rate $r_{t}$, with a no-borrowing constraint $a_{t}^{i j} \geq 0$. They are endowed with one unit of housing with nominal price $q_{t}^{j}$, which can be used as collateral for mortgage borrowing. House prices follow a random walk with drift,

$$
\log \left(q_{t}^{j}\right)=\mu_{q}^{j}+\log \left(q_{t-1}^{j}\right)+v_{t}^{j}
$$

\footnotetext{
${ }^{23}$ Results are also similar when using only data from before 2008.
} 
where $\mu_{q}^{j}$ is region-specific trend house price growth and $v_{t}^{j}$ is a mean zero individual house price shock that is i.i.d. over time but is perfectly correlated within a region.

We assume that both earnings and house prices are random walks for two reasons. The first is computational: it allows us to reduce the state space, as we show in Appendix A.3. The second is because it simplifies aggregation: households can be collected into regions and aggregated in a straightforward manner without adding additional state variables because aggregate, regional, and idiosyncratic household shocks enter symmetrically in the problem.

Since our empirical evidence focuses on refinancing for non-moving households, we assume for simplicity that agents cannot buy or sell houses and that mortgage debt is of infinite maturity. Nominal mortgage debt requires a constant mortgage payment $r_{\tau_{0}}^{m} m_{\tau_{0}}^{i j}$ every period, which is determined at the moment of debt issuance $\tau_{0}$. However, households can refinance their mortgage at any time $\tau>\tau_{0}$ by paying a fixed monetary $\operatorname{cost} F_{\tau}^{i j} q_{\tau}^{j}{ }^{24}$ We assume that $F_{t}^{i j}$ is an i.i.d. stochastic process that is uncorrelated with house prices or income in order to generate heterogeneity in refinancing decisions conditional on other household states and thus better fit the data, but our conclusions are similar if this randomness is eliminated.

When refinancing, households lock in the current nominal interest rate $r_{\tau}^{m}$ and future mortgage payments $r_{\tau}^{m} m_{\tau}^{i j}$. Furthermore, we assume that when refinancing, households always borrow up to the maximum amount allowed by the loan-to-value requirement $\gamma$. This simplifies the household decision problem and computations in our benchmark model, but we show in Section 8.2 that relaxing this assumption has little effect on our conclusions. This implies that the new mortgage balance is $m_{\tau}^{i j}=\gamma q_{\tau}^{j}$ and that cashed-out equity is $m_{\tau}^{i j}-m_{\tau_{0}}^{i j}$. These borrowing constraints capture the primary features of fixed-rate mortgages with options to refinance common in the US. Finally, we assume nominal interest rates $\left\{r_{t}, r_{t}^{m}\right\}$ follow an exogenous Markov process, which we discuss in the calibration.

Household Problem. For notational clarity, we drop agent and region indices $i j$ when describing the household problem. We start by describing how households' sequential budget constraints at time $t$ depend on refinancing decisions and then formally state the household problem and value function.

In a period where the household does not refinance, the sequential budget constraint is

$$
p_{t} c_{t}+a_{t+1} \leq a_{t}\left(1+r_{t}\right)+y_{t}-\gamma r_{\tau_{0}}^{m} q_{\tau_{0}}
$$

where $c_{t}$ is period $t$ real consumption and $p_{t}$ is the price level. In a period where the household refinances, the sequential budget constraint is

$$
p_{t} c_{t}+a_{t+1} \leq a_{t}\left(1+r_{t}\right)+y_{t}-\gamma r_{t}^{m} q_{t}+\gamma\left(q_{t}-q_{\tau_{0}}\right)-F_{t} q_{t}
$$

In order to state the household problem recursively, we express all variables relative to house prices. In particular, define $\tilde{x}_{t}=\frac{q_{\tau_{0}}}{q_{t}}$ as the inverse of accumulated equity and $\left\{\tilde{a}_{t}, \tilde{y}_{t}, \tilde{p}_{t}\right\}$ as real assets, real earnings, and consumption good prices in terms of house prices. Furthermore, in order to bound the value function and ensure real variables have a well-defined stationary distribution, we exogenously bound $\tilde{y}$ between $[\underline{y}, \bar{y}]$, and assume earnings and house prices grow on average at identical rates (i.e.,

\footnotetext{
${ }^{24}$ We assume the fixed cost is proportional to current house prices so that these costs remain relevant in the presence of house price growth and because this is necessary to make the household value function homogeneous in house prices.
} 
$\left.\mu_{y}=\mu_{q}\right)$. Finally, as with nominal interest rates, we assume $\tilde{p}_{t}$ follows an exogenous Markov process which is possibly correlated with local house prices and earnings but grows on average at rate $\pi$.

Then, the value function of a household with assets $\tilde{a}$, earnings $\tilde{y}$, accumulated equity $\tilde{x}$, mortgage rate and balance $\left\{r_{0}^{m}, \gamma \tilde{x}\right\}$, and facing prices $\tilde{p}$, current nominal mortgage rate $r^{m}$, nominal interest rate $r$, and fixed cost $F$ can be written recursively as,

$$
\begin{aligned}
V\left(\tilde{a}, \tilde{y}, \tilde{x}, r_{0}^{m}, r^{m}, r, F, \tilde{p}\right) & =\max \left\{V^{n o r e f i}\left(\tilde{a}, \tilde{y}, \tilde{x}, r_{0}^{m}, r^{m}, r, F, \tilde{p}\right), V^{r e f i}\left(\tilde{a}, \tilde{y}, \tilde{x}, r^{m}, r, F, \tilde{p}\right)\right\} \\
V^{n o r e f i}\left(\tilde{a}, \tilde{y}, \tilde{x}, r_{0}^{m}, r^{m}, r, F, \tilde{p}\right) & \left.=\max _{\left\{\hat{a}^{\prime}, c\right\}} u(c)+\beta \mathbb{E}\left[V\left(\hat{a}^{\prime} \frac{\tilde{x}^{\prime}}{\tilde{x}}, \tilde{y}^{\prime}, \tilde{x}^{\prime}, r_{0}^{m}, r^{m^{\prime}}, r^{\prime}, F^{\prime}, \tilde{p}^{\prime}\right)\right) \mid\left(\tilde{y}, \tilde{x}, r^{m}, r, F, \tilde{p}\right)\right] \\
\text { s.t. } \quad \tilde{p} c+\hat{a}^{\prime} & \leq \tilde{a}(1+r)+\tilde{y}-\gamma r_{0}^{m} \tilde{x} \\
\hat{a}^{\prime} & \geq 0, c \geq 0 \\
\log \left(\tilde{x}^{\prime}\right) & =-\mu_{q}+\log (\tilde{x})-v \\
\log \left(\tilde{y}^{\prime}\right) & =\mu_{y}-\mu_{q}+\log (\tilde{y})+\varepsilon-v \\
V^{r e f i}\left(\tilde{a}, \tilde{y}, \tilde{x}, r^{m}, r, F, \tilde{p}\right) & \left.=\max _{\left\{\hat{a}^{\prime}, c\right\}} u(c)+\beta \mathbb{E}\left[V\left(\hat{a}^{\prime} \frac{\tilde{x}^{\prime}}{\tilde{x}}, \tilde{y}^{\prime}, \frac{\tilde{x}^{\prime}}{\tilde{x}}, r^{m}, r^{m^{\prime}}, r^{\prime}, F^{\prime}, \tilde{p}^{\prime}\right)\right) \mid\left(\tilde{y}, \tilde{x}, r^{m}, r, F, \tilde{p}\right)\right] \\
\text { s.t. } \quad \tilde{p} c+\hat{a}^{\prime} & \leq \tilde{a}(1+r)+\tilde{y}-\gamma r^{m}+\gamma(1-\tilde{x})-F \\
\hat{a}^{\prime} & \geq 0, c \geq 0 \\
\log \left(\tilde{x}^{\prime}\right) & =-\mu_{q}+\log (\tilde{x})-v \\
\log \left(\tilde{y}^{\prime}\right) & =\mu_{y}-\mu_{q}+\log (\tilde{y})+\varepsilon-v
\end{aligned}
$$

Inspecting this problem, we can see the household's incentives to refinance. When the current interest rate $r^{m}$ is below the rate when the household last refinanced $r_{0}^{m}$, the household can secure a permanently lower mortgage payment, even if house prices are unchanged. When the current house price is above the price when the household last refinanced, the household can refinance to cash-out accumulated equity $\frac{1}{\tilde{x}_{t}}$ even if rates have not changed, but then faces greater future mortgage payments. Furthermore, when $\mu_{q}>0$, households accumulate equity, on average, when not refinancing. Once enough time has passed to acquire substantial equity, it is optimal to refinance and cash out this equity. This logic is typical of fixed adjustment cost models, where inaction is optimal until the state changes enough to justify paying the fixed cost. These models are often stylized enough that the state-space is one-dimensional with optimal policies characterized by a single adjustment "threshold." This is not true in our setup since we have a richer state-space, with a state (assets $\tilde{a}_{t}$ ) evolving endogenously when not refinancing. Numerical solutions nevertheless yield refinancing decisions characterized by threshold equity levels, which depend on assets, income, fixed costs, and interest rates.

Finally, in order to characterize policy functions numerically, it is helpful to eliminate a state variable. By assuming that households period utility function is $u\left(c_{t}\right)=\frac{c_{t}^{1-\sigma}}{1-\sigma}$ with $\sigma \geq 1$ and $\tilde{p}$ is a random walk with a drift, we show in the Appendix that we can eliminate $\tilde{p}$ as a state variable because the value function is homogenous of degree $\sigma-1$ in $\tilde{p}$. We denote this transformed value function $J\left(\tilde{a}, \tilde{y}, \tilde{x}, r_{0}^{m}, r^{m}, r, F\right)$. The Appendix also provides a detailed description of our computational procedure. In practice, because we wish to compute aggregate consumption as well as its cross-region variance, we need $\tilde{p}$ to have a well-defined stationary distribution. As such, we assume that consumption good prices are proportional to local house prices, implying that $\tilde{p}$ grows at a constant rate $\pi-\mu_{q}$ 
and $\tilde{c}$ can be interpreted as real consumption. ${ }^{25}$

Mortgage Lenders. We introduce mortgage lenders because we are interested in computing aggregate consumption responses to changes in interest rates. If we ignored lenders when computing aggregate consumption, we would potentially miss important offsetting equilibrium effects. For example, when borrowers refinance after a decline in interest rates, the dividends accruing to lenders decrease, which should reduce their consumption (see Greenwald, 2016).

However, a large fraction of mortgage debt is ultimately held by foreign lenders, and we do not want to count changes in their consumption as offsets against the consumption of domestic borrowers. Thus, we assume that mortgage debt is paid into a mutual fund and that a share $\theta$ of this fund is held by a representative US lender while share $1-\theta$ is held by foreign lenders (e.g., Chinese investors). This means that the representative lender ultimately holds a fixed fraction $\theta$ of outstanding mortgage debt. For simplicity, we assume the representative lender is a permanent income consumer and receives certain dividend payments $d$ from the mutual fund (a consequence of a law of large numbers for households). Given a law of motion for dividends $d^{\prime}=\tilde{G}($.$) , the lender's value function is: { }^{26}$

$$
\begin{aligned}
V_{R}\left(a_{R}, d, r\right) & =\max _{c_{R}, a_{R}^{\prime}} u\left(c_{R}\right)+\beta_{R} V\left(a_{R}^{\prime}, d^{\prime}, r^{\prime}\right) \\
\text { s.t. } \quad c_{R}+a_{R}^{\prime} & \leq a_{R}(1+r) e^{-\pi}+\theta d \\
c_{R} & \geq 0
\end{aligned}
$$

Recursive Equilibrium Definition. A Recursive Equilibrium is an initial distribution $S$ for $\left\{\tilde{a}, \tilde{y}, \tilde{x}, r_{0}^{m}, F\right\}$ across households $i$ in regions $j$; initial lender assets $a_{R}^{0}$; a law of motion for $d^{\prime}, r^{m}$ and $r$; value functions $J\left(\tilde{a}, \tilde{y}, \tilde{x}, r_{0}^{m}, r^{m}, r, F\right), V_{R}\left(a_{R}, d, r\right)$; and policy functions $\left[\hat{a}^{\prime}, \tilde{c}, \tilde{x}, \mathbb{I}^{r e f i}\right]\left(\tilde{a}, \tilde{y}, \tilde{x}, r_{0}^{m}, r^{m}, r, F\right)$ and $\left[a_{R}^{\prime}, c_{R}\right]\left(a_{R}, d\right)$ such that

1. The policy functions solve households' and lender's problems.

2. For all realizations of $\left\{\tilde{y}_{t}(i, j), \tilde{x}_{t}(i, j), F_{t}(i, j), r_{t}^{m}, r_{t}\right\}_{t=0}^{\infty}$ across households and regions $(i, j)$, the law of motion for dividends $G\left(S, r^{m}, r\right)$ implied by the policy functions is equal to the perceived law of motion by lenders $\tilde{G}($.$) and satisfies$

$$
d_{t}=\int\left[\left(1-\mathbb{I}_{t}^{r e f i}(i, j)\right) \gamma r_{0, t}^{m}(i, j) \tilde{x}_{t}(i, j)+\mathbb{I}_{t}^{r e f i}(i, j)\left(\gamma r_{t}^{m}+F_{t}(i, j)-\gamma\left(1-\tilde{x}_{t}(i, j)\right)\right)\right] d i d j
$$

This equilibrium definition does not impose market clearing on the asset and consumption market because we take interest rates, goods and house prices, and income as exogenously determined. However, we assume the mortgage market clears by introducing the representative lender. Finally, a region in this economy is defined as a collection of households that experience common shocks to house prices and income. Aggregates are simply obtained by adding up all regions.

\footnotetext{
${ }^{25}$ While we make this assumption mainly for simplicity and convenience, Stroebel and Vavra (2016) show that local retail prices indeed respond strongly to changes in local house prices. As an alternative, we have also performed all our computations by exogenously bounding $\tilde{p}$ and our quantitative results are almost identical.

${ }^{26}$ The law of motion is determined in equilibrium as a function of the refinancing decisions of all households. Since we do not endogenize interest rates, this is straightforward since we can calculate the present value response of dividends to a decline in interest rates entirely from the borrower side and then separately calculate lender consumption responses.
} 


\subsection{Calibration Strategy}

The model is annual and most parameters are standard. As is common in the risk-sharing literature, we set $\sigma=2$ to generate an intertemporal elasticity of substitution of $1 / 2$. We assume a constant nominal risk-free rate $r=0.03$, inflation rate of $\pi=.02$, and set $\beta=0.95$. For simplicity, we set $\beta_{R}=$ $\frac{1}{1+r} e^{-\pi}$ so that lenders perfectly smooth consumption. For our baseline results, we assume the nominal mortgage rate is constant at $r^{m}=0.06$ and then show the response to a one-time, unanticipated permanent decline to $r^{m}=0.05$, which roughly matches 30-year fixed rates before and after QE1. This specification illustrates effects transparently in the simplest possible environment and facilitates numerical calculations, since it eliminates $r^{m}$ expectations from the value function. In Section 8, we instead assume that $r^{m}$ follows an AR process and show that this delivers very similar quantitative conclusions. We set $\gamma=0.8$, so that new mortgages require 20 percent equity and $\theta=0.5$ to account for the substantial fraction of US mortgage debt held abroad, either directly (about 20 percent in 2008 Flow of Funds data) or indirectly through ownership of other institutions (such as banks) that hold mortgage debt. We show robustness to this assumption in Section 8.

Following Kaplan and Violante (2010), income shocks are normally distributed with standard deviation of 0.1 to match earnings changes in PSID data. This is the total standard deviation of household income, but some portion of income is common to households in a region. The standard deviation of this common component is set to 0.025 , to match our regional data. As described above, trend income and house price growth are assumed identical. We calibrate house prices to match the annual growth rate and standard deviation of nominal MSA house price changes from 1990-2014 in CoreLogic data of 0.025 and 0.065 . We assume that in the stochastic steady-state, shocks to house prices and income are independent. This independence on average is assumed when households make their policy decisions, but one of the primary questions we explore in our model is how particular realizations of shocks affect the consequences of monetary policy. During the Great Recession, house prices fell substantially on average but there were substantial differences across regions, which were highly correlated with income changes. Since our empirical evidence is drawn from this period, we calibrate the remaining parameters of the model to match the distribution of house prices and income in 2008 and the refinancing responses across regions following QE1. We call this calibration our baseline economy.

More specifically, to construct our baseline economy, we initialize the model from the stochastic steady-state, but in period $t$, we hit the economy with the aggregate house price decline of $12.5 \%$ observed in 2008. Households are also hit with an additional regional house price shock which can take the value $-12.5 \%, 0 \%,+12.5 \%$ so that $1 / 3$ of regions experience a total house price decline of $25 \%$, $1 / 3$ experience a decline of $12.5 \%$ and $1 / 3$ experience no decline. The $25 \%$ decline is picked to match the house price decline for the lowest housing equity quartile in our empirical analysis, while the $0 \%$ change matches that in the highest housing equity quartile. This means regions in our model can be mapped directly to those in our empirical analysis. Similarly, we calibrate regions so they differ by $-2 \mathrm{SD}, 0$ and $+2 \mathrm{SD}$ of the regional income shock. If these income shocks were uncorrelated with house prices our simulated economy would have 9 regions, representing the $3 \times 3$ combinations of house price and income shocks. However, we instead assume regional house price and income shocks are perfectly correlated in our baseline model to match the very high correlation in the Great Recession. This means our baseline economy effectively has three regions: relatively high house price and income, middle 
house price and income and low house price and income.

Finally, the fixed cost process is calibrated to match the regional responses to mortgage rate reductions under QE1. In particular, we assume that each household draws an i.i.d. fixed cost each period that can take on either a high or a low value and pick the levels of the high and low fixed costs and their relative probabilities to target a monthly refinancing rate just prior to QE1 of 0.0025 , an increase in the refinancing rate of 0.0025 in the lowest house price region, an increase of 0.0075 in the middle house price region, and an increase of 0.011 in the highest house price region. This matches the simple elasticity in the data between house price growth and refinancing.

We calibrate to the 2008 period rather than the stochastic steady-state for several reasons. First, this is the period for which we have strong empirical evidence on the distribution of house price changes, income and refinancing responses from our QE1 event study. Second, our loan level data starts in 2005. It is unclear that any year over the housing boom-bust represents a "normal" steady-state period. Furthermore, by design, monetary stimulus is correlated with recessions and so any empirical evidence on the effects of interest rate reductions is going to come from periods with negative aggregate conditions. That is, any empirical measure of refinancing elasticities to interest rate reductions will always be primarily identified from recession periods. Therefore, we explicitly target this elasticity during such a period in the model. Finally, we focus on the elasticity of refinancing to interest rate reductions across regions rather than aggregate changes in refinancing since aggregate relationships may be contaminated by other confounding unmodeled aggregate shocks.

Although not targeted by our calibration, we document in the Appendix that the household level distribution of equity in the 2008 calibration of the model is a good fit to its empirical counterpart. In both the model and data there is substantial household heterogeneity in equity, with a non-trivial fraction of households more than $20 \%$ underwater. While it would be desirable to also compare model and data relationships between home equity, financial assets and consumption at either the household or regional level, unfortunately, the data necessary to make these comparisons does not exist. Nevertheless, we view the model fit in the Appendix as well as the fact that the model reproduces cross-region refinancing patterns before and after QE1 as a reassuring check on its quantitative usefulness.

\subsection{Theoretical Results in the 2008 Baseline Economy}

Figure 9 shows the threshold property for refinancing decisions in a stationary environment with permanently high or low mortgage rates for a household with median income and assets, as well as in a non-stationary environment right after a permanent mortgage rate decline. ${ }^{27}$ The refinancing equity threshold is lower when mortgage rates are permanently low than when they are permanently high, leading to more frequent refinancing. More importantly, right after a mortgage rate decline, households refinance at even lower levels of equity. Intuitively, refinancing is more frequent in an economy with low mortgage rates because the cost of borrowing-future mortgage payments-is lower while the benefit—equity cash-out net of fixed costs—is independent of mortgage rates. ${ }^{28}$

Figure 10 shows the impulse response of each region to a decline in mortgage rates from 0.06 to 0.05 in the baseline economy which matches economic conditions in 2008. The top panel shows the

\footnotetext{
${ }^{27}$ Since households cannot sell housing, extractable equity is all equity above the fraction $1-\gamma$ required when refinancing.

${ }^{28}$ Appendix Figure A-11 shows how the refinancing threshold changes with assets and earnings.
} 
Figure 9: Refinance Decision Follows a Threshold Policy

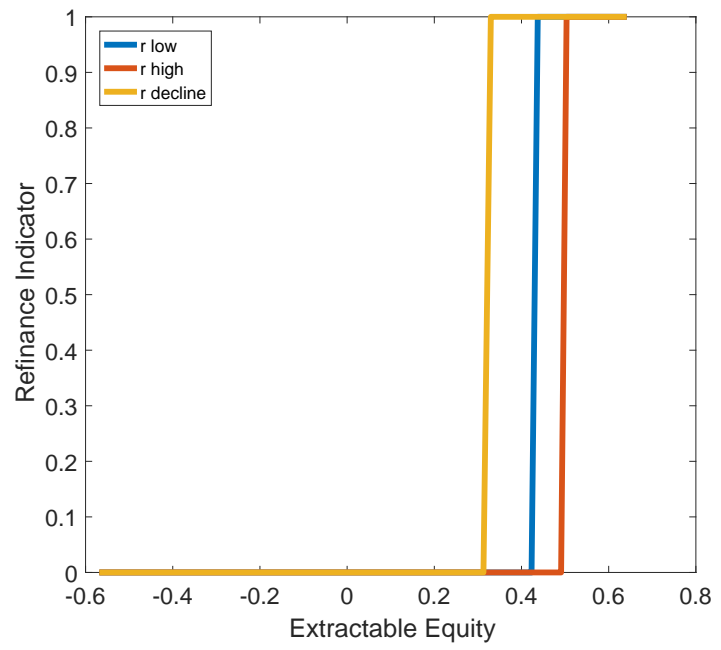

change in the fraction of loans refinancing at a monthly rate. By construction, this matches the changes in Figure 3, since the model is calibrated to hit these numbers. Just as in the data, regions with high equity are more likely to refinance in response to the decline in rates. The bottom panel shows that real consumption also responds more in high equity regions. While we do not have broad consumption data at the regional level, this is consistent with empirical patterns for auto spending in Figure 5.

Figure 10: Response to Interest Decline by Region
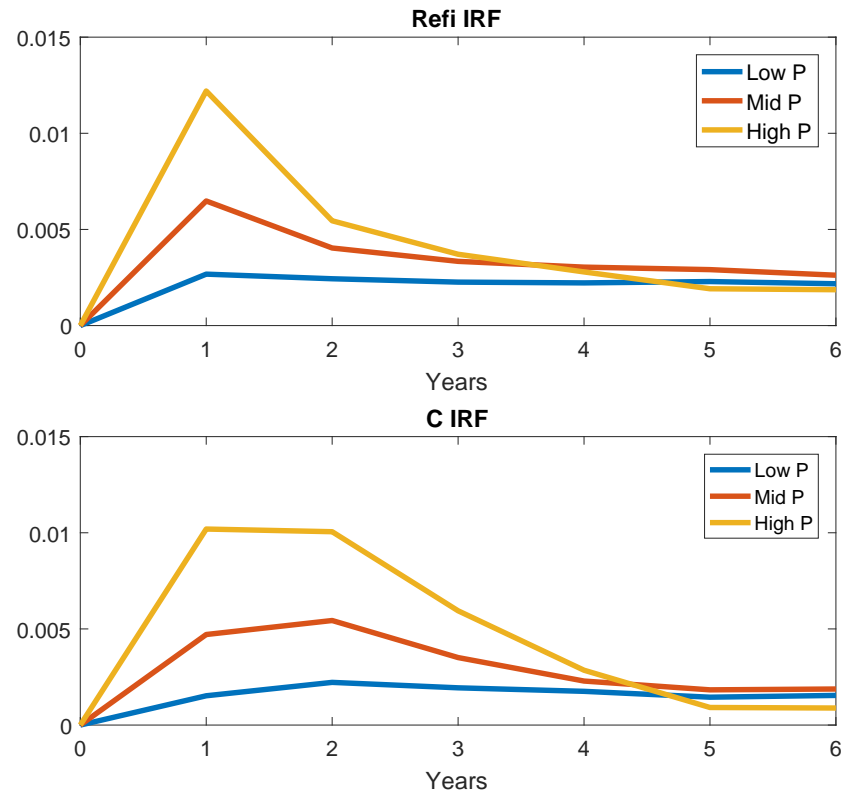

For the baseline 2008 calibration, the refinancing impulse response function (IRF) shows the change in the monthly fraction of households refinancing in response to a one percentage point reduction in mortgage rates. The consumption (C) IRF shows the change in log consumption in response to the same one percentage point reduction in mortgage rates.

We next compute aggregate consumption and the variance of log consumption across regions. The blue lines in Figure 11 show responses to the decline in mortgage rates in our 2008 baseline economy and give our first important theoretical result: a reduction in interest rates increases aggregate consumption but also increases the variance of consumption across regions. This increase in variance 
Figure 11: Aggregate Stimulus vs. Cross-Region Inequality in 2008 and 2001
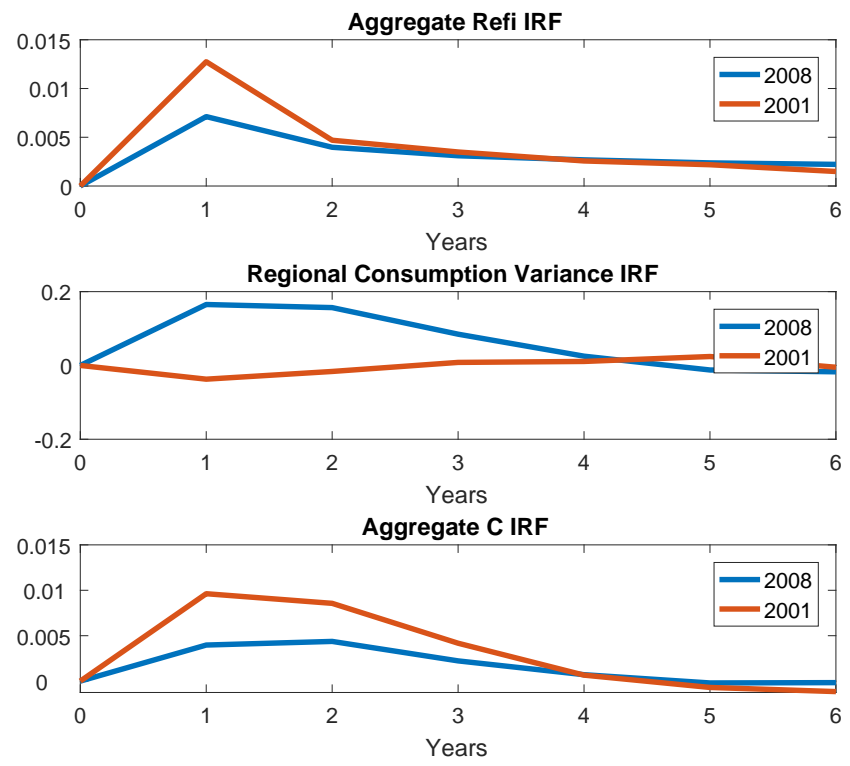

Impulse response functions show the change in the monthly fraction of households refinancing, log aggregate consumption and $\log$ consumption variance across regions in response to a one percentage point reduction in mortgage rates. See text for the description of the baseline economy calibrated to match November 2008 as well as the model specification for the 2001 recession.

occurs because consumption increases most in regions with high house prices. ${ }^{29}$ Since house prices and income are correlated in this economy, these regions already have the highest income and consumption before the interest rate declines. Thus, while monetary policy increases overall consumption, it does so mainly by stimulating consumption in locations that are already doing relatively well.

This trade-off between aggregate stimulus and inequality is strongly suggested by our empirical results showing a strong correlation between house prices, income, refinancing and auto spending around QE. However, the model addresses the concern that 1) our empirical results measure only crossregion effects on borrowers and not offsetting aggregate effects from lenders and 2) we do not have comprehensive empirical measures of regional consumption. Despite these potential concerns, our model nevertheless implies that under economic conditions in 2008, rate declines moderately increased aggregate consumption but that these benefits flowed most strongly to regions doing relatively well.

In terms of quantitative magnitudes, our model implies that a 1 percentage point rate decline under economic conditions in 2008 leads to an increase in aggregate consumption of $0.41 \%$. We show below that this response more than doubles to $0.92 \%$ under economic conditions in 2001. For an aggregate point of comparison, VAR-based estimates which do not allow for time-varying responses imply aggregate consumption responses on the order of $0.5-2 \%$. The standard errors in such time-series estimates are large, but these numbers nevertheless suggest that the refinancing channel of monetary policy is an important part of the overall monetary transmission mechanism, especially when there is substantial housing equity in the economy.

What drives these aggregate effects and why do declines in lender consumption not fully offset increases in consumption by borrowers? First, some mortgage debt is owned by foreign lenders. Second,

\footnotetext{
${ }^{29}$ Note that MPCs out of equity are mildly higher in the worst-off region relative to the best-off regions (0.52 vs 0.46$)$ but that substantially greater equity extraction in the best-off region swamps this difference in MPCs.
} 
borrowers consume a large fraction of extracted equity on impact while lenders smooth consumption by using the income they receive from future repayment of that borrowing, as shown in the Appendix. To explore these effects more concretely, we decompose the IRF of consumption on impact arising from two different channels: 1 ) intertemporal effects from changing the timing of borrowing and lending and 2) wealth transfers between lenders and borrowers arising from changes in the present value of monthly payments. The first channel represents pure cash-out effects taking the present value of payments as given while the second channel arises from both changes in the mortgage rate (holding mortgage balances constant) and from changes in the level of mortgage balances (holding rates constant). ${ }^{30}$ Importantly, channel 1) is identically zero for lenders since they only care about the net present value of payments and not their timing. This means that this term is independent of equilibrium effects arising from lender offsets and so will not vary with the foreign share of lenders.

We find that in our baseline calibration, the total aggregate consumption response on impact arising from pure cash-out effects (i.e., the first channel) is $0.26 \%$, relative to a total consumption response of $0.41 \%$. Thus, in our baseline model, cash-out effects represent more than half of total aggregate effects. Remaining effects arise from a net increase in domestic consumption as monthly mortgage payments from borrowers to lenders decline. In our baseline model, these payment effects are fairly large, but this depends importantly on the fact that a substantial fraction of lenders are abroad and so have no effect on domestic consumption. In a closed economy version of the model in which all lenders are domestic, the cash-out effect is again $0.26 \%$, but the total effect falls to $0.25 \%$, so that $105 \%$ of the aggregate consumption response to interest rates on impact is driven by intertemporal cashout effects. ${ }^{31}$ Unsurprisingly, total aggregate consumption effects are even larger $(0.57 \%)$ in a partial equilibrium version of the model where all lenders are foreign so that there are no lender consumption offsets. Together these results show that equilibrium lender effects matter, but they do not completely undo the consumption response of borrowers because of the presence of cash-out refinancing.

\subsection{Counterfactual Analysis}

That our model reproduces the behavior of the economy just before and after QE1 gives us confidence in using it for more ambitious counterfactual analysis. We now show that the theoretical effects of monetary policy are highly non-linear with respect to the regional distribution of housing equity. This means that accounting for time-variation in this distribution, which we documented in Section 5, is crucial for correctly predicting the aggregate and regional consequences of monetary policy.

\subsubsection{8 vs. 2001 Economic Conditions}

Figure 11 compares the impulse response function of aggregate refinancing activity, aggregate consumption and cross-region consumption inequality to an interest rate shock in the 2008 baseline model to that which would occur if regional house price patterns in 2008 had instead looked like those in 2001. Under the 2001 model distribution of shocks, house prices are constant for the lowest one-third

\footnotetext{
${ }^{30}$ Formally, we measure effect 2 by computing the net present value of payment changes for both borrowers and lenders and multiplying that times the domestic MPC out of wealth for borrowers and lenders. Effect 1 is then the difference between this payment effect and the total consumption response on impact.

${ }^{31}$ The small effect of the payment channel is consistent with the logic in Greenwald (2016). The payment effect is slightly negative in the closed economy because the MPC out of permanent shocks for borrowers is slightly less than 1.
} 
of regions, rise by $5 \%$ for the middle third, rise by $10 \%$ for the highest third of regions, and regional house prices and income are uncorrelated.

As seen in Figure 11, changing the equity distribution dramatically changes the consequences of monetary policy. In 2001, the same decline in interest rates raises aggregate consumption by 2.25 times as much as in 2008. ${ }^{32}$ This means QE1 would have had much larger stimulative effects if enacted under the equity distribution in 2001 as opposed to 2008. There are two reasons for the larger consumption response. First, as shown in the top panel, the aggregate refinancing response to the rate decline is nearly twice as large in 2001 because fewer borrowers are underwater. Second, households that refinance have more equity to extract in 2001, which contributes to an additional consumption boost. Interestingly, as seen in the middle panel of the figure, inequality across regions falls mildly when rates fall in 2001 so that there is not always a trade-off between stimulus and cross-region inequality.

Figure 12: Distribution of Equity and Refinancing Probability: 2008 Calibration vs 2001

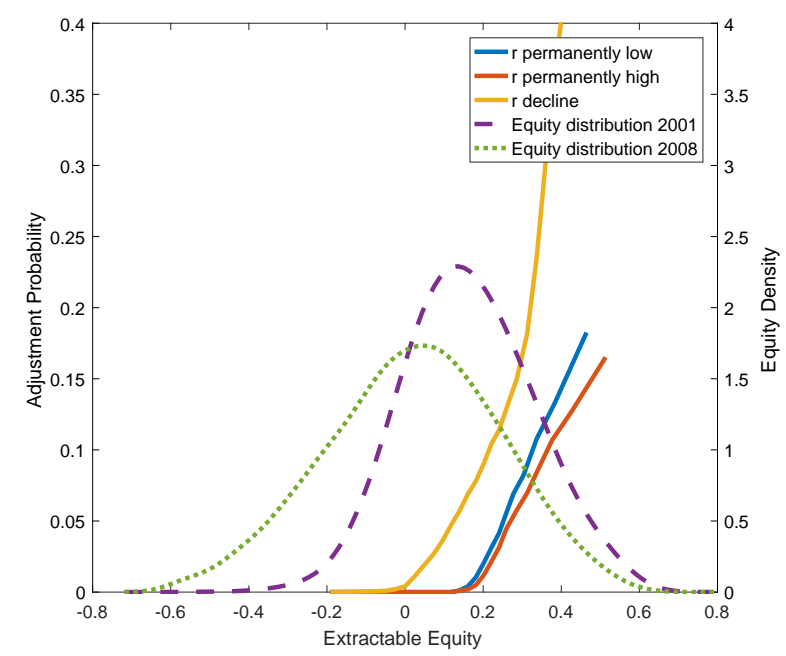

Note: This figure shows the simulated distribution of equity and the fraction of households refinancing under two different equity distributions.

To understand why the 2008 distribution of equity makes refinancing respond less to monetary policy than in 2001, it is useful to illustrate how equity interacts with refinancing decisions. The solid upward sloping lines in Figure 12 show the probability of refinancing as a function of extractable equity under different interest rate policies. These are analogous to the thresholds in Figure 9 but averaging over the joint distribution of assets and income rather than conditioning on a particular value of these variables. When the interest rate is permanently 0.05 (in blue) households are more willing to extract equity than when the interest rate is permanently 0.06 (in red) since borrowing is less costly. This means that the blue refinancing hazard lies slightly above the red refinancing hazard. The line in yellow is the most interesting since it shows the refinancing probability in the period when interest rates fall from 0.06 to 0.05 . When rates fall, many more households refinance since refinancing delivers the benefit of extracting equity plus the benefit of locking in a lower rate. This means that the yellow line is substantially above the red line.

The vertical distance between the yellow and red lines shows the fraction of households who are

\footnotetext{
${ }^{32}$ Specifically, consumption rises by $0.41 \%$ in the first year in 2008 vs. $0.92 \%$ in 2001 . The consumption of borrowers rises by $0.56 \%$ in 2008 and $1.15 \%$ in 2001 , so lender offsets are similar in both years.
} 
induced to refinance by the interest rate decline at each level of extractable equity. The aggregate increase in refinancing induced by the rate decline will then be the vertical difference between the yellow and red lines, weighted by the distribution of equity when the interest rate falls. This means that when the distribution of equity changes, the aggregate refinancing response to rate declines will change. The distribution of equity in our 2008 calibration is shown in dotted green and that in 2001 is shown in dashed purple. In 2008, the distribution of equity shifts left and fans out relative to 2001. On net, this leaves much less mass of the equity distribution in the region where the difference between the yellow and red lines is large. That is, fewer refinancing decisions are triggered by rate declines in 2008 and so the refinancing impulse response to interest rates is reduced.

\subsubsection{Housing Equity Statistics and the Consequences of Monetary Policy}

\section{Figure 13: Effects of Changing Equity Distribution}

\section{(a) Average Equity Effects}
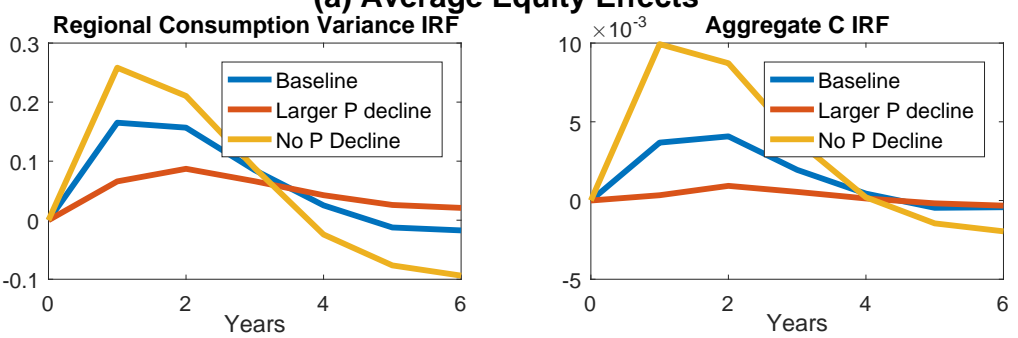

(b) Equity Variance Effects
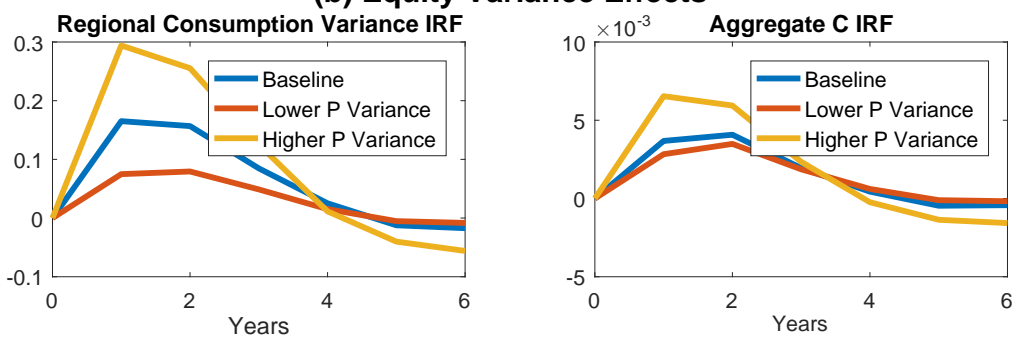

(c) Income-Equity Correlation Effects
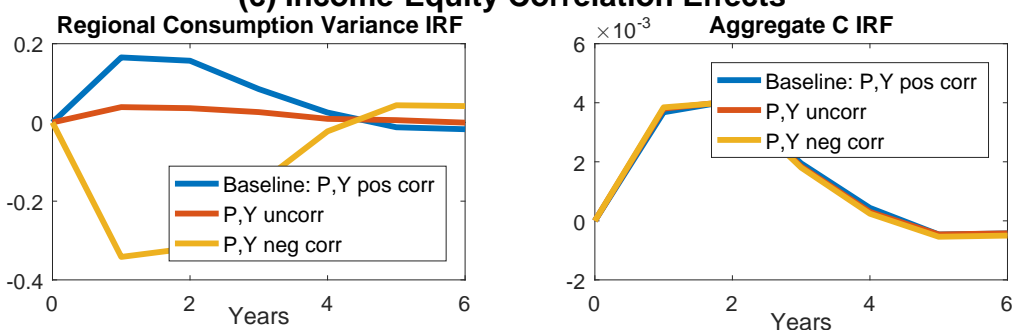

Impulse response functions show the change in log aggregate consumption and in log consumption variance across regions in response to a one percentage point reduction in mortgage rates. The baseline economy includes a $12.5 \%$ aggregate house price decline. In panel a, the "larger P decline" calibration features a $25 \%$ decline in house prices. The variance of equity and its correlation with income are fixed at the 2008 calibration across all simulations. In panel $b$, the high variance calibration doubles the difference between high and low house price regions, while the low variance calibration halves it. All economies feature the same baseline decline in house prices and correlation with income. In the bottom panel, the baseline calibration has income and house prices positively correlated across regions. In the other two calibrations they are uncorrelated or negatively correlated. All simulations feature the same baseline decline in house prices and variance across regions.

The distribution of equity in 2008 in the model is different in three ways from 2001. We now show the independent roles of changes in the level of equity, the cross-region variance of equity, and the correlation between regional income and regional equity for responses to rate declines. 
Panel (a) of Figure 13 shows the effect of changing the mean of the equity distribution at the time of a decline in interest rates. As the level of house prices rises, both inequality and aggregate consumption respond by more to the same decline in interest rates. Aggregate consumption responses increase with house prices, since more households are pushed into the part of the equity distribution where refinancing decisions respond to rate changes, and households also have more equity to consume conditional on refinancing. Cross-region inequality responds more to rate declines when house prices rise because refinancing decisions and resulting consumption responses are highly convex in equity. In regions with negative equity, few households refinance and consumption responses are always near zero. This is true whether households are deeply underwater or only mildly underwater. In contrast, the consumption response to interest rates increases rapidly with equity as equity rises. This means that shifting the distribution of the equity to the right has no effect on consumption responses for those on the left side of the distribution, while it increases them substantially for those on the right side of the distribution. Since initial levels of equity and income are positively correlated in our 2008 baseline, an increase in average equity increases the response of cross-region inequality to rate declines.

Panel (b) of Figure 13 shows the effects of changing the variance of equity across regions. An increase in the variance of equity amplifies both the response of consumption inequality and aggregate consumption to rate declines. The intuition is almost identical to that for the effects of mean shifts and again follows immediately from Figure 12. Moving households with low equity to even lower equity has no effect on consumption responses to monetary policy, since these households do not refinance anyway. In contrast, additional equity amplifies the consumption response of those households on the right side of the distribution with substantial equity.

Finally, Panel (c) of Figure 13 shows effects of changing the correlation between income and equity. If income and equity are uncorrelated, then interest rate declines have almost no effect on crossregion inequality and when income and equity are negatively correlated, declines in interest rates substantially reduce cross-region inequality. In contrast, the correlation between income and equity has almost no effect on aggregate consumption impulse responses. The intuition for inequality effects is straightforward. Consumption levels are higher in high income than low income regions. Consumption responses to interest rate changes are higher in high equity than in low equity locations. Thus, when income and equity are correlated, interest rate declines exacerbate the initial consumption inequality. If income and house prices are instead uncorrelated, as in the stochastic steady-state or our 2001 calibration, then changes in consumption when interest rates fall are largely uncorrelated with initial levels of consumption. If instead they are negatively correlated, then inequality is reduced.

The intuition for the lack of aggregate effects is slightly more subtle and reflects two offsetting forces. Overall, consumption growth is largest for regions with high house price growth and low income, since they have more equity and are also more liquidity constrained. However, low income regions also have lower initial consumption levels than high income regions. This means that the change in consumption levels for high equity-high income regions is similar to that of high equity-low income regions, so that changing the proportion of such regions by altering the correlation between income and house prices has a negligible effect on aggregate consumption responses.

Of course, as shown in Figure 12, the interaction between refinancing and the equity distribution is highly non-linear, so the effects of changing any one moment of the equity distribution will always depend on the initial distribution of equity. For example, effects of a given aggregate house price shock 
on monetary policy will depend on both the initial mean and variance of equity, since both features of the initial distribution will determine how the mean shift interacts with non-linear refinancing decisions. The above analysis shows the effects of particular changes under the 2008 initial distribution, but the policy function in Figure 12 implies the equity distribution will matter much more generally.

An additional robustness analysis in the Appendix illustrates this more concretely by showing that shifts in the mean $(\mu)$ of the equity distribution have effects on monetary policy that depend on the standard deviation $(\sigma)$ of the distribution. In particular, we have just shown that the aggregate consumption response to rate cuts grows with mean equity: $\frac{\partial I R F}{\partial \mu}>0$. In the Appendix we show that this positive relationship is diminishing with $\sigma: \frac{\partial^{2} I R F}{\partial \mu \partial \sigma}<0$. That is, the same increase in mean house prices has a smaller effect on the response of consumption to rate drops in a high $\sigma$ environment. This is because when $\sigma$ is large, more households are either deeply underwater or have so much equity that they will extract it even without a decrease in rates. A rightward shift in the equity distribution then has relatively modest effects, since it does not induce deeply underwater households to refinance, and makes households with substantial equity even less sensitive to monetary policy. These results demonstrate that the effects of shocks to average equity for monetary policy cannot be determined without knowing the full equity distribution. A corollary of this result is that understanding the refinancing channel of monetary policy requires a full accounting of the distribution of equity and so cannot be analyzed in frameworks which abstract from heterogeneity.

\section{Interaction with Mortgage Modification Policies}

The analysis thus far argues that monetary policy in 2008 provided the least stimulus to regions which needed it most and that this dampened its aggregate effects. We now show that various complementary mortgage modification programs which capture elements of policies implemented in the Great Recession can boost the effectiveness of monetary policy in such situations.

We explore two mortgage modification policies: "debt forgiveness" and "relaxed refinancing requirements." We intentionally implement these policies in a stylized fashion in order to starkly illustrate their interactions with monetary policy, but the first policy captures elements of the mortgage write-downs available to some borrowers under HAMP, while the second is more similar to the HARP program. ${ }^{33}$ We model debt forgiveness by assuming that a portion of mortgage debt for any household that is underwater in 2008 is forgiven. In particular, all households with an LTV greater than $\gamma$ have their loans adjusted so that LTV $=\gamma \cdot{ }^{34}$ Under the relaxed refinancing requirements policy, we allow underwater households to refinance rates without meeting the LTV requirement. To reflect the fact that these policies also explicitly eliminated appraisal and other fees associated with refinancing, we assume that underwater households can refinance without paying the fixed cost under both policies.

\footnotetext{
${ }^{33}$ Existing research has shown that institutional features such as servicer participation and market power matter for the consequences of these policies as actually implemented (Agarwal et al., 2016, 2017). Also, especially with modification programs, which in practice usually focus on delinquent borrowers, moral hazard is an important concern that we do not consider. We are not evaluating the specifics of program implementations in the Great Recession or the detailed institutional design of any such programs. We are instead interested in the broad ways in which such programs, independently implemented by the fiscal authority, might affect the consequences of monetary policy.

${ }^{34} \mathrm{We}$ account for the negative effect of this policy on lenders, although in reality, lenders would likely be compensated by the government, which in turn would raise taxes. But these taxes would likely be borne disproportionately by the richer lenders. Even with lump-sum taxes from all households, borrowers with forgiven debt would receive a net transfer.
} 
Figure 14: Mortgage Modification Effects

(a): Response to Mortgage Modification w / Constant $r^{m}(\mathbf{b})$ : Response to Mortgage Modification $+r^{m}$ Decline
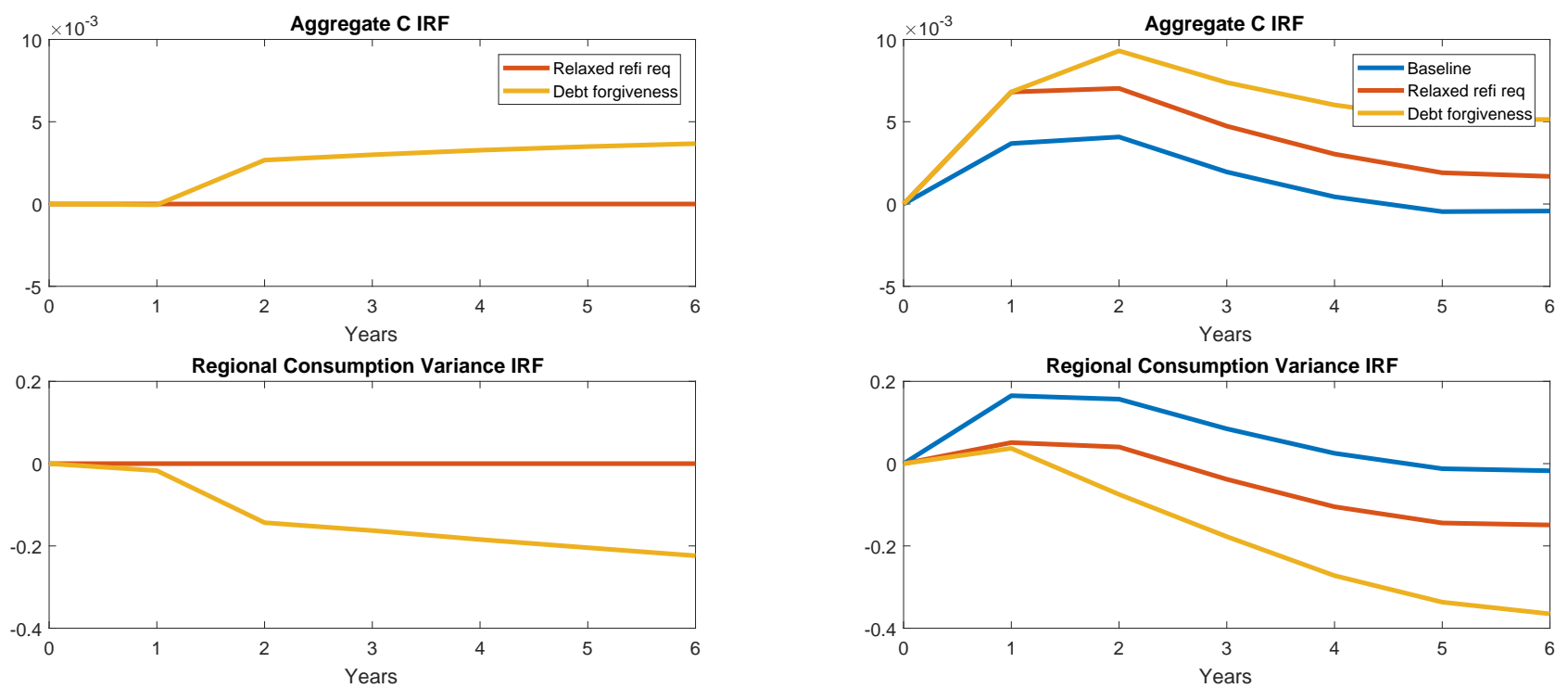

(c): Response to $r^{m}$ Decline, Taking Mortgage Modification Programs as Given
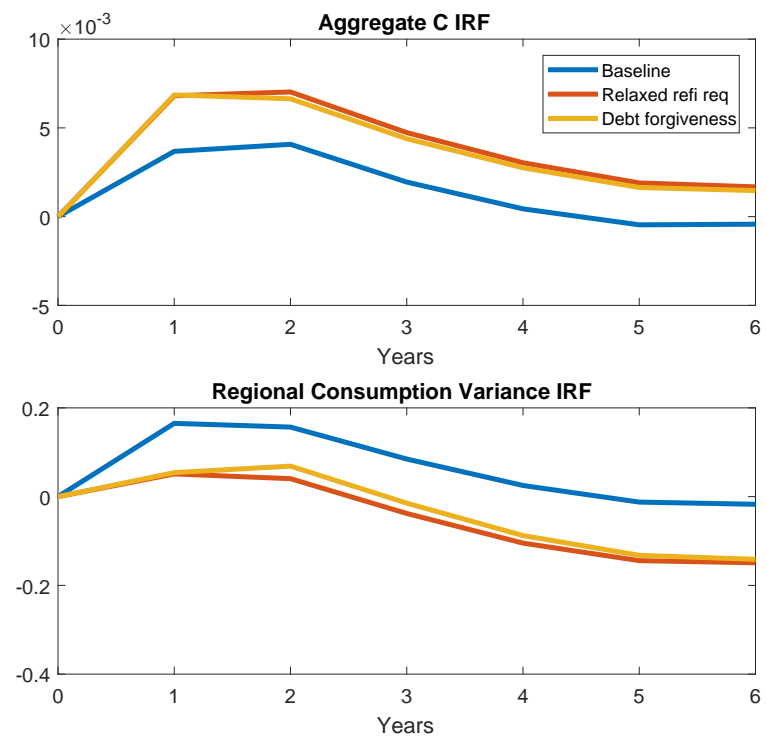

Panel (a) of this figure shows the effects of the debt reduction and relaxed refinancing requirement policies described in the text when interest rates are held fixed. Panel (b) shows the effects of simultaneously reducing rates and implementing the modification policies. Panel (c) shows the change in output and inequality from reducing interest rates and implementing mortgage modification relative to an economy that implements mortgage modification but has no decline in rates. 
Panel (a) of Figure 14 shows the response to these modification programs, holding interest rates constant. That is, it shows the effects of the programs alone with no simultaneous monetary policy change. The debt reduction program increases total consumption in the economy as it redistributes resources from unconstrained lenders to more constrained borrowers. ${ }^{35}$ It also reduces cross-region inequality, since debt forgiveness is available only to underwater households. In contrast, relaxing refinancing requirements has no effect when interest rates are held constant because underwater households have no reason to refinance, even if it is costless, when rates are constant. Thus, this policy has no effect in the model unless accompanied by a reduction in mortgage rates.

Panel (b) of Figure 14 shows the response to simultaneously lowering rates and implementing mortgage modification. That is, it shows the combined effects of these policies. For comparison, we also show the baseline economy with a rate decline but no mortgage modification. Relative to the baseline, the combined policies lead to larger increases in spending and smaller increases in inequality.

Since impulse responses in panel (b) of Figure 14 are computed relative to an economy without either mortgage modification or monetary policy, they tell us the combined effects of these policies. In contrast, panel (c) isolates impacts of monetary policy from direct effects of mortgage modification. In particular, we compute consumption statistics with both rate declines and mortgage modification relative to an economy with mortgage modification but no rate decline. Clearly, the presence of either modification program increases the effectiveness of monetary policy and reduces its inequality effects. Interestingly, from the perspective of monetary policy, these two mortgage modification programs work nearly identically. Both policies increase the sensitivity of underwater households to changes in rates and so amplify the response of spending to interest rate declines. The fact that debt forgiveness has larger effects than relaxed refinancing requirements in panel (b) arises because this policy has direct effects on the economy independently of rate changes, while the relaxed refinancing requirements policies work only through their interaction with interest rates. Since debt forgiveness has both direct effects as well as interaction effects with monetary policy, the combined effects are ultimately larger. However, implications for the efficacy of monetary policy are nearly identical.

Thus, even though the regional distribution of shocks in 2008 substantially hampered monetary policy transmission, there is at least some scope for mitigating these effects under such conditions. Policies that help underwater households refinance can interact importantly with interest rate changes to amplify effects of monetary policy and minimize their consequences for cross-region inequality.

\section{Robustness and Model Extensions}

In this section, we consider many model extensions and show that time-variation in the consequences of monetary policy continues to hold. While the quantitative magnitudes vary a bit across specifications, the qualitative conclusions are very robust since they are driven by two simple features of the economy: 1) underwater households cannot refinance without putting new cash into the house, which makes policy functions very non-linear in equity, and 2) the regional distribution of equity changes over time. Time-varying refinancing responses to rate changes arise immediately from the interaction of these two features. Since this non-linearity is highly robust across models (and indeed in any rea-

\footnotetext{
${ }^{35}$ These effects are tiny on impact but grow with time. This is consistent with conclusions in Ganong and Noel (2017) that debt forgiveness has little effect on consumption if, as in our experiment, households still have no equity after forgiveness.
} 
sonable model, underwater households should not be able to refinance and tap into home equity), it is unsurprising that our conclusions are equally robust. Our discussion is intentionally brief but additional details are provided in the Appendix for interested readers.

\subsection{Accounting for Additional Heterogeneity}

\subsubsection{ARM Shares}

Our baseline analysis assumes that all mortgages have fixed rates. In reality, a substantial fraction of households have adjustable-rate mortgages (ARMs) whose rates reset even if households do not refinance. The presence of ARMs has some potential to change the refinancing channel of monetary policy. On the one hand, with ARMs, payments decrease when rates decline even if households do not refinance. To the extent that borrowers have higher MPCs than lenders, this should amplify the spending response to monetary policy (e.g., Auclert, 2015). On the other hand, the presence of ARMs reduces the interaction between cash-out decisions and interest rate declines since households do not need to accelerate equity extraction to take advantage of lower rates today. This makes cash-out-based spending less responsive to monetary policy.

Accounting for ARMs also potentially matters for cross-region inequality, since ARM shares of outstanding loans in November 2008 were higher in MSAs with lower equity. We show these patterns in the Appendix. ARM shares increased more during the boom years in areas with larger price increases, which subsequently experienced larger busts. Since ARMs were more prevalent in low equity regions, it is possible more mortgages experienced rate declines in these regions despite our previous evidence that fixed-rate mortgages were less likely to be refinanced.

The importance of ARM offsets depends crucially on what fraction of ARM borrowers actually saw rate resets after QE1. There are many reasons why not all ARM borrowers benefit from rate declines: (i) most ARMs are "hybrids" with initial fixed-rate periods of 3-10 years, (ii) ARMs typically have "rate floors," which are often set at the initial rate of the loan, and (iii) the initial fixed-rate period often coincides with an interest-only (IO) period during which the borrower pays only interest and not principal. When the IO period ends, required payments jump up, which can more than offset simultaneous rate decreases. The Appendix shows the share of ARMs that experience significant rate reductions of 1 percentage point or more from November 2008 - June 2009 against $E_{j, \text { Nov2008 }}^{\text {. Cross- }}$ MSA differences in rate resets are muted relative to differences in ARM shares. Overall, the variation in ARM resets with $E_{j, N o v 2008}^{m e d}$ is less than half that of FRM refinancing propensities so that declines in effective rates were still larger in high equity MSAs after accounting for ARMs.

To explore the role of ARMs for our theoretical results, we solve a model in which some households borrow using FRMs while others use ARMs. ARMs in the model adjust every period to the current mortgage rate, and we calibrate regional ARM shares to match the data. In light of the above discussion, this overstates the actual cross-region variation in ARM resets after QE1. Thus, it is a conservative upper bound on the extent to which ARMs change our results. However, even under this conservative calibration, ARMs have little effect on our conclusions. Low equity regions have more ARM but less FRM rate resets. On net, the FRM effect dominates so that there are more rate reductions in high equity regions. Moreover, low equity regions have no cash-out activity since there is no equity to remove, 
while high equity regions have significant cash-out and spending response to rate declines. ${ }^{36}$

We also separately decompose the role of ARM and FRM borrowers in determining aggregate time-series variation in spending responses to rate declines. Clearly, time-variation is much larger for FRM borrowers than ARM borrowers, and aggregate spending patterns are much closer to those of FRM borrowers since they are a larger share of the economy. However, the spending response of ARM borrowers still declines by $20 \%$ in 2008 relative to 2001. It is also interesting to note that in 2001, FRM borrowers respond more to rate declines than ARM borrowers, in contrast to typical intuition that more flexible mortgages amplify responses to monetary policy. This is because when FRM borrowers actively refinance, they also extract equity and thus front-load their increase in spending, while passive rate resets under ARMs do not result in equity extraction.

\subsubsection{Strength of Cross-Region Effects}

Our baseline model calibrates refinancing costs to match the raw correlation between refinancing and equity across regions in the data after QE1. However, as discussed earlier, the strength of this relationship depends on what additional covariates are included in regressions. To explore the robustness of our results to smaller responsiveness of local refinancing to housing equity, we solve a model with less regional heterogeneity in refinancing by doubling fixed costs, which roughly halves the cross-region differences in refinancing after QE1. Clearly the exact magnitude of our effects is moderately reduced, but the qualitative patterns remain unchanged and time-variation remains economically significant.

\subsubsection{Preceding Booms}

Does the boom-bust nature of the Great Recession where regions with the largest house price declines previously had the largest house price booms change our implications for cross-region inequality? To assess this, we repeat our baseline exercise but in a model where the house price bust is preceded by a boom of equal magnitude. We find that our conclusions are unchanged with such an exercise.

\subsection{Endogenous Cash-out}

In our baseline model, we abstract from the distinction between cash-out and non-cash-out refinancing by assuming households always extract all available equity when refinancing. We make this assumption largely for tractability, but find that it makes little difference for our conclusions. In particular, the Appendix shows that our results are very similar in a model where households can choose between a cash-out refi, modeled as before, and a pure rate refi, in which they lower their rate but do not cash-out any equity. Allowing households to choose between cash-out and non-cash-out refi makes little difference because households in high equity locations typically extract equity when refinancing anyway, and households in low equity locations on average have little equity to extract, so that the distinction between a cash-out and a rate refi is less relevant.

\footnotetext{
36 Since this result is driven by variation in equity, it is consistent with results in Di Maggio et al. (2017) that after conditioning on equity, greater ARM shares are associated with larger spending responses to rate changes.
} 


\subsection{Interest Rate Process}

In our baseline, we assume mortgage rates are constant across time and show responses to one-time unanticipated declines in these rates. In response to QE1, mortgage rates declined and remained low for an extended period of time. This one-time shock results in the simplest environment and increases the computational tractability of the model, which allows some of the robustness exercises in this section. However, we also explored how our results change when $r^{m}$ instead follows an AR process, with persistence of 0.89 and standard deviation of 0.0055 to match 30-year mortgage rates from 19902015. We find that our results are quantitatively similar under both specifications. Given this, we use the simpler one-time shock as our baseline.

Our baseline model also assumes that monetary policy lowers the long-term mortgage rate $r^{m}$ but not the short rate $r$. This describes the behavior of rates during QE1 since short-term rates were at the zero lower bound. However, monetary policy typically results in both rates falling. We find that our results are similar when we lower both $r$ and $r^{m}$ to maintain a constant spread. This means that our results apply to QE1, but also to more conventional monetary policy since Gilchrist, Lopez-Salido, and Zakrajsek (2015) argue that "the efficacy of unconventional policy in lowering real borrowing costs is comparable to that of conventional policy" throughout the yield curve. Since both conventional and unconventional monetary policy move mortgage rates, our results thus apply to monetary policy in general. ${ }^{37}$ However, our results are quite different when we instead lower only $r$ and not $r^{m}$. This experiment shows that the time-varying effects of monetary policy that we emphasize in this paper work through the refinancing channel since the standard intertemporal channel arising from pure changes in short-rates is both small and invariant to the distribution of equity.

\subsection{Income Process}

The solution to the equity extraction problem balances transaction costs against the desire to extract housing equity. Since our baseline model includes only permanent income shocks, desired equity extraction is largely determined by past and current house price shocks and interest rate behavior rather than by a desire to smooth transitory income shocks. Introducing persistent but not permanent income shocks would substantially complicate the model solution, but it is straightforward to introduce completely transitory income shocks and thus a role for equity extraction in smoothing income shocks. Doing so yields results that are very similar to the baseline model. ${ }^{38}$ Furthermore, our baseline analysis assumes that regional income and house price shocks are uncorrelated. Since one of our points is that the correlation between regional income and house prices changes across time, it is not obvious what the correct correlation to feed into the model is. Nevertheless, we find that our baseline findings are relatively conservative since results are amplified if we instead assume that regional income and house price shocks are perfectly correlated.

\footnotetext{
${ }^{37}$ Using the high frequency monetary policy shocks from Gertler and Karadi (2015), we have explored whether the passthrough of short-term monetary policy shocks to mortgage rates varies with house price growth in the economy. Running a regression of monthly changes in the 30-year FRM rate on federal fund rate shocks interacted with annual national house price growth, we find strong pass-through of federal fund rates to mortgage rates but no interaction with house price growth. This suggests that any time-variation in the transmission of short to long rates that might exist in the data is orthogonal to time-variation in the refinancing channel of monetary policy arising from movements in the distribution of equity.

${ }^{38}$ The standard deviation of these temporary shocks is set to 0.05 to match various estimates from earnings data.
} 


\subsection{Amortization and Lifecycle Effects}

Our model features interest-only mortgages and so households do not accumulate equity through amortization. This means that our baseline calibration may understate the speed of equity accumulation in the data. Since households cannot buy or sell housing in our baseline model, faster house price growth is similar to including amortization, and we find that our conclusions are amplified if we increase house price growth. Thus, our baseline is again relatively conservative. Furthermore, lifecycle effects mean that households tend to accumulate equity as they age. Lifecycle effects can potentially have interesting interactions with the refinancing channel of monetary policy, as explored thoroughly in Wong (2016). As Wong emphasizes, these effects may change over time with population aging, but this is due to long-run secular trends and thus unlikely to drive the variation in effects of monetary policy at business cycle frequencies, which are the focus of our analysis. We thus abstract from lifecycle effects since they would substantially complicate our analysis by introducing another state variable. ${ }^{39}$

\subsection{General Equilibrium Effects}

Our baseline analysis allows for equilibrium offsets from the interaction between borrowers and lenders, but the size of these offsets depends on the domestic share of lenders. Our baseline assumes 50 percent of mortgage payments ultimately go to non-US lenders, but measuring the foreign share of lenders is difficult since a large share of mortgage debt is held by commercial banks, which are owned in part by foreigners. As an additional robustness exercise, we explore two extreme assumptions for mortgage debt holdings. This also allows us to assess the importance of equilibrium lender forces for our results. ${ }^{40}$ As the foreign share of lenders declines, equilibrium effects grow in importance and aggregate consumption responds less to rate cuts. However, short-run effects remain positive even in the unrealistic case where all mortgage payments go to domestic households so none of our conclusions about short-run stimulus-inequality trade-offs are altered. This is because, as discussed above, cash-out refinancing is an important part of stimulus effects. Since we assume lenders are equally distributed geographically, their behavior is irrelevant for cross-region results.

While we endogenize lender offsets, our model treats income and house prices as exogenous to simplify the analysis and provide more transparent intuition for our main mechanism. However, endogenizing income and house prices in a more fully fledged DSGE framework should amplify our conclusions. We find that refinancing activity and consumption responses to interest rates are stronger in well-off regions. If some portion of spending is on non-tradable goods and if greater mortgage borrowing drives up house prices, then income and house prices will rise more in initially well-off locations, amplifying initial inequality. Similarly, endogenizing aggregate income and house prices will amplify aggregate time variation if greater aggregate spending generates greater aggregate income, as in New Keynesian models. In fact, in the representative agent model of Greenwald (2016), endogenizing house prices indeed amplifies the feedback from equity shocks to monetary stimulus. ${ }^{41}$

We also take aggregate inflation as exogenous. If inflation rises when interest rates fall, this introduces a nominal debt revaluation effect which transfers resources from lenders to borrowers. Such

\footnotetext{
${ }^{39}$ Note also that our empirical results explicitly control for cross-region variation in demographics.

${ }^{40}$ Note that this is isomorphic to changing the MPC out of permanent income for lenders and so also provides robustness to changing the consumption behavior of lenders.

${ }^{41}$ We thank Dan Greenwald for computing these results.
} 
interactions are previously explored extensively in Auclert (2015).

Finally, we take both $r$ and $r^{m}$ as given and do not impose liquid asset market clearing. However, when $r^{m}$ falls, liquid savings rise mildly. If we imposed asset market clearing, this would lead to a small decline in $r$ and increase consumption through standard intertemporal substitution channels. Furthermore, this asset response increases with the strength of the refinancing response to $r^{m}$. Thus, imposing asset market clearing would complicate the model but amplify our effects.

\subsection{Housing Adjustment and Default}

We do not allow households to buy/sell housing or default on mortgages. Allowing households to move to extract equity would complicate the setup but would produce similar non-linear interactions between equity and consumption. Introducing a construction sector and endogenous housing should also amplify our results. When households have more equity, there is more scope to purchase larger houses and increased housing demand will 1) drive up house prices and amplify initial equity differences and 2) drive up construction, amplifying initial income differences.

Introducing an option to default and move to rental housing should similarly amplify cross-region effects, especially in an environment with endogenous house prices. Only underwater households face default risk. When rates fall, mildly underwater households may put cash into their homes to refinance, lower payments and avoid default but this is infeasible for deeply underwater households. As foreclosures have negative spillovers to local house prices, the places initially hit by large house price declines may enter house-price-foreclosure spirals. Since underwater homeowners in these locations have little ability to refinance into lower payments, rate declines will have little effect on default in the hardest hit locations and, thus, limited ability to arrest such foreclosure spirals. ${ }^{42}$

\section{Conclusions}

The Great Recession led to a prolonged period of monetary stimulus throughout much of the developed world. These policies are typically studied through the lens of representative agent New Keynesian models, which emphasize the importance of intertemporal substitution. In this paper, we explore a complementary channel of monetary transmission through collateralized lending and show that understanding this channel requires moving beyond a representative borrower. Non-linear interactions between collateral constraints, refinancing and spending mean that the distribution of housing equity plays a crucial role in the economy's response to interest rate declines.

Using an equilibrium, heterogeneous household model of mortgage borrowing, we argue that the cross-region distribution of housing equity during the Great Recession hampered the ability of monetary policy to stimulate aggregate spending through the refinancing channel. Furthermore, large variation in house price growth that was strongly correlated with local economic activity meant that monetary stimulus largely flowed to the locations which needed it least. These theoretical conclusions rest on the distribution of equity, which is assumed away in typical representative agent analyses.

\footnotetext{
${ }^{42}$ Of course, the welfare consequences of default must also account for the fact that homeowners may get some benefit from living in their homes during lengthy foreclosure processes and could get some benefit in certain situations from strategic default. However, we make no claims on the welfare consequences of default and merely argue that it would amplify the effects of cross-region equity on monetary policy that are the focus of our analysis.
} 
Under alternative distributions of housing equity, such as that observed in 2001, aggregate monetary stimulus is much more powerful and can potentially moderate regional business cycles.

We provide evidence of these collateral effects using novel household-level data on mortgage debt and refinancing. We show that after QE1, there was an aggregate increase in refinancing but that there was little response in the hardest hit regions, where many households were underwater. The empirical distribution of house price growth was quite different during the 2001 recession: aggregate house price growth was positive throughout the recession, and regional house price growth was uncorrelated with local unemployment. Consistent with our theoretical predictions, there was much more refinancing activity during the 2001 easing cycle than during the Great Recession, and refinancing was actually more common in regions with high unemployment. Thus, the data confirms that variation over time in the collateral distribution is key for understanding the time-varying consequences of monetary policy.

Our data come from the US mortgage market, so our analysis focuses on regional house price shocks since they are the dominant source of shocks to home equity. Changes in the distribution of other types of collateral will generate many of the same implications for monetary policy, but the relevant sources of shocks and heterogeneity may differ. For example, sectoral shocks may play an important role in influencing the distribution of collateral across firms and influence the response of investment to monetary policy through similar mechanisms. Variation across time in economic activity and its correlation with housing equity and other forms of collateral is also not unique to the US. Europe has experienced persistent cross-country differences in economic growth that are highly correlated with house price movements. While the prominence of fixed-rate mortgages and other institutional features of mortgage contracts differs between the US and Europe and across countries within Europe, Section 8.1.1 shows that our conclusions are not particularly sensitive to variation in fixed-rate shares. We leave a more thorough analysis of the effects of the collateral distribution in these alternative contexts to future work, but our analysis suggests that central banks are likely to face trade-offs which vary importantly with the distribution of collateral. Since this distribution varies over time, tracking its evolution is crucial for accurately assessing the effects of monetary policy (see Fuster, Guttman-Kenney, and Haughwout, 2016, for an effort along these lines). 


\section{References}

Abel, Joshua and Andreas Fuster. 2018. “How Do Mortgage Refinances Affect Debt, Default, and Spending? Evidence from HARP." Staff Report 841, Federal Reserve Bank of New York.

Agarwal, Sumit, Gene Amromin, Itzhak Ben-David, Souphala Chomsisengphet, Tomasz Piskorski, and Amit Seru. 2016. "Policy Intervention in Debt Renegotiation: Evidence from the Home Affordable Modification Program." Journal of Political Economy forthcoming.

Agarwal, Sumit, Gene Amromin, Souphala Chomsisengphet, Tim Landvoigt, Tomasz Piskorski, Amit Seru, and Vincent Yao. 2017. "Mortgage Refinancing, Consumer Spending, and Competition: Evidence From the Home Affordable Refinance Program." Working Paper 21512, NBER.

Alpanda, Sami and Sarah Zubairy. 2017. "Household Debt Overhang and Transmission of Monetary Policy." Working Paper.

Arrow, Kenneth J., Theodore Harris, and Jacob Marschak. 1951. "Optimal Inventory Policy." Econometrica 19 (3):250-272.

Auclert, Adrien. 2015. "Monetary Policy and the Redistribution Channel." Working Paper, MIT.

Avery, Robert B., Neil Bhutta, Kenneth P. Brevoort, and Glenn B. Canner. 2011. “The Mortgage Market in 2010: Highlights from the Data Reported under the Home Mortgage Disclosure Act." Federal Reserve Bulletin 97 (6).

Barro, Robert. 1972. "A Theory of Monopolistic Price Adjustment." Review of Economic Studies 39 (1).

Beraja, Martin, Erik Hurst, and Juan Ospina. 2016. "The Aggregate Implications of Regional Business Cycles." Working Paper 21956, National Bureau of Economic Research.

Berger, David, Veronica Guerrieri, Guido Lorenzoni, and Joseph Vavra. 2015. "House Prices and Consumer Spending." Working Paper 21667, NBER.

Berger, David and Joseph Vavra. 2015. “Consumption Dynamics During Recessions.” Econometrica 83 (1).

Bernanke, Ben S., Mark Gertler, and Simon Gilchrist. 1999. "The financial accelerator in a quantitative business cycle framework." In Handbook of Macroeconomics, vol. 1. Elsevier, 1341-1393.

Bhutta, Neil and Benjamin J. Keys. 2016. "Interest Rates and Equity Extraction during the Housing Boom." American Economic Review 106 (7):1742-1774.

Brady, Peter J., Glenn B. Canner, and Dean M. Maki. 2000. “The Effects of Recent Mortgage Refinancing." Federal Reserve Bulletin 86 (July):441-450.

Caballero, Ricardo and Eduardo Engel. 1999. "Explaining Investment Dynamics in U.S. Manufacturing: A Generalized (S,s) Approach." Econometrica 67.

Canner, Glenn, Karen Dynan, and Wayne Passmore. 2002. "Mortgage Refinancing in 2001 and Early 2002." Federal Reserve Bulletin 88 (December):469-481.

Caplin, Andrew, Charles Freeman, and Joseph Tracy. 1997. "Collateral Damage: Refinancing Constraints and Regional Recessions." Journal of Money, Credit and Banking 29 (4):496-516.

Charles, Kerwin Kofi, Erik Hurst, and Matthew J. Notowidigdo. 2013. “Manufacturing Decline, Housing Booms, and Non-Employment." Working Paper 18949, NBER. 
Chen, Hui, Michael Michaux, and Nikolai Roussanov. 2013. "Houses as ATMs? Mortgage Refinancing and Macroeconomic Uncertainty." Working Paper 19421, NBER.

Dell'Ariccia, Giovanni, Deniz Igan, and Luc Laeven. 2012. "Credit booms and lending standards: Evidence from the subprime mortgage market." Journal of Money, Credit and Banking 44 (2-3).

Di Maggio, Marco, Amir Kermani, Benjamin J. Keys, Thomas Piskorski, Rodney Ramcharan, Amit Seru, and Vincent Yao. 2017. "Interest Rate Pass-Through: Mortgage Rates, Household Consumption, and Voluntary Deleveraging." American Economic Review forthcoming.

Di Maggio, Marco, Amir Kermani, and Christopher Palmer. 2016. “How Quantitative Easing Works: Evidence on the Refinancing Channel." Working Paper 22638, NBER.

Frame, W. Scott, Andreas Fuster, Joseph Tracy, and James Vickery. 2015. "The Rescue of Fannie Mae and Freddie Mac." Journal of Economic Perspectives 29 (2):25-52.

Fratantoni, Michael and Scott Schuh. 2003. "Monetary policy, housing, and heterogeneous regional markets." Journal of Money, Credit and Banking 35 (4):557-589.

Fuster, Andreas, Benedict Guttman-Kenney, and Andrew Haughwout. 2016. "Tracking and Stress-Testing U.S. Household Leverage." Staff Report 787, Federal Reserve Bank of New York.

Fuster, Andreas, Stephanie H. Lo, and Paul S. Willen. 2017. “The Time-Varying Price of Financial Intermediation in the Mortgage Market." Staff Report 805, Federal Reserve Bank of New York.

Fuster, Andreas and Paul S. Willen. 2010. "\$1.25 Trillion is Still Real Money: Some Facts About the Effects of the Federal Reserve's Mortgage Market Investments." Public Policy Discussion Paper 10-4, Federal Reserve Bank of Boston.

Ganong, Peter and Pascal Noel. 2017. "The Effect of Debt on Default and Consumption: Evidence from Housing Policy in the Great Recession." Working Paper, Harvard University.

Garriga, Carlos, Finn E. Kydland, and Roman Sustek. 2013. “Mortgages and Monetary Policy.” Working Paper 19744, NBER.

Gertler, Mark and Peter Karadi. 2015. "Monetary Policy Surprises, Credit Costs, and Economic Activity." American Economic Journal: Macroeconomics 7 (1):44-76.

Gilchrist, Simon, David Lopez-Salido, and Egon Zakrajsek. 2015. "Monetary Policy and Real Borrowing Costs at the Zero Lower Bound." American Economic Journal: Macroeconomics 7 (1).

Greenwald, Daniel L. 2016. “The Mortgage Credit Channel of Macroeconomic Transmission." Working Paper, MIT Sloan.

Guren, Adam, Arvind Krishnamurthy, and Timothy McQuade. 2017. "Mortgage Design in an Equilibrium Model of the Housing Market." Working Paper.

Hanson, Samuel G., David O. Lucca, and Jonathan H. Wright. 2017. "Interest Rate Conundrums in the TwentyFirst Century." Staff Report 810, Federal Reserve Bank of New York.

Hedlund, Aaron, Fatih Karahan, Kurt Mitman, and Serdar Ozkan. 2017. "Monetary Policy, Heterogeneity, and the Housing Channel." Working Paper.

Huggett, Mark. 1993. "The risk-free rate in heterogeneous-agent incomplete-insurance economies." Journal of Economic Dynamics and Control 17 (5):953-969. 
Hurst, Erik, Benjamin J. Keys, Amit Seru, and Joseph S. Vavra. 2016. "Regional Redistribution Through the US Mortgage Market." American Economic Review 106 (10).

Hurst, Erik and Frank Stafford. 2004. "Home Is Where the Equity Is: Mortgage Refinancing and Household Consumption." Journal of Money, Credit, and Banking 36 (6):985-1014.

Iacoviello, Matteo. 2005. "House prices, borrowing constraints, and monetary policy in the business cycle." American Economic Review 95 (3):739-764.

Kaplan, Greg and Giovanni L. Violante. 2010. "How Much Consumption Insurance beyond Self-Insurance?" American Economic Journal: Macroeconomics 2 (4):53-87.

Mian, Atif, Kamalesh Rao, and Amir Sufi. 2013. "Household Balance Sheets, Consumption, and the Economic Slump." Quarterly Journal of Economics 128 (4):1687-1726.

Mian, Atif and Amir Sufi. 2014. "What Explains the 2007-2009 Drop in Employment?" Econometrica 82 (6):21972223.

Rubio, Margarita. 2011. "Fixed- and Variable-Rate Mortgages, Business Cycles, and Monetary Policy." Journal of Money, Credit and Banking 43 (4):657-688.

Sheshinski, Eytan and Yoram Weiss. 1977. "Inflation and Costs of Price Adjustment." Review of Economic Studies 44 (2):287-303.

Stroebel, Johannes and Joseph Vavra. 2016. "House prices, local demand, and retail prices." Tech. rep., National Bureau of Economic Research.

Vavra, Joseph. 2014. "Inflation Dynamics and Time-Varying Volatility: New Evidence and an Ss Interpretation." Quarterly Journal of Economics 129 (1).

Winberry, Thomas. 2016. “Lumpy Investment, Business Cycles and Stimulus Policy.” Working Paper, University of Chicago.

Wong, Arlene. 2016. "Population Aging and the Transmission of Monetary Policy to Consumption." Working Paper, Northwestern University. 


\section{Online Appendix}

\section{A.1 MSA Groups Used in Figures 3, 4, and 5}

Note: For large MSAs that are subdivided into Metropolitan Divisions, we use the latter (throughout the paper).

MSAs in the quartile with lowest $E^{\text {med }}$ in November 2008:

Akron, OH; Anderson, IN; Bakersfield, CA; Bangor, ME; Battle Creek, MI; Bay City, MI; Bradenton-Sarasota-Venice, FL; Canton-Massillon, OH; Cape Coral-Fort Myers, FL; Carson City, NV; Cleveland-Elyria-Mentor, OH; Dalton, GA; Danville, IL; Dayton, OH; Deltona-Daytona Beach-Ormond Beach, FL; Detroit-Livonia-Dearborn, MI; El Centro, CA; Elizabethtown, KY; Elkhart-Goshen, IN; Fairbanks, AK; Flint, MI; Fort Lauderdale-Pompano Beach-Deerfield Beach, FL; Fort Walton BeachCrestview-Destin, FL; Fort Wayne, IN; Fresno, CA; Grand Rapids-Wyoming, MI; Greeley, CO; Hagerstown-Martinsburg, MDWV; Hanford-Corcoran, CA; Holland-Grand Haven, MI; Indianapolis-Carmel, IN; Jackson, MI; Jacksonville, FL; KalamazooPortage, MI; Kankakee-Bradley, IL; Lake Havasu City-Kingman, AZ; Lakeland-Winter Haven, FL; Lansing-East Lansing, MI; Las Vegas-Paradise, NV; Madera-Chowchilla, CA; Mansfield, OH; Memphis, TN-MS-AR; Merced, CA; Miami-Miami BeachKendall, FL; Modesto, CA; Monroe, MI; Muskegon-Norton Shores, MI; Napa, CA; Naples-Marco Island, FL; Niles-Benton Harbor, MI; Oakland-Fremont-Hayward, CA; Ocala, FL; Orlando-Kissimmee, FL; Oxnard-Thousand Oaks-Ventura, CA; Palm Bay-Melbourne-Titusville, FL; Palm Coast, FL; Panama City-Lynn Haven-Panama City Beach, FL; Pensacola-Ferry Pass-Brent, FL; Phoenix-Mesa-Scottsdale, AZ; Port St. Lucie, FL; Providence-New Bedford-Fall River, RI-MA; Punta Gorda, FL; Redding, CA; Reno-Sparks, NV; Riverside-San Bernardino-Ontario, CA; Sacramento-Arden-Arcade-Roseville, CA; Saginaw-Saginaw Township North, MI; Salinas, CA; San Diego-Carlsbad-San Marcos, CA; Santa Rosa-Petaluma, CA; Sebastian-Vero Beach, FL; Springfield, OH; St. George, UT; Stockton, CA; Sumter, SC; Tampa-St. Petersburg-Clearwater, FL; Terre Haute, IN; Toledo, $\mathrm{OH}$; Vallejo-Fairfield, CA; Visalia-Porterville, CA; Warren-Troy-Farmington Hills, MI; Weirton-Steubenville, WV-OH; West Palm Beach-Boca Raton-Boynton Beach, FL; Wheeling, WV-OH; Winchester, VA-WV; Worcester, MA; Youngstown-WarrenBoardman, OH-PA; Yuba City, CA; Yuma, AZ.

MSAs in the quartile with highest $E^{\text {med }}$ in November 2008:

Albany-Schenectady-Troy, NY; Alexandria, LA; Anderson, SC; Asheville, NC; Athens-Clarke County, GA; Austin-Round Rock, TX; Baltimore-Towson, MD; Barnstable Town, MA; Baton Rouge, LA; Beaumont-Port Arthur, TX; Bellingham, WA; Bethesda-Frederick-Rockville, MD; Billings, MT; Binghamton, NY; Bismarck, ND; Blacksburg-Christiansburg-Radford, VA; Boulder, CO; Bridgeport-Stamford-Norwalk, CT; Buffalo-Niagara Falls, NY; Burlington-South Burlington, VT; CambridgeNewton-Framingham, MA; Cedar Rapids, IA; Charleston, WV; Charlottesville, VA; Cleveland, TN; College Station-Bryan, TX; Corvallis, OR; Cumberland, MD-WV; Dubuque, IA; Duluth, MN-WI; Durham-Chapel Hill, NC; Edison-New Brunswick, NJ; Elmira, NY; Eugene-Springfield, OR; Fargo, ND-MN; Florence, SC; Fort Smith, AR-OK; Glens Falls, NY; Grand Forks, ND-MN; Grand Junction, CO; Great Falls, MT; Greenville-Mauldin-Easley, SC; Harrisburg-Carlisle, PA; Harrisonburg, VA; Hartford-West Hartford-East Hartford, CT; Honolulu, HI; Hot Springs, AR; Houma-Bayou Cane-Thibodaux, LA; Huntsville, AL; Iowa City, IA; Johnson City, TN; Kingsport-Bristol-Bristol, TN-VA; Lafayette, LA; Lake Charles, LA; Lancaster, PA; Lawrence, KS; Lebanon, PA; Longview, WA; Lynchburg, VA; Midland, TX; Missoula, MT; Mobile, AL; Mount VernonAnacortes, WA; Nassau-Suffolk, NY; New Orleans-Metairie-Kenner, LA; New York-White Plains-Wayne, NY-NJ; Ocean City, NJ; Philadelphia, PA; Pittsburgh, PA; Pittsfield, MA; Portland-Vancouver-Beaverton, OR-WA; Raleigh-Cary, NC; Reading, PA; Roanoke, VA; Salem, OR; San Angelo, TX; San Francisco-San Mateo-Redwood City, CA; San Jose-Sunnyvale-Santa Clara, CA; Seattle-Bellevue-Everett, WA; Sioux City, IA-NE-SD; Sioux Falls, SD; Spokane, WA; State College, PA; Trenton-Ewing, NJ; Tulsa, OK; Victoria, TX; Wenatchee-East Wenatchee, WA; Williamsport, PA; Wilmington, NC; Yakima, WA; York-Hanover, PA. 


\section{A.2 Additional Data Description}

\section{A.2.1 CRISM}

We start with a 50\% sample of all McDash (also known as LPS) mortgages linked to Equifax credit records that were outstanding for at least one month between January 2007 and December 2010. The CRISM data set provides the linked Equifax credit records for each McDash mortgage for the lifetime of the loan, including an additional 6 months before origination and after termination. This link is done directly by Equifax. Credit records provide a consumer's total outstanding debt amounts in different categories (first-lien mortgages, second-lien mortgages, home equity lines of credit [HELOCs], auto loans, etc.). Additionally, in any month, Equifax provides the origination date, amount, and remaining principal balance of the two largest (in balance terms) first mortgages, closed-end seconds, and HELOCs outstanding for a given consumer.

We convert these records into a loan-level panel with each loan's type, origination month, origination amount, termination month, and remaining principal balance for all months that the loan is outstanding. We restrict our sample to those consumers who start our sample with two or fewer loans in each category and never have more than three of any of these types of loans outstanding. ${ }^{1}$ This amounts to about $96 \%$ of the population of Equifax borrower IDs, and these IDs cover about $90 \%$ of the loans in McDash. In creating this loan-level data set, we assume that the month in which the loan stops appearing in Equifax is the month that it was terminated.

The variables that McDash provides are already in the form of a loan-level panel and include: origination date, origination amount, remaining principal balance, termination date, termination type, lien type, interest type, property zip code, and purpose type. We match these to our Equifax panel. We consider an Equifax loan/McDash loan pairing a match if the origination date of the Equifax loan is within 1 month and the origination amount is within $\$ 10,000$ of the McDash loan. If more than one loan is matched, we use the origination amount, date, termination date, zip code, and termination balance as tiebreakers. We are able to match more than $93 \%$ of McDash loans using these restrictions, with more than $80 \%$ matching the origination information perfectly (up to $\$ 1$ in balances due to rounding).

We use the set of Equifax/McDash matched loans as our universe in our analysis. Owing to the restrictions above, this amounts to about $82 \%$ of the McDash universe. We also verify that we are correctly measuring the termination date and termination balance using the Equifax records by checking these variables against their McDash counterparts for the matched loans.

Over our period of interest (2008-9), our sample contains about 15 million mortgages per month; per MSA-month, we have on average 39,200 mortgages. One way to assess the coverage of our sample is to compare the outstanding mortgage balances by MSA to those in the FRBNY Consumer Credit Panel (CCP). The balances in our sample correspond on average to $29 \%$ of those in the CCP (with little variation over time), with a cross-sectional standard deviation across MSAs of $5 \%$ (the 25th percentile is at $26 \%$, the 75 th percentile at $32 \%$ ). Since we start with a $50 \%$ random sample from CRISM and apply some filters as explained above, this means that CRISM covers over $60 \%$ of outstanding mortgages over this period.

\section{A.2.2 Measuring Refinancing Propensities}

Our goal is to measure the proportion of outstanding loans in an MSA that were refinanced in a given month. For the denominator, we start with all outstanding first liens (where lien type is measured using the McDash variable) in our Equifax/McDash matched universe, but exclude in each month loans that terminate in the next month because they were transferred to another servicer or terminate

\footnotetext{
${ }^{1}$ This restriction allows us to infer the origination month, origination balance, and balance of the third largest loan of any loan type even though this information does not appear explicitly in Equifax, where if the third largest loan is also the newest loan, we assume its origination month to be the first month it appears in Equifax. We also drop loans that do not have complete consecutive Equifax records.
} 
for unknown reasons (since we will be looking at the proportion of loans that are voluntarily paid off and refinanced).

We count a loan as being refinanced if: (1) its McDash termination type is a "voluntary payoff," and (2) for that consumer, there is another loan that is opened around the time of the first loan's termination on the same property (i.e. the new loan is a refinance, rather than a new purchase loan). More specifically, the most clear indicator that the new loan was a refinance is if the loan has a matching McDash loan (about 70\%), and that McDash loan is marked as a refinance loan (in McDash's purpose type variable). On the other hand, the loan is clearly a new purchase loan if the purpose type is marked as such. However, about $25 \%$ of McDash loans have purpose type "Unknown" or "Other," and about $30 \%$ of the new loans are not matched in McDash (they only appear in Equifax, since McDash does not cover the entire market) and thus have no purpose type attached.

We thus use the following rules to identify refinances. We start by looking for any loan in the Equifax data set that has an open date within 4 months of the McDash loan's termination date. We find at least one such loan for about $81 \%$ of the voluntary terminations in 2008 and 2009 . We classify these new loans as a refinance if either:

- The loan also appears in McDash and is tagged as a refinance in the purpose-type variable $(61 \%$ of the McDash-matched loans).

- The loan also appears in McDash and is tagged as an "Unknown" or "Other" purpose type, and has the same property zip code as the original loan.

- The loan appears only in Equifax but the borrower's Equifax address does not change in the 6 months following the termination of the original loan.

This allows us to compute our measure of interest, the balance-weighted refinance propensity, as (balance outstanding in $\mathrm{t}-1$ of loans that were refinanced in month $\mathrm{t}$ ) / (balance outstanding in McDash in month $\mathrm{t}-1$ that does not terminate for unknown reason in month $\mathrm{t}$ ).

As a check, we calculate the refinance propensities separately for the three different cases above (McDash, known purpose; McDash, unknown purpose; Equifax), and find that these refinance propensities are very similar.

\section{A.2.3 Measuring Cash-outs}

To measure cash-out refinancings, we need to both identify refinances and how the balance of the new loan compares to the outstanding balace of the loan(s) paid off in the process.

We begin with Equifax/McDash first liens (again using the McDash lien type variable), and keep only those loans that have a McDash purpose type of refinance or unknown/other. Our algorithm to identify whether our new loan is a refinance is similar to the algorithm above. This time, we look for a loan (or loans) in Equifax that terminate(s) around the time when the new loan is originated and check that this loan looks like it was refinanced. We use McDash refinances rather than outstanding loans as our point of reference for these statistics so that we can better represent all refinances, rather than introducing potential bias through only seeing refinances of McDash loans.

Specifically, we call any loan in the Equifax data set that terminates between -1 and 4 months from our new loan's close date a "linked" loan, including first mortgages as well as closed-end seconds and HELOCs, and we call the new loan a refinance if:

- The loan is a known refinance in McDash. (For $86 \%$ of these, we find a linked loan in either McDash or Equifax. For the remaining $14 \%$, we would consider these refinances where there was no previous loan on the property.)

- The loan has an "Unknown" or "Other" purpose type in McDash and a linked loan in McDash that has a matching property zip code. 
- The loan has an "Unknown" or "Other" purpose type in McDash and a linked loan that appears only in Equifax, but the consumer's Equifax address does not change in the 6 months after the new loan was opened.

If there is more than one linked loan that is a first mortgage in Equifax, we link only the loan that is closest in balance to the origination amount of the new mortgage. We also allow to be linked only those Equifax loans that exist in the Equifax data for at least three months to prevent the refinanced loan balance from being counted in the old balance of the loan.

For each of these cases, we can then calculate the cash-out amount as the difference between the origination amount on the refinance loan and the balance of the linked loan(s) at termination. In order to capture the correct origination amount on the refinance loan, we want to ensure that we are also including any "piggyback" second liens that are opened with the refinance loan that we find in McDash. Thus, we look for any loan in the Equifax record linked to our refinance loan that has an Equifax open date within three months of our refinance loan and an origination balance of less than $25 \%$ of our loan's origination balance if labeled a first mortgage and less than $125 \%$ of the refinance loan's origination balance if labeled a HELOC or CES, and add the balance of these piggyback seconds to the refi origination amount when calculating cash-out amounts. ${ }^{2}$ To eliminate outliers, we also drop cash-out and "cash-in" amounts that are greater than $\$ 1,000,000$. These amount to dropping less than $0.05 \%$ of the refinance loans.

At the MSA level, this allows us to calculate the amount cashed out relative to the total outstanding balance in month $\mathrm{t}-1$. To estimate total dollar amounts cashed out, we scale up the amount cashed out by the ratio of total housing debt outstanding in an MSA according to the FRBNY Consumer Credit Panel (CCP) relative to the total outstanding balance in our CRISM sample. (The CCP amounts are available as end-of-quarter snapshots, so we interpolate between them to get a monthly series.)

In Figure A-9, we compare the total estimated quarterly cash-out amounts to those estimated on prime conventional loans by Freddie Mac. ${ }^{3}$ The figure shows that the two series co-move closely and also show similar levels. The higher level in CRISM is expected, since the Freddie Mac series does not include subprime/Alt-A as well as FHA and VA loans.

\section{A.2.4 Measuring CLTVs/Equity}

We start with all matched first-lien McDash loans. For a given month, we take the corresponding Equifax record and assign all outstanding second liens to the outstanding first liens in Equifax using the rule that each second lien is assigned to the largest first lien (in balance terms) that was opened on or before the second lien's opening date. We then add the assigned second lien balance(s) to the McDash balance of our original loan as our measure of secured debt on a property, which is the numerator of CLTV. For the denominator, the estimated updated property value, we start from the appraisal amount of the property at the time of the McDash loan origination and update it based on the local home price index from CoreLogic (using the zip-code-level index if available, and the MSA-level index if not).

Equity is simply defined as $1-C L T V$. When taking medians within an MSA (our measure $E_{j, t}^{\text {med }}$ ), we weight individual observations by their current outstanding first-lien loan balance (from McDash).

\section{A.2.5 Household-level Analysis of Car Spending Around Refinancing}

In Section 4.4.1, we study the response of car purchases to refinancing at the borrower level. To do so, we start out with a random 50\% sample of borrowers in our CRISM sample who refinance at some

\footnotetext{
${ }^{2}$ We impose these upper bounds because we want to avoid picking up other first lien mortgages (to purchase another property) the borrower might originate at the same time.

${ }^{3}$ To make the two comparable, we multiply our CRISM total by $1 / 0.9175$, where 0.9175 is the share of mortgage balances in CRISM that is in MSAs (as opposed to micropolitan statistical areas or rural areas) as of November 2008.
} 
point over the year 2009. (We only use 50\% for computational reasons.) We obtain monthly information on these borrowers' car loans from their Equifax credit records (we sum two categories, "auto bank"loans provided by banks, credit unions, savings and loan associations-and "auto finance"-loans provided by automobile dealers and automobile financing companies) starting 6 months before the refinancing date until 12 months after. We only retain borrowers for whom there is only one refinancing in the data over this period. This leaves us with 676,425 refinancers.

We mark a borrower as obtaining a new car loan in a month if the total balance of car loans outstanding increases by $\$ 2,000$ or more (following Agarwal et al., 2017); results are similar if we use different cutoffs. For Figure 6, we distinguish between non-cashout-refinances and cash-out refinances, where a refinance is categorized as the latter if 0.98 times the balance of the refinance loan (including simultaneously opened junior liens, as described in Section A.2.3) is at least $\$ 5,000$ above the balance of the old loan(s) that are paid off. Subtracting the 2 percent of the new loan amount is done in order to account for the fact that some of the cashed out amount may be used to cover costs associated with the refinancing. This threshold is close to the binary indicator used by GSEs, and conclusions are not sensitive to altering the cutoff. According to this metric, 44 percent of refinances in our 2009 sample were cash-outs.

\section{A.2.6 HMDA}

For robustness, in Figure A-5 we use a different measure of refinancing activity based on data made available as part of the Home Mortgage Disclosure Act (HMDA), which requires mortgage lenders to report information on mortgage applications and originations. The HMDA data are generally perceived to be the most comprehensive and representative source of information on mortgage applications and originations, with market coverage estimated to be around $90 \% .{ }^{4}$ For each application, HMDA reports the geographic location of the property, the desired loan amount, the loan purpose (purchase or refinance), and whether the loan application led to an origination, was rejected by the lender, or was withdrawn by the borrower. ${ }^{5}$ While the public-use HMDA data contain only calendar year indicators, the private-use version of the data set (available to users within the Federal Reserve System) also contains the exact application date and the exact action date. The action date is the date on which the loan is originated, the application is rejected, or the application is withdrawn. These exact dates make the data suitable for high frequency event studies (see, for example, Fuster and Willen, 2010). In all our analysis using HMDA data, we retain only applications that led to originations (action code $=1$ ), and always use the application date (rather than the action date). We drop multifamily properties and mortgages with an origination amount $>\$ 3$ million (about $0.015 \%$ of loans).

While the HMDA data are ideal for measuring the flow volume of mortgage origination activity across locations, it has two prominent limitations. First, for refinance loans, the HMDA data do not include any information on the loan that is paid off. As a result, we cannot use the HMDA data to estimate the extent to which households are removing cash from their mortgage during the refinancing process-a limitation we overcome with the CRISM data we focus on in the main paper. Second, the HMDA data do not include any information on the loans after they are originated. Thus, HMDA is not informative about how many outstanding mortgages there are in an MSA. The stock of outstanding mortgages is necessary to measure a refinancing propensity.

To obtain an estimate of the number of outstanding mortgages in each MSA, we supplement HMDA with data from the 2008 American Community Survey (ACS), which reports the number of outstanding mortgages (but not their amount) and the number of households for fine geographic areas. Since the ACS samples only a fraction of the population, we scale up the number of households based on Census information on the overall number of households in the US in 2008. We use the same scaling factor for the number of mortgages in each location. By combining the ACS data with the

\footnotetext{
${ }^{4}$ See, for instance Dell' Ariccia, Igan, and Laeven (2012).

${ }^{5}$ There are actually three designated loan types within the HMDA data: origination, refinancing, and home improvement. We combine the home improvement loans with the refinancing ones in our work below.
} 
HMDA data, we can compute the number of loan originations per number of outstanding mortgages for each location within the U.S.

The measures of MSA-level refinancing propensities in late 2008/early 2009 are highly correlated between the HMDA data and the CRISM data, once we account for the lag in CRISM relative to HMDA. The population-weighted cross-sectional correlation between the HMDA refinance propensity in December 2008 and the CRISM refinance propensity in January (February) 2009 is 0.87 (0.88). Pooling the second half of 2008 and the first half of 2009, the correlation between HMDA and CRISM propensities is 0.84 for the one-month-forward and 0.78 for the two-month-forward CRISM propensities.

\section{A.2.7 Other Data}

We now briefly describe some additional data used in our analysis. We measure unemployment rates for each MSA using data from the BLS's Local Area Unemployment Statistics. Our measure of labor income is based on the Individual Income Tax ZIP Code Data made available by the Internal Revenue Service. We first cumulate wage and salary incomes at the MSA level and then divide by the number of tax returns. We exclude tax returns from the top income category $(>\$ 200,000)$ since those households can play a dominant role in driving average income changes; however, they are likely not the ones for which payment-to-income constraints (which we want to proxy for) are most relevant. Including those households, using adjusted gross income instead of wage and salary income, using the growth over 2007-2008 instead of 2008-2009, or using the income level instead of the growth rate does not change any of our conclusions in the regression tables below.

Our MSA-level demographic controls come from the ACS. We combine the 2007 and 2008 data to ensure the sample sizes are large enough to minimize measurement error. We measure each MSA's age composition, education composition, the percentage of homeowners, and the percentage of households with a mortgage. We restrict the ACS data to those individuals between the ages of 21 and 75 (inclusive) that were not living in group quarters (e.g., dorms, prisons, or medical facilities).

\section{A.3 Model Proofs and Description of Numerical Solution}

We provide here the proof of the homogeneity of the value function as well as a description of our computational procedure.

To show the homogeneity property, we proceed by guess and verify. The value functions for refinancing and not refinancing are

$$
\begin{aligned}
V^{n o r e f i}\left(\tilde{a}, \tilde{y}, \tilde{x}, r_{0}^{m}, r^{m}, r, F, 1\right) \tilde{p}^{\sigma-1} & =\max _{\left\{\hat{a}^{\prime}\right\}} \frac{\left(\tilde{a}(1+r)+\tilde{y}-\gamma r_{0}^{m} \tilde{x}-\hat{a}^{\prime}\right)^{1-\sigma}}{1-\sigma} \tilde{p}^{\sigma-1} \\
& +\beta \mathbb{E}\left[V\left(\hat{a}^{\prime} \frac{\tilde{x}^{\prime}}{\tilde{x}}, \tilde{y}^{\prime}, \tilde{x}^{\prime}, r_{0}^{m}, r^{m^{\prime}}, r^{\prime}, F^{\prime}, 1\right)\left(\tilde{p}^{\prime}\right)^{\sigma-1} \mid \tilde{y}, \tilde{x}, r^{m}, r, F, 1\right] \\
V^{r e f i}\left(\tilde{a}, \tilde{y}, \tilde{x}, r^{m}, r, F, 1\right) \tilde{p}^{\sigma-1} & =\max _{\left\{\hat{a}^{\prime}\right\}} \frac{\left(\tilde{a}(1+r)+\tilde{y}-\gamma r^{m}+\gamma(\tilde{x}-1)-F-\hat{a}^{\prime}\right)^{1-\sigma}}{1-\sigma} \tilde{p}^{\sigma-1} \\
& +\beta \mathbb{E}\left[V\left(\hat{a}^{\prime} \frac{\tilde{x}^{\prime}}{\tilde{x}^{\prime}}, \tilde{y}^{\prime}, \frac{\tilde{x}^{\prime}}{\tilde{x}}, r^{m}, r^{m^{\prime}}, r^{\prime}, F^{\prime}, 1\right)\left(\tilde{p}^{\prime}\right)^{\sigma-1} \mid \tilde{y}, \tilde{x}, r^{m}, r, F, 1\right]
\end{aligned}
$$

Then we can eliminate $\tilde{p}$ as a state variable to obtain the transformed value function,

$$
\begin{aligned}
J\left(\tilde{a}, \tilde{y}, \tilde{x}, r_{0}^{m}, r^{m}, r, F\right) & =\max \left\{J^{n o r e f i}\left(\tilde{a}, \tilde{y}, \tilde{x}, r_{0}^{m}, r^{m}, r, F\right), J^{r e f i}\left(\tilde{a}, \tilde{y}, \tilde{x}, r^{m}, r, F\right)\right\} \\
J^{n o r e f i}\left(\tilde{a}, \tilde{y}, \tilde{x}, r_{0}^{m}, r^{m}, r, F\right) & =\max _{\left\{\hat{a}^{\prime}\right\}} \frac{\left(\tilde{a}(1+r)+\tilde{y}-\gamma r_{0}^{m} \tilde{x}-\hat{a}^{\prime}\right)^{1-\sigma}}{1-\sigma}
\end{aligned}
$$




$$
\begin{aligned}
& +\beta e^{(1-\sigma)\left(\mu_{q}-\pi\right)} \mathbb{E}\left[J\left(\hat{a}^{\prime} \frac{\tilde{x}^{\prime}}{\tilde{x}}, \tilde{y}^{\prime}, \tilde{x}^{\prime}, r_{0}^{m}, r^{m^{\prime}}, r^{\prime}, F^{\prime}\right) \mid \tilde{y}, \tilde{x}, r^{m}, r, F\right] \\
J^{r e f i}\left(\tilde{a}, \tilde{y}, \tilde{x}, r^{m}, r, F\right) & =\max _{\left\{\tilde{a}^{\prime}\right\}} \frac{\left(\tilde{a}(1+r)+\tilde{y}-\gamma r^{m}+\gamma(\tilde{x}-1)-F-\hat{a}^{\prime}\right)^{1-\sigma}}{1-\sigma} \\
& +\beta e^{(1-\sigma)\left(\mu_{q}-\pi\right)} \mathbb{E}\left[J\left(\hat{a}^{\prime} \frac{\tilde{x}^{\prime}}{\tilde{x}}, \tilde{y}^{\prime}, \frac{\tilde{x}^{\prime}}{\tilde{x}}, r^{m}, r^{m^{\prime}}, r^{\prime}, F^{\prime}\right) \mid \tilde{y}, \tilde{x}, r^{m}, r, F\right]
\end{aligned}
$$

In order to solve the transformed value function, we discretize $\log \tilde{x}$ using 60 grid points evenly spaced with width $\mu_{q}$ between 0.45 and $-1.025,64$ grid points for $\tilde{a}$ between 0 and 1, with more grid points near the lower asset values to account for the concavity of the value function, and 46 grid points for $\tilde{y}$ evenly spaced in logs between -0.5 and 0.5 . The stochastic shock can take on 3 values: $-1 S D, 0$, and +1 SD with probabilities computed using the Tauchen algorithm. Households assume that interest rates will remain constant in the future, and the model is solved with both $r^{m}=0.06$ and $r^{m}=0.05$. The short-term interest rate $r$ is permanently set to 0.03 . The model is then solved using value function iteration. Finally, the model is simulated using 50,000 households and 9 regions. Households are initialized at median income and no assets in a middle income, middle house price region and 300 years of the model are discarded as an initial burn-in. Using a longer burn-in period or changing initial conditions prior to the burn-in period leaves results unchanged.

A number of alternative models are explored in Sections 7 and 8 which involve changes to the baseline computational setup.

In the version of the model with ARMs, we assume that the households with ARMs' current payment moves one-for-one with the current mortgage rate when not refinancing. In particular, the $J^{\text {nore } i} i$ is identical except that $r_{0}^{m}$ is always equal to $r^{m}$.

We calibrate the ARM share in bad regions to 30 percent, the ARM share in the middle regions to 20 percent and in the good regions to 10 percent. As described in the text, this is a conservative calibration for assessing the importance of ARMs since it overstates the actual variation in interest rate flexibility across space in 2008 as most ARMs do not have substantive rate resets during the QE episode.

We next explore a version of the model in which the housing bust in 2008 is preceded by a house price boom. Specifically, we assume that in the period before the Great Recession, there is an aggregate house price increase of $10 \%$ and a regional shock of $\pm 7.5 \%$ that is perfectly negatively correlated with the shock during the bust. This roughly captures house price movements in the last year of the housing boom. We do not recalibrate parameters in this exercise to match the effects of QE1, but they are similar to the baseline.

We then move to a model which partially endogenizes the cash-out decision when refinancing. In particular, we let households choose between two different options when refinancing: 1) Extracting all of their housing equity when refinancing, as in our baseline. 2) Extracting no equity and only resetting the rate. In this model, we now have three value functions: $J^{\text {noref } i}, J^{\text {refi and cash-out }}, J^{\text {refi rate only }}$. $J^{r e f i}$ and cash-out is identical to $J^{r e f i}$ in the original problem (except with a continuation value that maximizes over three rather than two value functions). When doing a pure rate-refi, the mortgage balance is unchanged but the household pays a fixed cost to change their fixed rate to the current mortgage

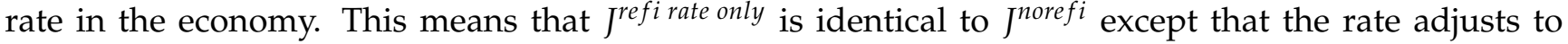
the current mortgage rate and the household must pay the refinancing cost. Note also that this value function is identical to that for the ARM model above, except that the household must pay the fixed cost to obtain the current rate instead of obtaining it for free:

$$
J^{\text {refi rate only }}\left(\tilde{a}, \tilde{y}, \tilde{x}, r^{m}, r, F\right)=\max _{\left\{\hat{a}^{\prime}\right\}} \frac{\left(\tilde{a}(1+r)+\tilde{y}-\gamma r^{m} \tilde{x}-F-\hat{a}^{\prime}\right)^{1-\sigma}}{1-\sigma}
$$




$$
+\beta e^{(1-\sigma)\left(\mu_{q}-\pi\right)} \mathbb{E}\left[J\left(\hat{a}^{\prime} \frac{\tilde{x}^{\prime}}{\tilde{x}}, \tilde{y}^{\prime}, \tilde{x}^{\prime}, r^{m}, r^{m^{\prime}}, r^{\prime}, F^{\prime}\right) \mid \tilde{y}, \tilde{x}, r^{m}, r, F\right]
$$

Also note that this model introduces no new parameters, so the calibration strategy is identical to that in the baseline model. Ultimately, few households in the model choose to do rate only-refinancing with no cash-out even when they have this option, because the general equity accumulation and extraction problem still plays a primary role in decisions. A household who is contemplating a rate only refinance today still knows that in the future, they will eventually want to extract equity. Since the fixed cost of refinancing is the same whether they extract equity or not today, it makes sense to extract equity when refinancing to secure the low rate rather than doing a rate refi today and then paying the fixed cost again in the near future to extract equity.

Since we write the above value functions for general interest rate processes, the statement of the problem with stochastic interest rates is identical to that in the baseline model with a one-time unanticipated shock. Computationally, in the baseline model with a one-time shock, we only need to solve the model for two values of $r^{m}$ to compute impulse responses, and we do not need to calculate expectations over $r^{m}$. In the model with stochastic mortgage rates, $r^{m}$ takes on 5 values with probabilities computed using the Tauchen algorithm, and this state-variable enters expectations in the value function. 


\section{A.4 Appendix Tables and Figures}

This section provides additional tables and figures referred to in the main text.

- Table A-1 provides descriptive statistics on the 381 MSAs in our sample, including all the local control variables used in regressions reported in Tables A-2 to A-5.

- Table A-2 documents the correlations between $E_{\text {Nov2008 }}^{\text {med }}$ and other local controls.

- Table A-3 provides the results from regressions of refinancing propensities on $E_{\text {Nov2008 }}^{\text {med }}$ and other local controls, all interacted with a post-QE indicator (equation (1)), discussed in Section 4.3.

- Table A-4 provides the results from regressions of cash-out shares on $E_{\text {Nov } 2008}^{\text {interacted with }}$ post-QE indicator and other local controls (including refinancing propensities in the last column), discussed in Section 4.4.

- Table A-5 provides the results from regressions of $\log$ (auto sales) on $E_{\text {Nov2008 }}^{\text {med }}$ interacted with postQE indicator, refinancing propensities and cash-out shares, discussed in Section 4.4 (footnote 17).

- Figure A-1 shows that refinancing activity in HMDA data follows similar patterns to those shown in Figure 1, and that there was no discernible increase in purchase mortgage activity around QE1.

- Figure A-2 shows that $E_{\text {Nov2008 }}^{\text {med }}$ is highly correlated with local shares of borrowers that have CLTV $>80$ or CLTV $>100$, illustrating that the equity of the median borrower correlates strongly with other moments of the equity distribution, as discussed in Section 4.2.

- Figure A-3 shows distributions of MSA-median and individual-level equity in January 2007 and November 2008, as discussed in Section 4.2.

- Figure A-4 shows the relationships between $E_{\text {Nov2008 }}^{\text {med }}$ and local house price growth over Jan 2007Nov 2008, and between $E_{\text {Nov } 2008}^{\text {med }}$ and changes in the local unemployment rate over Jan 2007-Nov 2008, as discussed in Section 4.2.

- Figure A-5 shows that the patterns shown in Figure 3 are very similar when using the HMDA data, where we can sum originated refinance mortgages by their application date. The figures show that activity jumped right after the QE1 announcement, and more so in high equity MSAs.

- Figure A-6 shows that there was essentially no variation in rates on new mortgages between high and low equity MSAs, as discussed in Section 4.2.

- Figure A-7 shows that there was no bunching in PTI ratios and no differences across high and low equity MSAs in the PTI distribution in 2009, while there is strong bunching and differences across MSA groups in CLTVs, as discussed in Section 4.2.

- Figure A-8 shows that non-housing debt increased in high equity MSAs relative to low equity MSAs following QE1, as discussed in Section 4.4.

- Figure A-9 shows that cash-out amounts in CRISM comove closely with those in Freddie Mac data, as disucssed in Appendix A.2.3.

- Figure A-10 shows that the household-level distribution of equity in the 2008 calibration of our model is a good fit to the empirical distribution shown in Figure A-3, as discussed in Section 6.2.

- Figure A-11 shows how the refinancing threshold in our model changes with assets and earnings.

- Figure A-12 shows the separate contributions of borrowers and lenders to the aggregate consumption impulse response in the 2008 baseline model shown in Figure 11. 
- Figure A-13 shows the consumption response in the model under different assumptions about the share of lenders that are in the domestic economy, as discussed in Section 8.6.

- Figure A-14 shows that shifts in the mean of the equity distribution have effects on monetary policy that depend on the variance of the distribution, as discussed in Section 6.4.2.

- Figure A-15 shows how ARM shares as of November 2008 and ARM payment reductions over

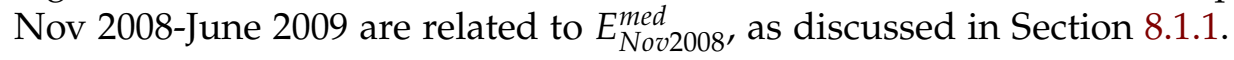

- Figures A-16-A-18 show results from additional robustness checks discussed in Section 8.

Table A-1: Descriptive Statistics. Data on 381 MSAs; statistics are unweighted.

\begin{tabular}{|c|c|c|c|c|c|c|c|}
\hline & Mean & SD & p10 & p25 & $\mathrm{p} 50$ & p75 & p90 \\
\hline Median equity share $\left(E^{\text {med }}\right)$, Jan 2007 & 0.293 & 0.066 & 0.209 & 0.243 & 0.289 & 0.345 & 0.383 \\
\hline Median equity share $\left(E^{\text {med }}\right)$, Nov 2008 & 0.160 & 0.110 & 0.015 & 0.120 & 0.190 & 0.230 & 0.261 \\
\hline$\Delta$ House Price Index, Jan 2007-Nov 2008 & -0.111 & 0.113 & -0.286 & -0.161 & -0.086 & -0.033 & 0.010 \\
\hline$\Delta$ Unemployment, Jan 2007-Nov 2008 & 2.297 & 1.370 & 0.700 & 1.400 & 2.100 & 3.000 & 4.100 \\
\hline$\Delta$ Labor Income, 2008-2009 & 0.003 & 0.022 & -0.022 & -0.009 & 0.003 & 0.017 & 0.025 \\
\hline \multicolumn{8}{|c|}{ Average mortgage characteristics as of Nov 2008 (based on CRISM): } \\
\hline FICO score & 701.8 & 17.4 & 679.4 & 689.4 & 701.6 & 714.9 & 723.5 \\
\hline Current interest rate $(\%)$ & 6.23 & 0.16 & 6.02 & 6.13 & 6.23 & 6.34 & 6.43 \\
\hline Loan age (months) & 39.3 & 3.8 & 34.6 & 36.6 & 39.1 & 41.6 & 44.8 \\
\hline Share jumbos (based on current balance) & 0.046 & 0.048 & 0.007 & 0.014 & 0.029 & 0.063 & 0.115 \\
\hline Average balance of non-jumbo loans (1000s) & 130.7 & 46.2 & 87.3 & 100.0 & 117.3 & 153.2 & 181.2 \\
\hline Share adjustable-rate mortgages & 0.136 & 0.098 & 0.057 & 0.070 & 0.098 & 0.171 & 0.272 \\
\hline Share GSE securitized & 0.615 & 0.097 & 0.498 & 0.572 & 0.631 & 0.676 & 0.721 \\
\hline Share privately securitized & 0.158 & 0.086 & 0.083 & 0.103 & 0.127 & 0.180 & 0.262 \\
\hline \multirow{2}{*}{\multicolumn{8}{|c|}{$\begin{array}{l}\text { Local demographics (based on ACS): } \\
\text { Years of education (shares) }\end{array}$}} \\
\hline & & & & & & & \\
\hline 12 & 0.147 & 0.033 & 0.105 & 0.124 & 0.146 & 0.170 & 0.192 \\
\hline $13-15$ & 0.315 & 0.042 & 0.262 & 0.287 & 0.316 & 0.339 & 0.371 \\
\hline 16 & 0.172 & 0.048 & 0.112 & 0.135 & 0.168 & 0.203 & 0.234 \\
\hline$>16$ & 0.266 & 0.026 & 0.236 & 0.250 & 0.263 & 0.281 & 0.300 \\
\hline \multicolumn{8}{|l|}{ Age group (shares) } \\
\hline $31-45$ & 0.286 & 0.026 & 0.252 & 0.271 & 0.285 & 0.303 & 0.318 \\
\hline $46-40$ & 0.340 & 0.024 & 0.311 & 0.326 & 0.340 & 0.356 & 0.370 \\
\hline$>60$ & 0.206 & 0.038 & 0.167 & 0.183 & 0.202 & 0.223 & 0.244 \\
\hline Homec & 0.779 & 0.053 & 0.712 & 0.751 & 0.785 & 0.813 & 0.839 \\
\hline Mortgage borrowers (share) & 0.543 & 0.065 & 0.454 & 0.505 & 0.552 & 0.591 & 0.619 \\
\hline
\end{tabular}

Table shows descriptive statistics for all 381 MSAs in our analysis sample, including the distribution of median equity shares $\left(E^{m e d}\right)$ in January 2007 and November 2008, the distribution of house price and unemployment rate changes (in percent and percentage points, respectively) between January 2007 and November 2008, the distribution of changes in average labor income between 2008 and 2009, distributions of a number of characteristics of the outstanding mortgages in each MSA as of November 2008 (taking balance-weighted averages within each MSA), and local demographic characteristics as of 2008. For years of education and age groups, the base categories ( $<12$ years of education; ages 21-30) are not shown. The share of mortgage borrowers is relative to all households, not just homeowners. 


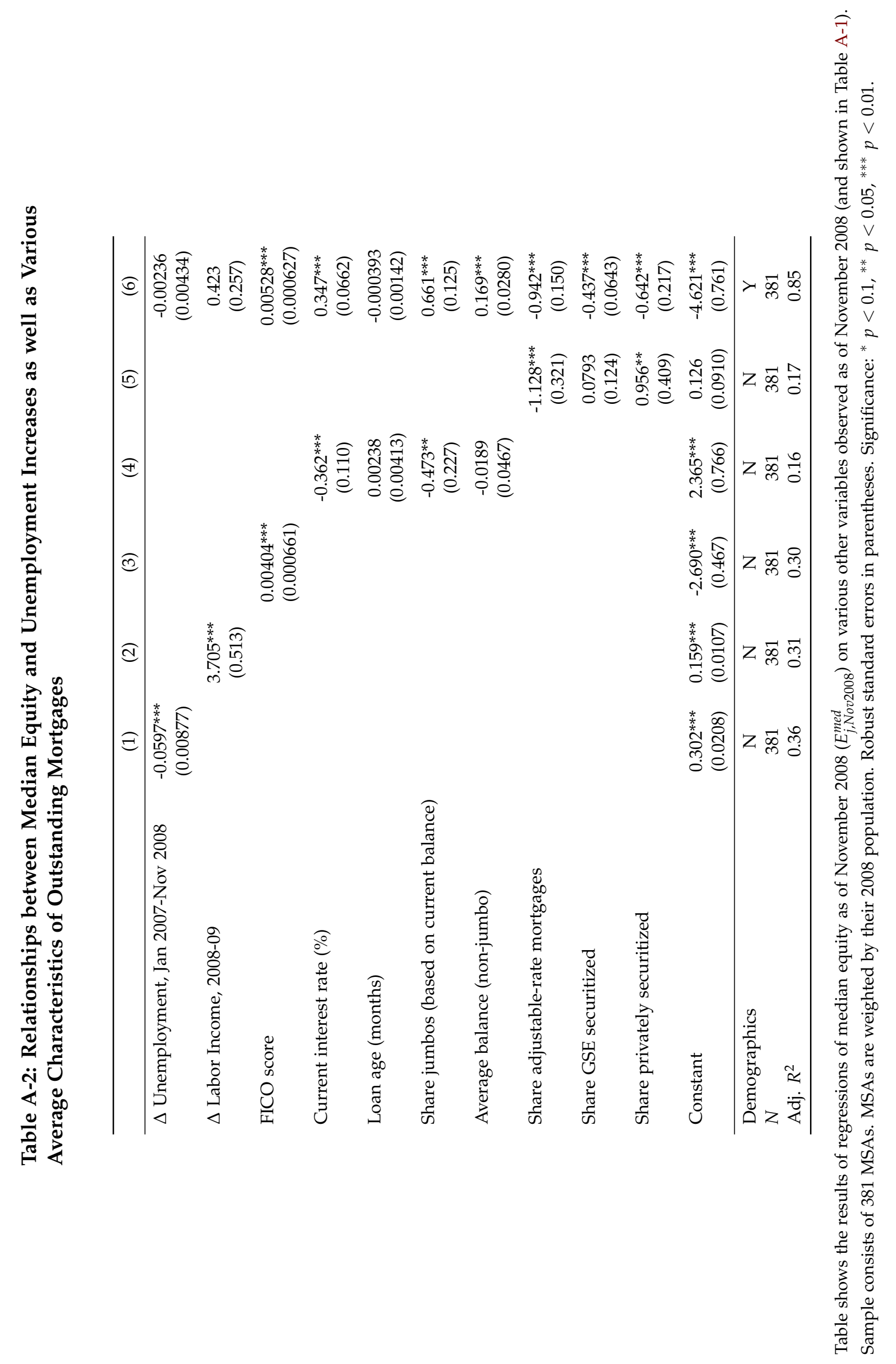




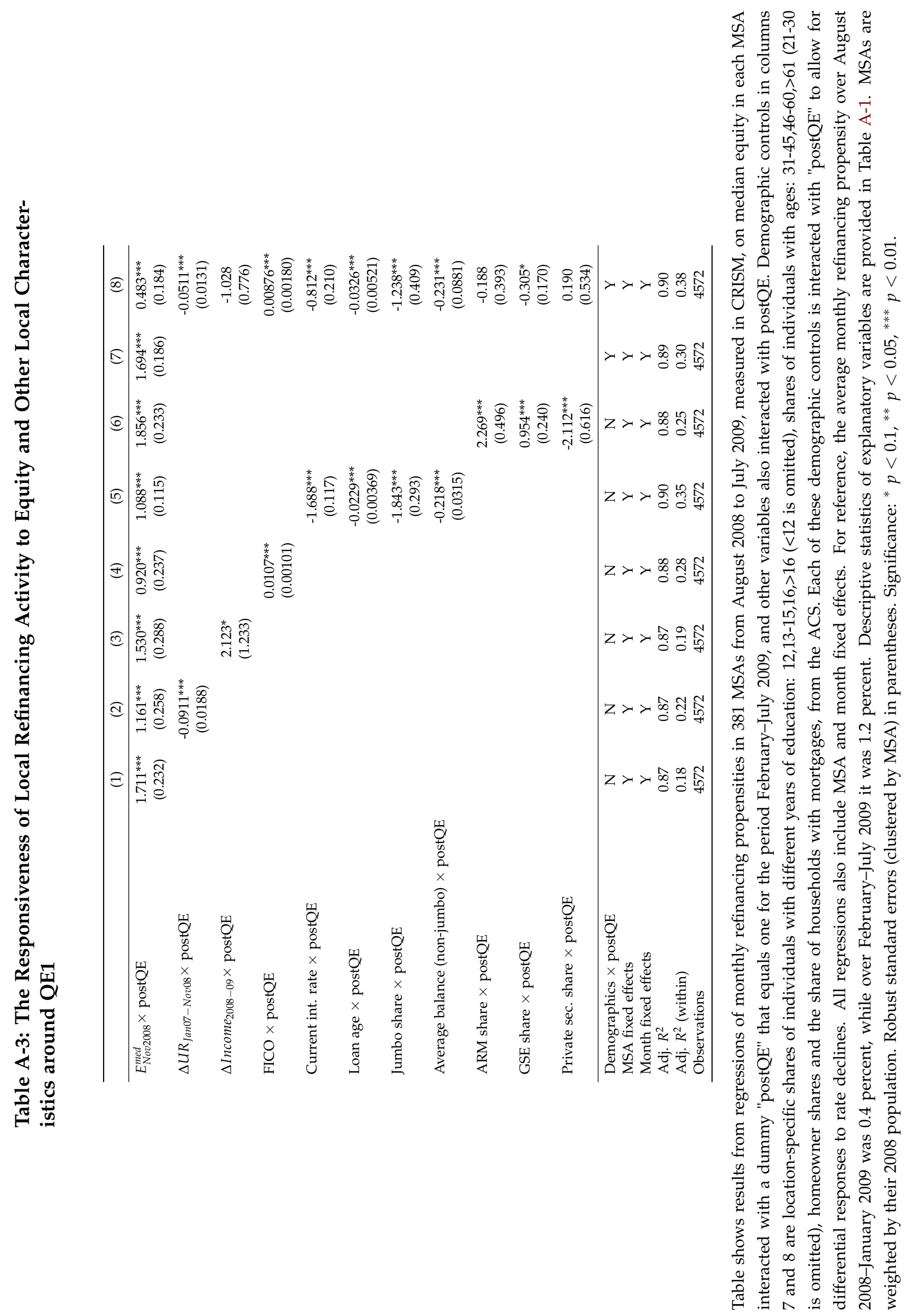




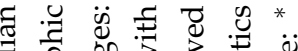

类 30 .

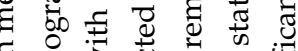

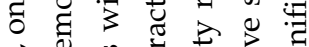

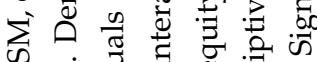

떵 궁

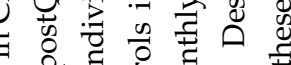

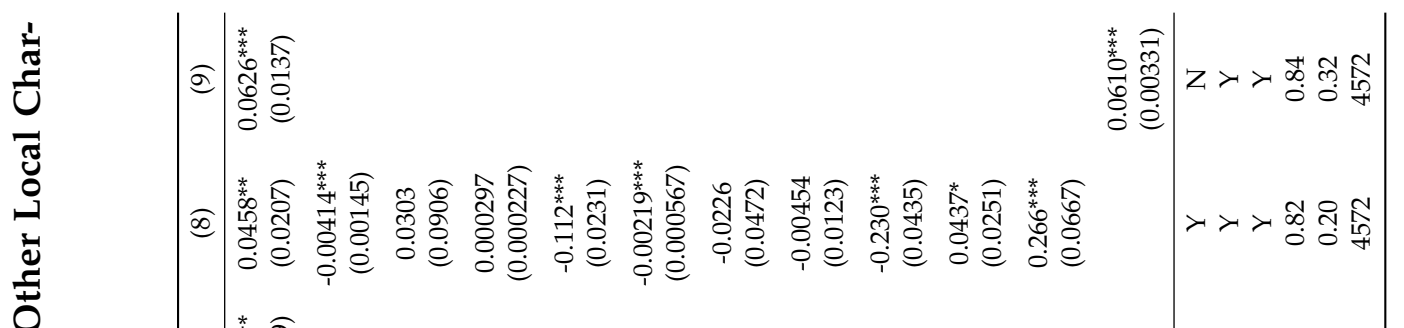

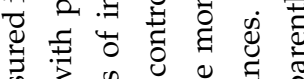

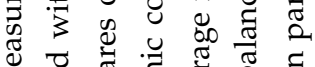

๘ च क्ष

今े $\widehat{0}$.

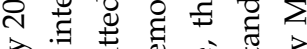

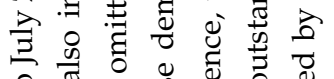

ब

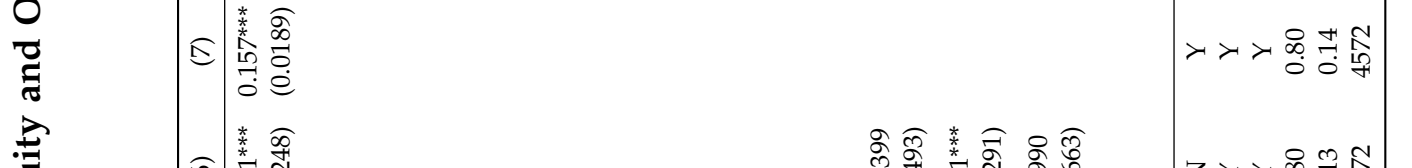

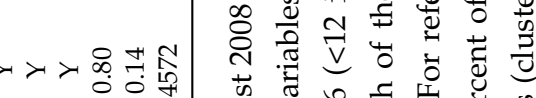

产

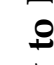

党

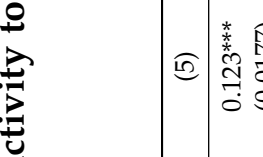

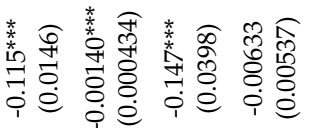

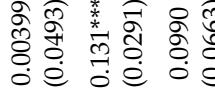

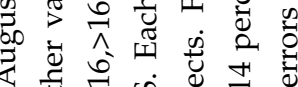

ये क्षे

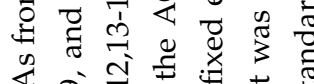

को वे

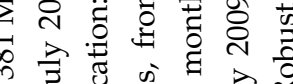

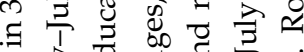

क्ष

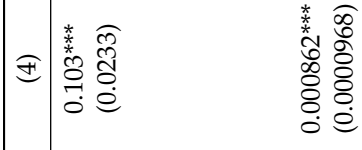

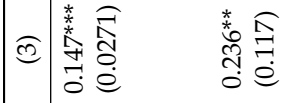

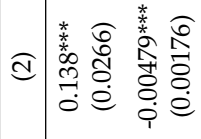

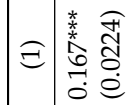

$\sum_{\bar{\omega}}$

के

$\simeq$

Е

$\ddot{7}$

4

닐

ส

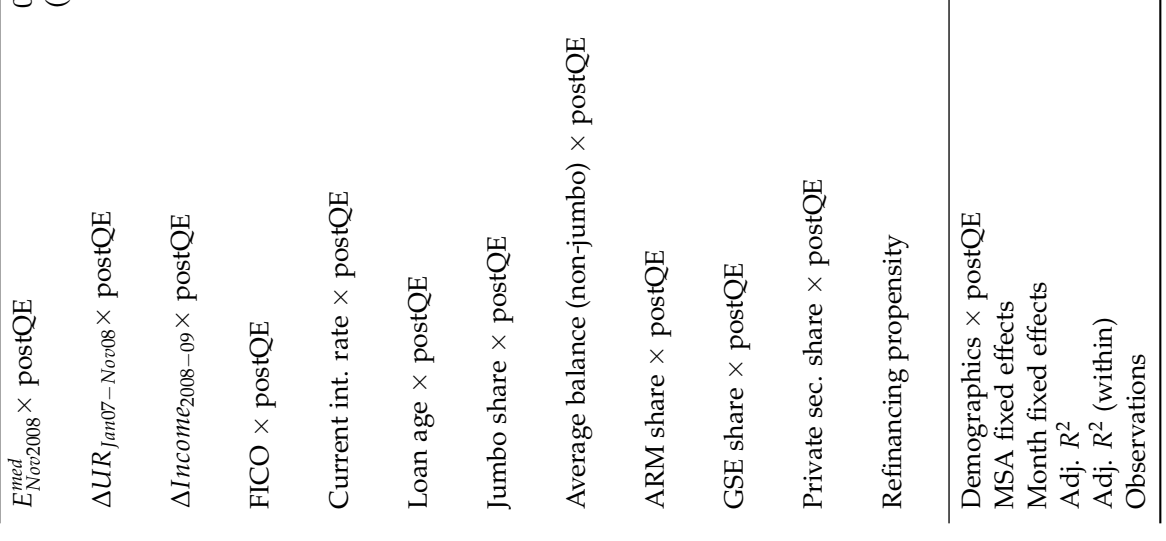

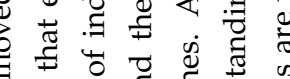

एँ

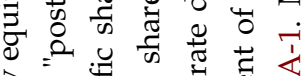

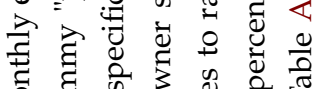

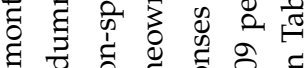

क 0 .

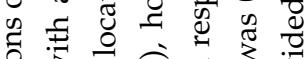

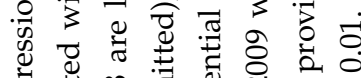

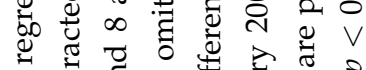

ह

의 $\pi$ के

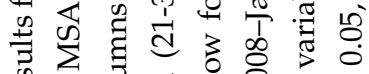

क्ष

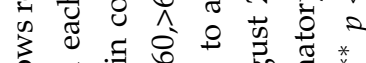

品

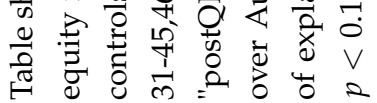




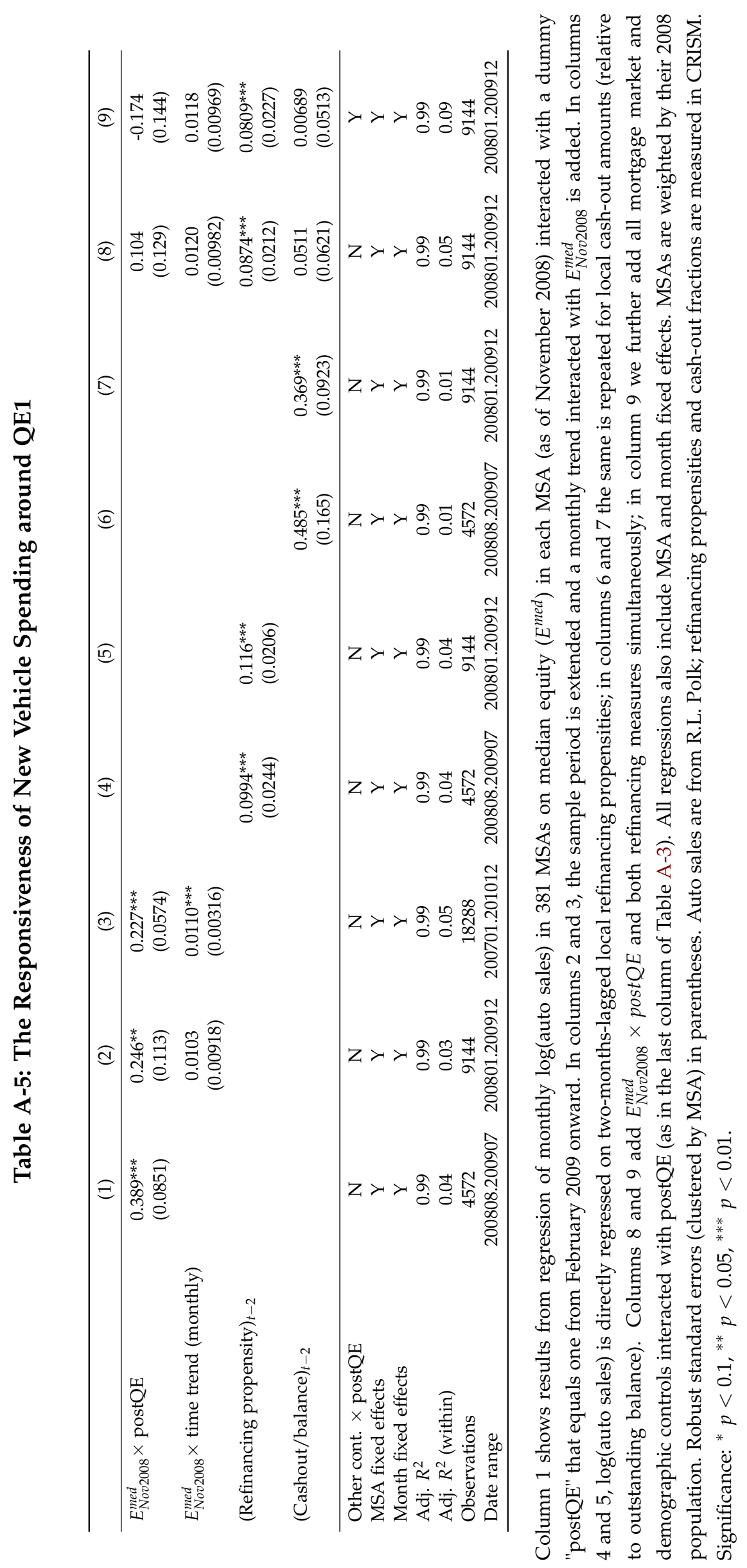


Figure A-1: Mortgage Activity in the US over 2000-2012, Based on HMDA Data

(a): Refinance Mortgage Originations

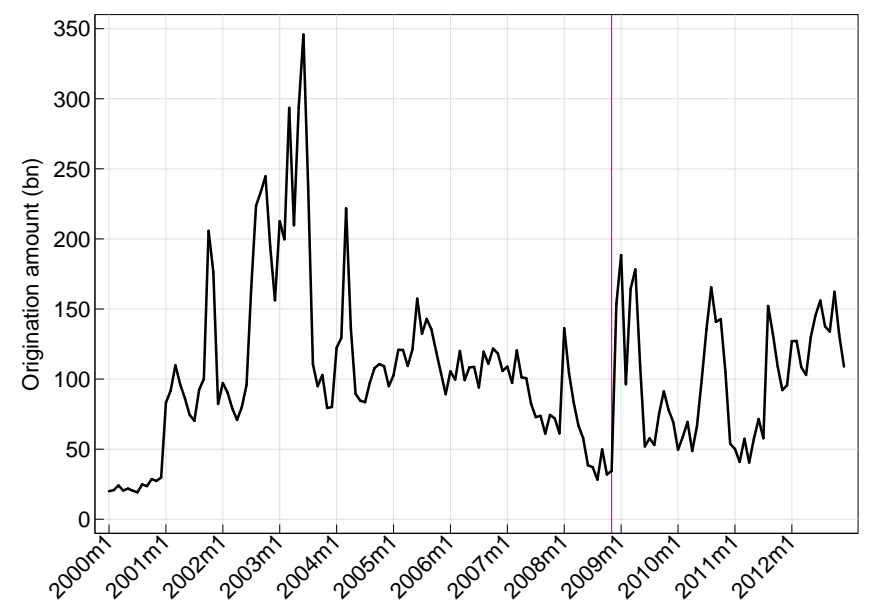

(b): Purchase Mortgage Originations

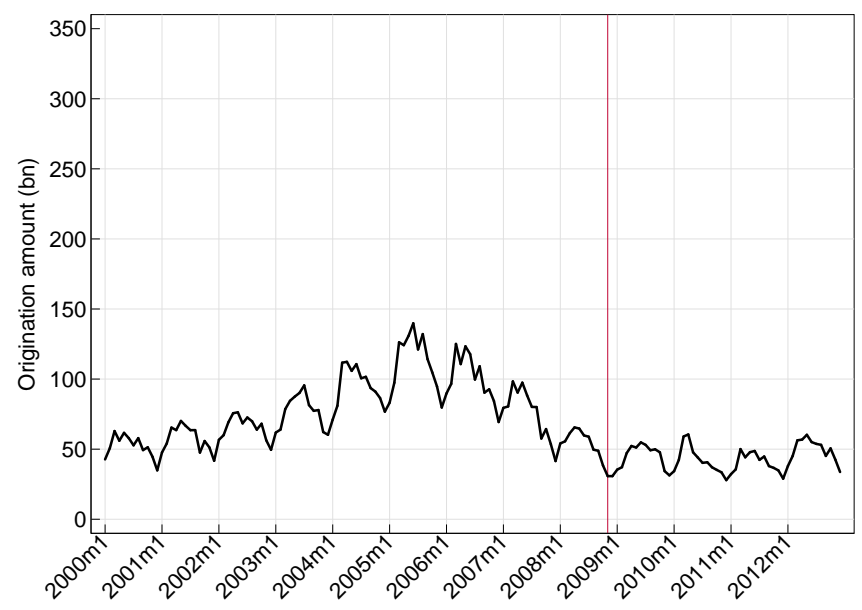

Figure shows mortgage originations on 1-4 unit homes in HMDA, by month in which the borrower applied for the loan. The vertical line indicates the month of the QE1 announcement (November 2008). 
Figure A-2: Median Equity vs. Fraction of Borrowers over CLTV 80 or CLTV 100 Thresholds, as of November 2008.

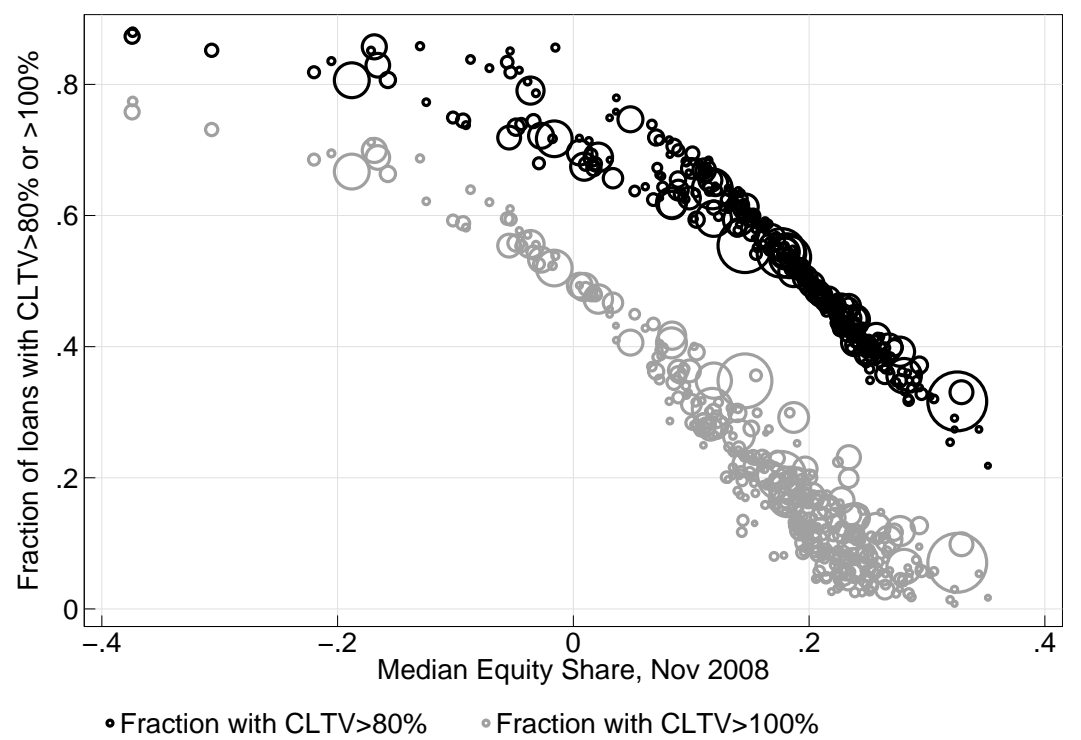

Figure shows the relationship between median equity in an MSA as of November $2008\left(E_{j, N o v 2008}^{\text {med }}\right)$ and the share of borrowers in the MSA who have an estimated CLTV in the same month higher than 80 percent (black circles) or higher than 100 percent (gray circles). Equity/CLTVs are measured based on CRISM. Each observation is an MSA, with 381 in total (per series). The size of the circle represents the 2008 population of the MSA.

Figure A-3: Distributions of Borrowers' Equity in their Homes - MSA Medians and Individual Level

(a): MSA Medians

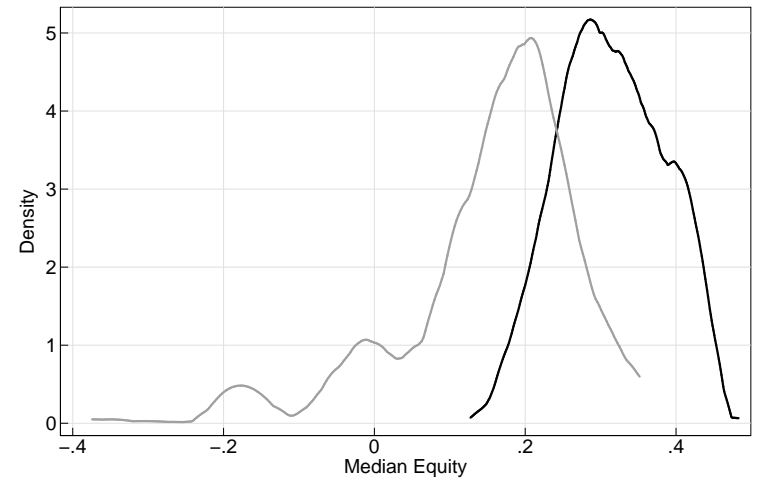

-January 2007 - November 2008 (b): Individual Level

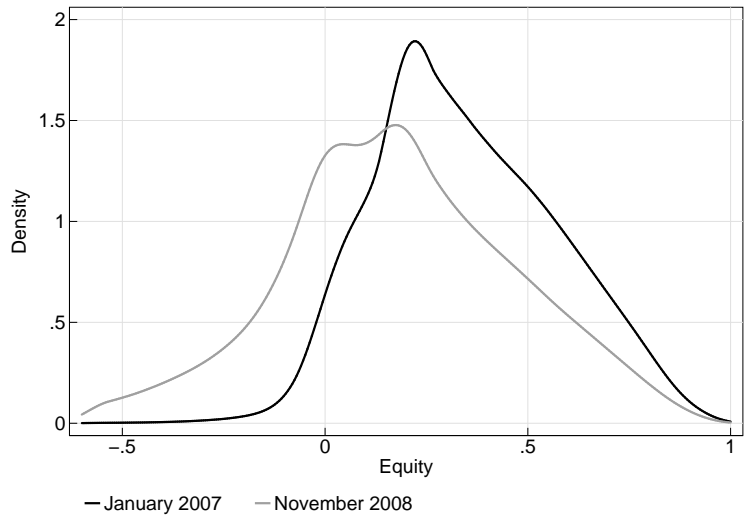

Panel (a) shows kernel density of $E_{j, t}^{\text {med }}$ across 381 MSAs in January 2007 and November 2008; MSAs are weighted by their 2008 population. Panel (b) shows kernel density of individual borrower equity in January 2007 and November 2008 ; borrowers are weighted by loan amount. Individual equity is more disperse than median equity at the MSA level because individual variation has life-cycle and other idiosyncratic components that are large relative to cross-region variation. 


\section{Figure A-4: Relationship between Equity and Other Measures of Economic Activity.}

(a): House Price Growth vs. Median Equity

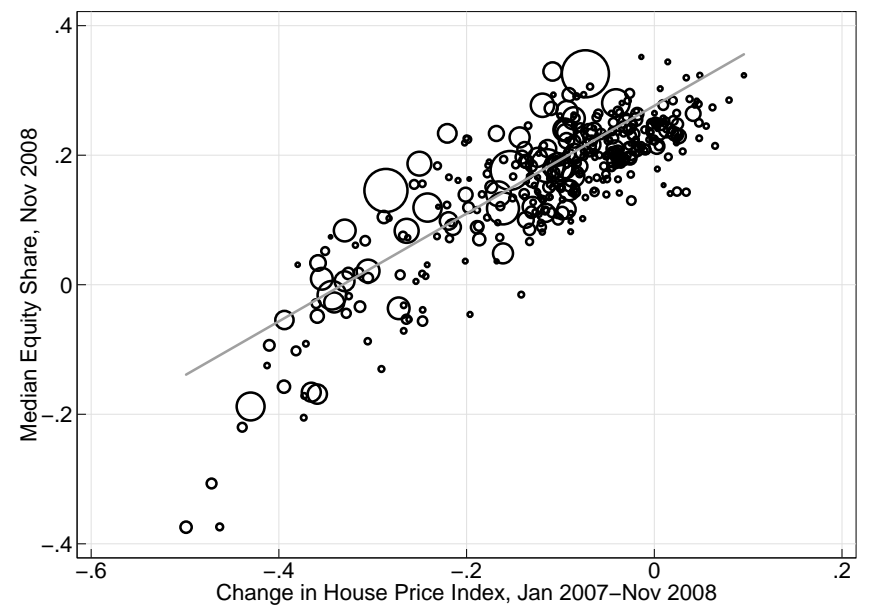

(b): Unemployment Rate Change vs. Median Equity

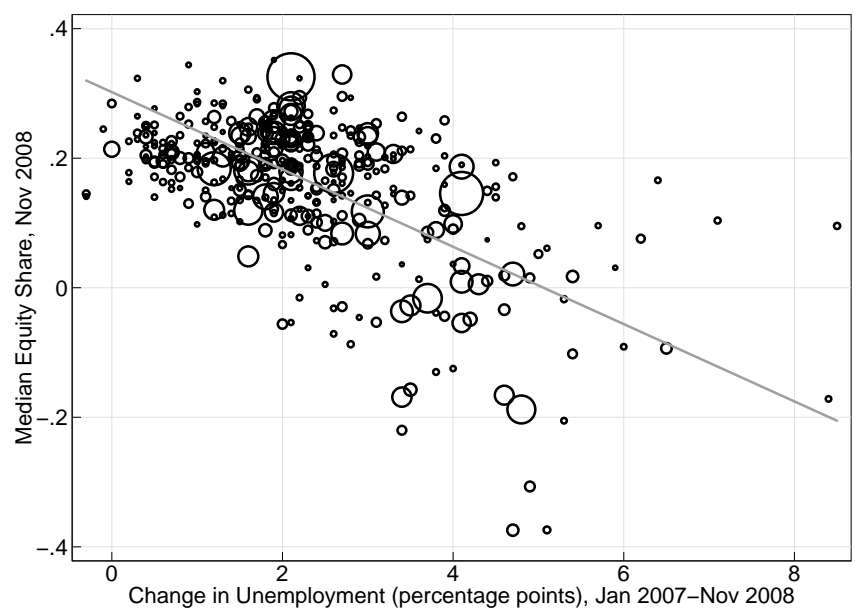

Panel (a) shows MSA house price growth between January 2007 and November 2008 vs. the median borrower's equity (as a share of estimated home value) in the MSA in November 2008. Each observation is an MSA, with 381 in total. The size of the circle represents the 2008 population of the MSA. The figure also shows the simple (population weighted) regression through the scatter plot: a 1 percent decline in house prices is associated with a 0.83 percentage point decrease in median equity (standard error 0.07) with an R-squared of 0.69. Panel (b) shows the change in an MSA's unemployment rate between January 2007 and November 2008 vs. the median borrower's equity (as a share of estimated home value) in the MSA in November 2008. The simple regression line shows that a 1 percentage point increase in the unemployment rate is associated with a 6.0 percentage point decline in median equity (standard error 0.09 ) with an R-squared of 0.36. 
Figure A-5: Mortgage Refinance Activity 2008-2009 in Top and Bottom Quartile of MSAs Defined by Median Equity in November 2008, Based on HMDA Data

\section{(a): Refinance Origination Volumes}

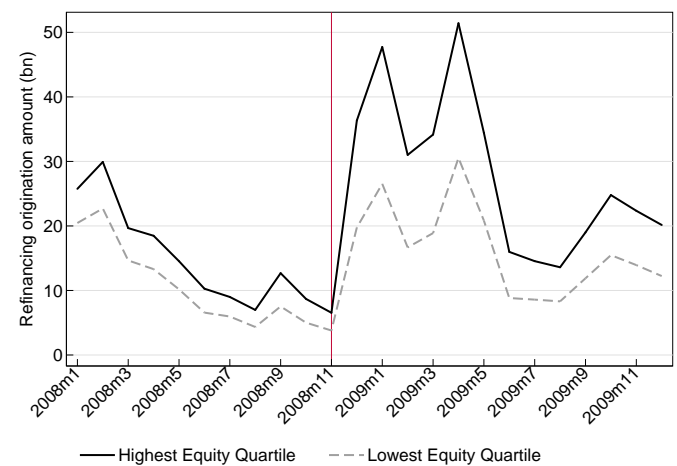

(b): Refinance Propensities

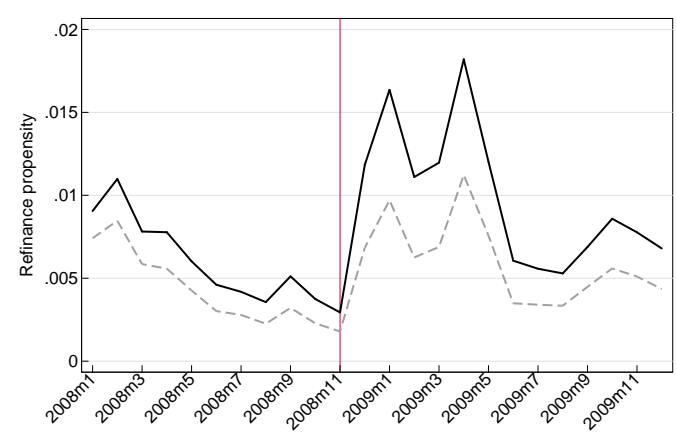

— Highest Equity Quartile _--- Lowest Equity Quartile

\section{(c): Total Origination Volumes (Refinance and Purchase)}

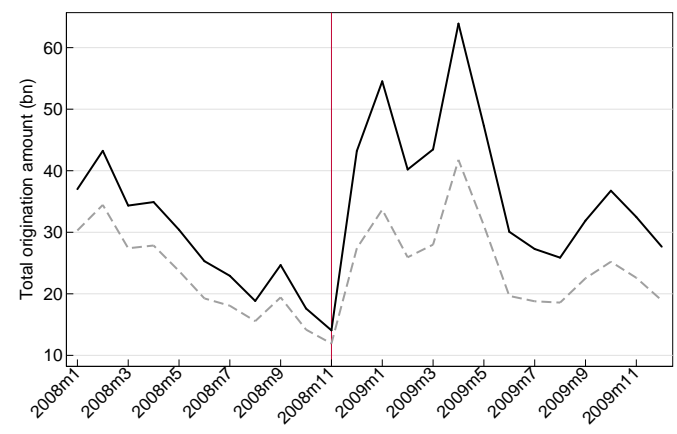

— Highest Equity Quartile - - - Lowest Equity Quartile

Panel (a) shows total mortgage refinance volume in HMDA by month in which borrower applied for the mortgage, where months are redefined such that they start on the 25th day of the prior month. Panel (b) shows corresponding refinance propensities, defined as the number of refinance originations in HMDA divided by the total number of mortgages outstanding as measured in the 2008 American Community Survey. Panel (c) shows total mortgage origination volume (purchase and refinance) in HMDA by month in which borrower applied for the mortgage. In all three panels, calculations are done at the level of MSA quartile groups and vertical lines indicate the month of the QE1 announcement (November 2008). 


\section{Figure A-6: No Spatial Variation in Mortgage Interest Rates}

\section{(a): Raw Interest Rates by Equity Quartile}

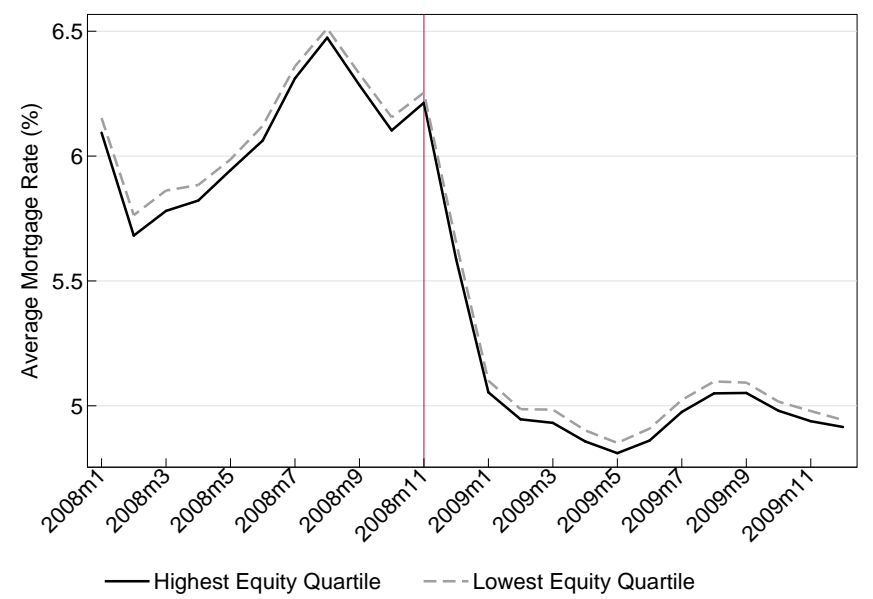

(b): Interest Rate Gaps After Controlling for Observables

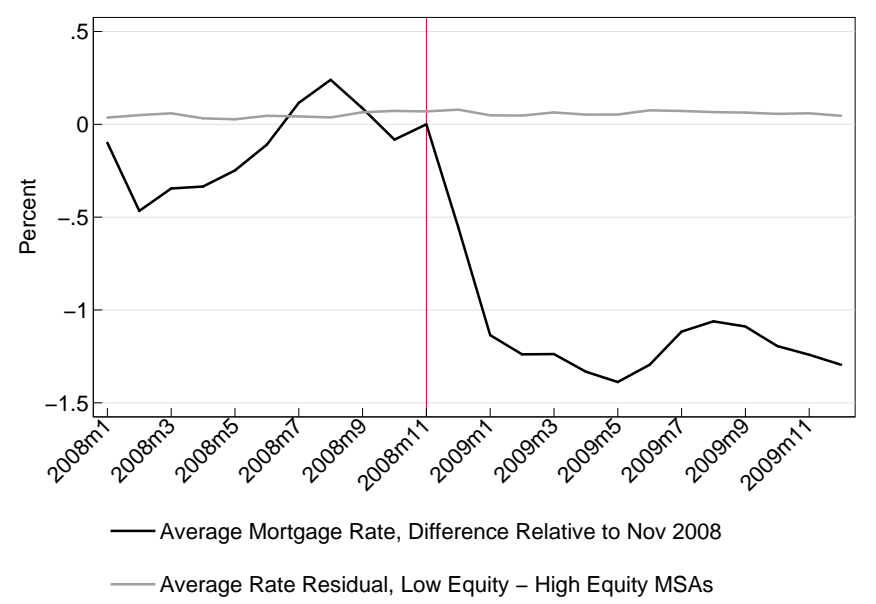

Panel (a) shows average interest rate on newly originated non-purchase mortgages in CRISM in the top and bottom MSA quartiles by $E_{j, N o v 2008}^{m e d}$, showing that the evolution of mortgage rates was almost identical across locations. In panel (b), the black line shows the difference in the average interest rate on newly originated mortgages relative to its level in November 2008. The gray line shows the gap between average rate residuals in the top and bottom MSA quartiles by $E_{j, \text { Nov2008 }}^{\text {med }}$ Rate residuals are obtained following Hurst et al. (2016), by regressing each newly originated mortgage's interest rate on quadratic functions of FICO and LTV, and dummies for different loan purposes (purchase, rate refi, cashout refi, unknown), all interacted with month dummies. The gap averages only around 5 basis points over our sample and does not increase after QE1. 
Figure A-7: 2009 Distributions of PTI and CLTV for Top and Bottom Quartile of MSAs Defined by Median Borrower Equity in November 2008

(a): PTI (2009)

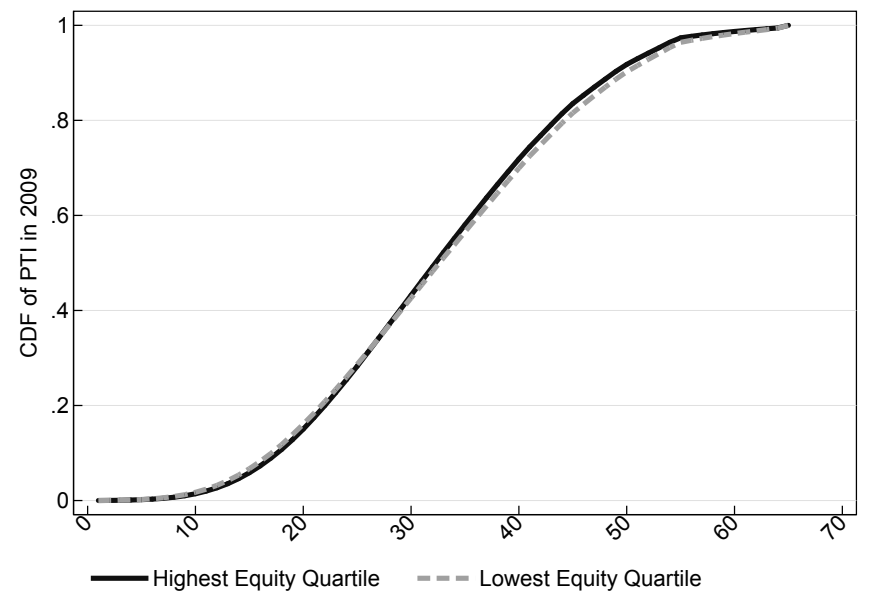

(b): CLTV (2009)

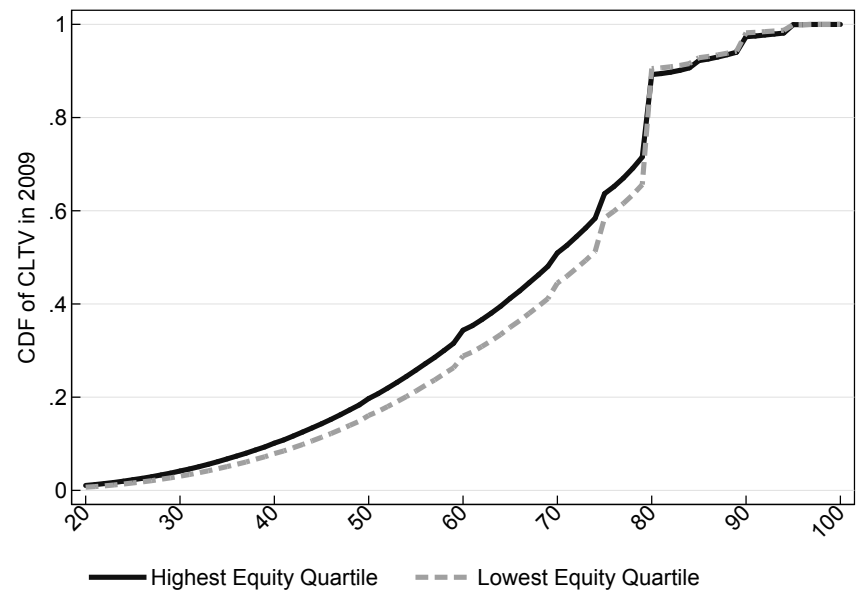

Figure shows the distribution of PTI and CLTV at origination in high and low equity MSA groups for loans originated in 2009 using the pooled sample of loans acquired by Fannie Mae and Freddie Mac in Single Family Loan Performance (SFLP) Data. In total, we observe $1,886,365$ originations in the highest equity quartile and 1,514,085 originations in the lowest equity quartile. We set the 48,537 loans with missing PTI equal to 0.65 since SFLP does not report PTI above 0.65 , but results are similar when instead excluding these loans. Panel (a) shows that the distribution of PTI exhibits little bunching and is similar in both high and low equity MSAs (as listed in Appendix A.1). Panel (b) shows that the distribution of CLTV (for the flow of new mortgages in SFLP) exhibits substantial bunching and that CLTVs on newly originated loans tend to be higher in MSAs where borrowers have less equity in outstanding mortgages (as measured in CRISM).

Figure A-8: Evolution of Non-Housing Debt for Top and Bottom Quartile of MSAs Defined by Median Borrower Equity in November 2008

(a): Non-Housing Debt per Person

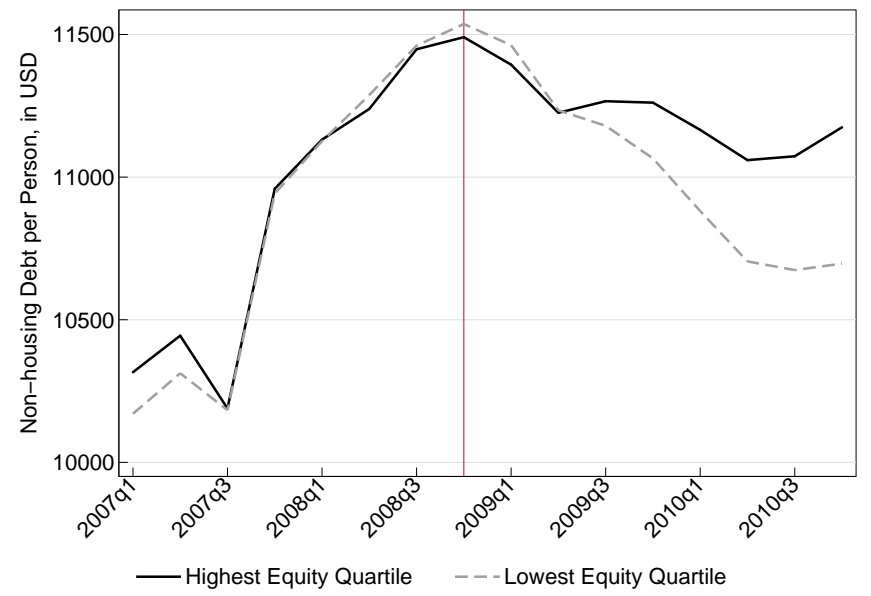

(b): Quarterly Change

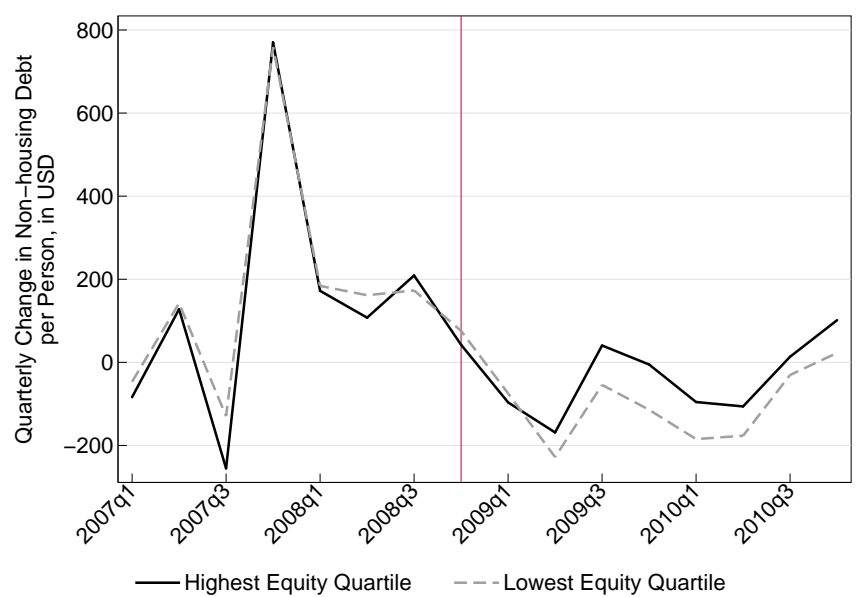

Figure shows level (panel (a)) and quarterly change (panel (b)) of non-housing debt per person in the FRBNY Consumer Credit Panel in the top and bottom MSA quartiles by $E_{j, N o v 2008}^{m e d}$. Non-housing debt includes auto loans, credit card balances, student loans, consumer finance loans (sales financing, personal loans), retail loans (department stores, home furnishings, gas, etc.), and unspecified "other" loans. 
Figure A-9: Estimated Cash-out Amounts from Freddie Mac vs. in our CRISM data

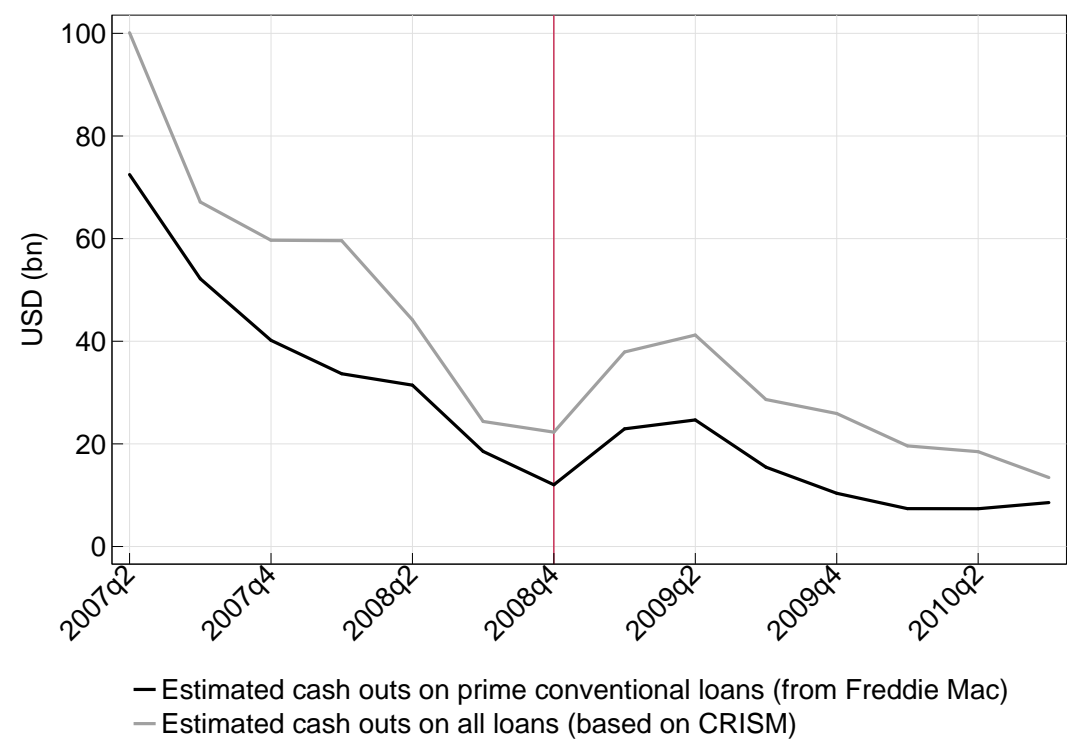

Figure shows estimated quarterly cash-out volumes on prime conventional (non-government) mortgages estimated by Freddie Mac (obtained from http://www.freddiemac.com/finance/docs/q4_refinance_2014.xls), as well as those we obtain based on the CRISM data (which also include FHA/VA loans) after scaling up as explained in Section A.2.3.

Figure A-10: 2008 Household Equity Distribution: Model vs. Data

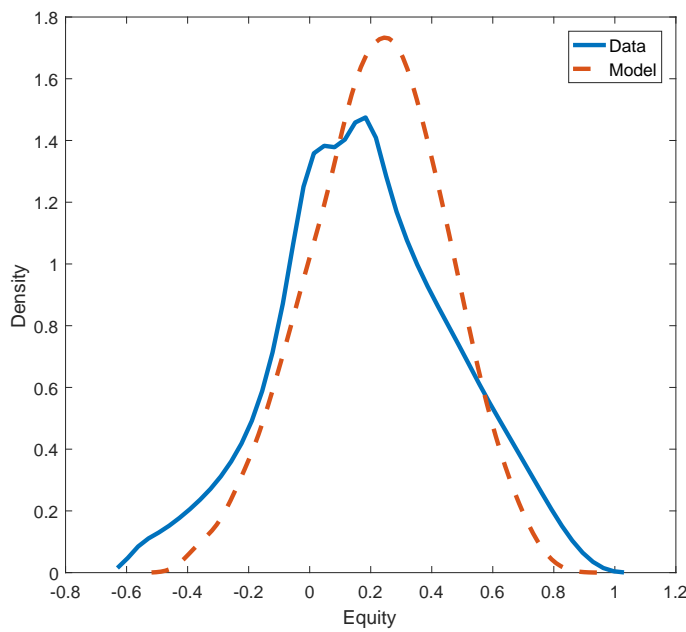

This figure compares the household level density of equity in 2008 with no reduction in interest rates to the empirical distribution just prior to QE1 in November 2008. 
Figure A-11: Relationship between Refinancing Threshold, Equity and Income

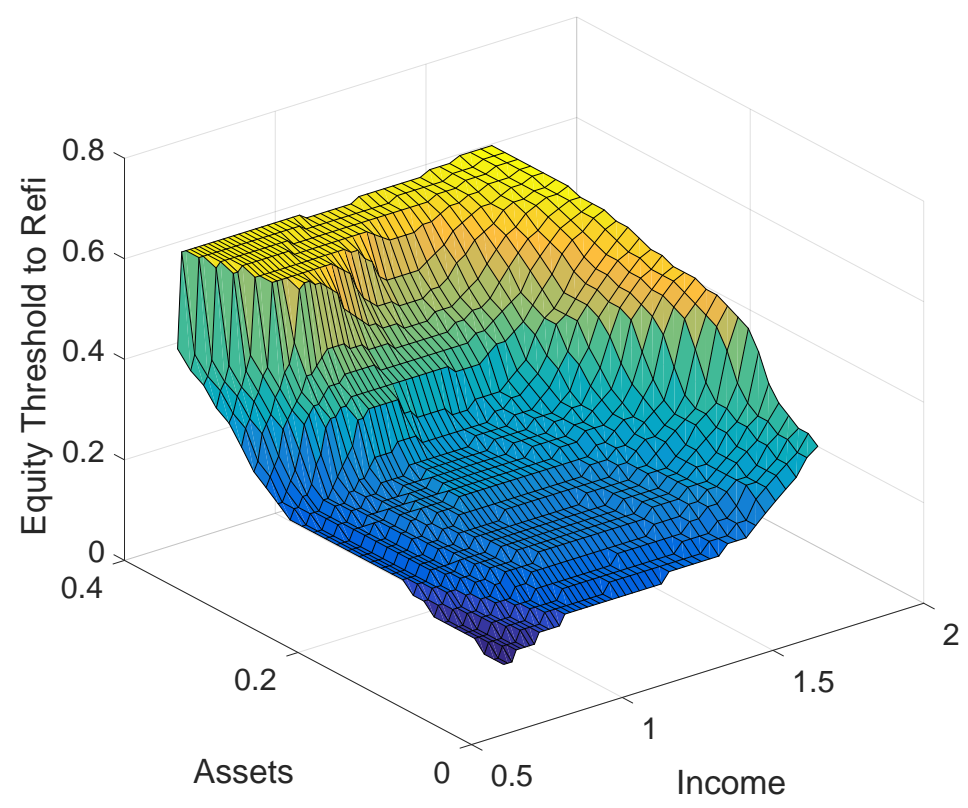

Figure shows refinancing threshold for each asset and income value for low fixed cost.

Figure A-12: Borrower and Lender Contribution to Aggregate Consumption Impulse

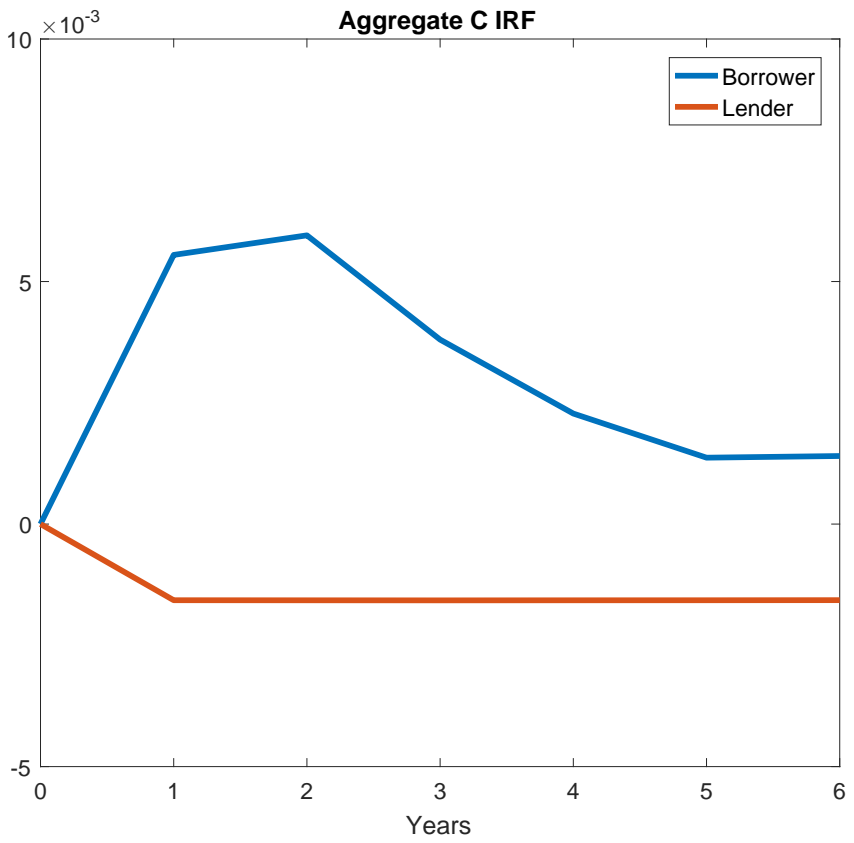

Figure shows the separate contributions of borrowers and lenders to the aggregate consumption impulse response in the 2008 baseline model shown in Figure 11. 


\section{Figure A-13: Importance of GE Effects from Lenders' Consumption}

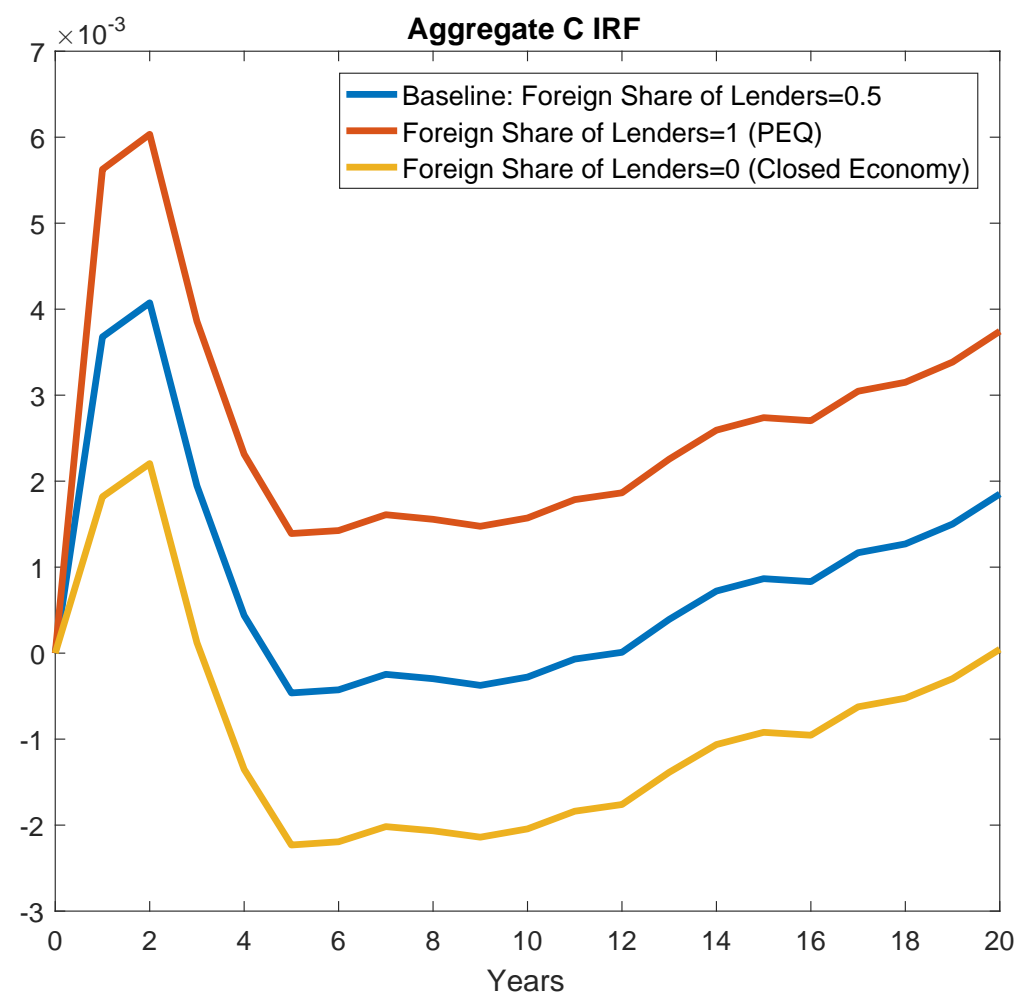

This figure shows aggregate consumption IRFs for alternative assumptions on what share of mortgage debt is held by domestic households, whose income will fall when interest rates decline. 
Figure A-14: Effect of $\sigma$ on $\Delta I R F_{f_{0}(\mu, \sigma)}$

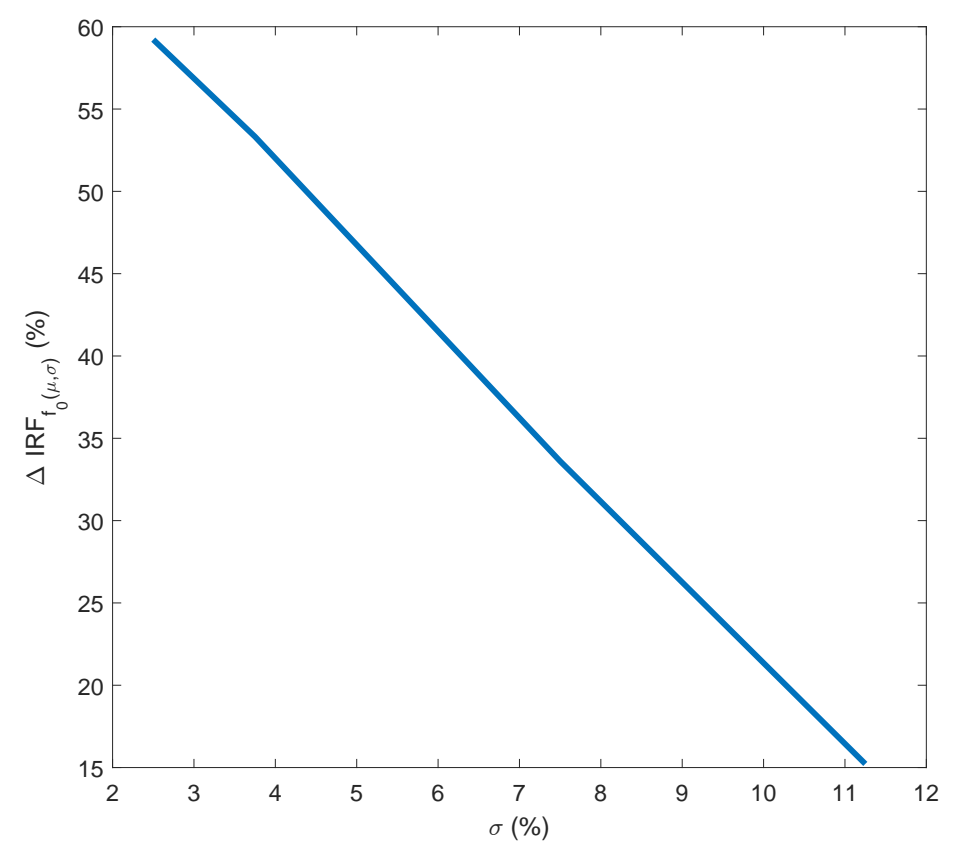

Figure shows how much a $10 \%$ increase in equity changes the aggregate consumption response to a $1 \%$ decrease in $r^{m}$, for different values of the cross-region standard deviation of equity. Let $I R F_{f_{0}(\mu, \sigma)}=\frac{\Delta C}{\Delta r^{m}}$ be the response on impact (in the first year) of consumption to a $1 \%$ decline in interest rates given an initial equity distribution $f_{0}$ with mean $\mu$ and standard deviation $\sigma$. Then let $\Delta I R F_{f_{0}(\mu, \sigma)}=\frac{I R F_{f_{0}(\mu+10, \sigma)}-I R F_{f_{0}(\mu, \sigma)}}{I R F_{f_{0}(\mu, \sigma)}} . \Delta I R F_{f_{0}(\mu, \sigma)}$ measures how a 10 percentage point increase in the mean of the equity distribution affects the impulse response of consumption to interest rates. This figure plots $\Delta I R F_{f_{0}(\mu, \sigma)}$ as we change the cross-region standard deviation of equity $\sigma$. The leftmost point in the figure sets $f_{0}(\mu, \sigma)$ equal to the stochastic steady-state distribution, and then we steadily increase the cross-region standard deviation of equity. In the stochastic steadystate with $\sigma=2.5 \%$, a $10 \%$ increase in house prices increases the aggregate consumption response to a $1 \%$ rate decline by almost $60 \%$. However, when $\sigma$ is higher, this same mean increase in house prices has a smaller effect on the response of consumption to a rate drop. 
Figure A-15: Adjustable-Rate Mortgage Shares pre-QE1 and Payment Reductions over Nov 2008 June 2009

(a): ARM Shares vs. Median Equity

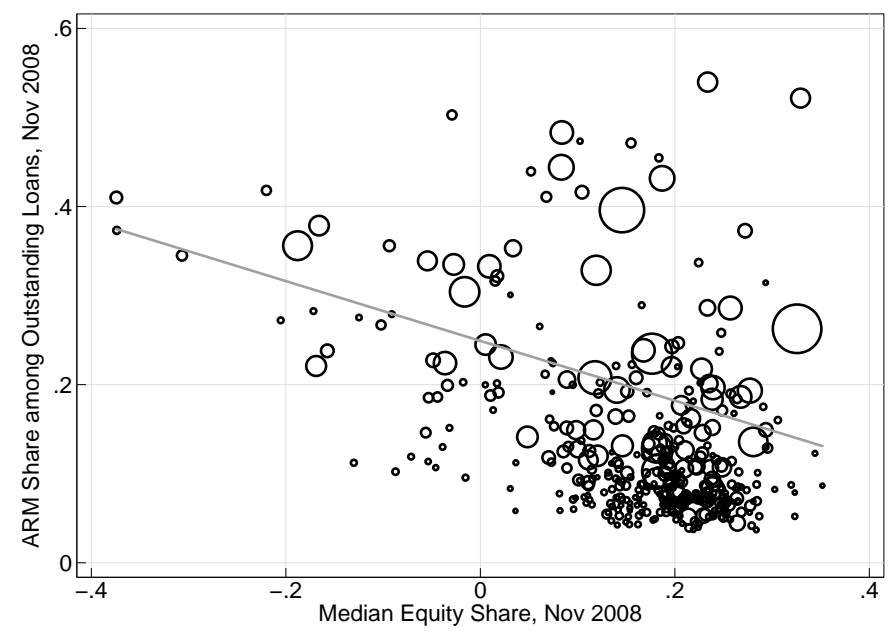

(b): Sizeable ARM Payment Reductions vs. Median Equity

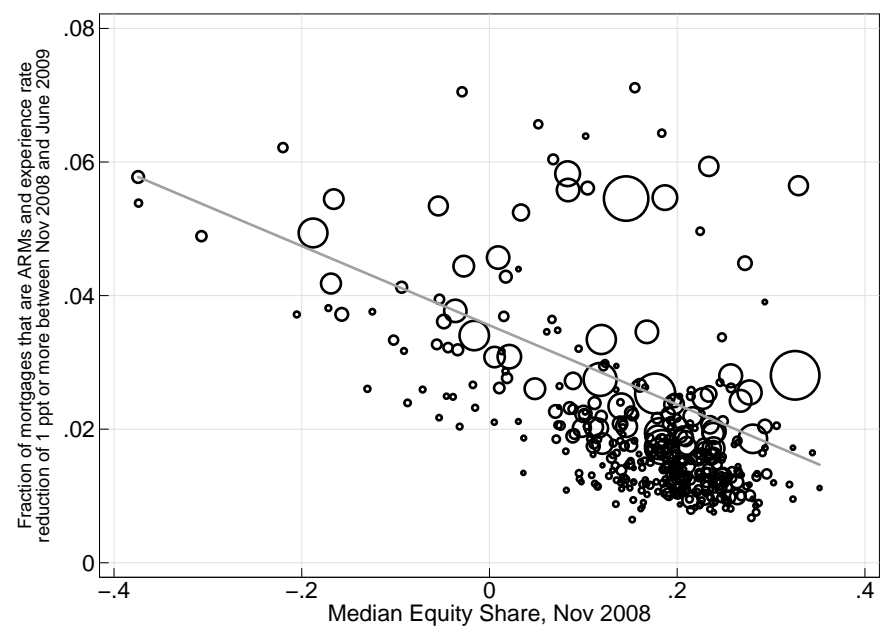

Figure shows scatter plots of the balance-weighted fraction of adjustable-rate mortgages (ARMs) in a given MSA (panel a) or the balance-weighted fraction that are ARMs and experience a rate reduction of 1 percentage point or more over November 2008 - June 2009 (panel b), as measured in the CRISM data, versus the median equity share ( $E^{\text {med }}$ ) within the MSA as of November 2008. When computing the share with rate drops, we also require that the recorded required monthly payment not increase over the same period (which may indicate that the loan's IO period expired). The size of the circle represents the 2008 population of the MSA. The gray lines represent simple regression lines fitting the scatter plot (population weighted). The regression line in panel $(\mathrm{b})$ has a slope of -0.059 (s.e. $=0.009)$. Meanwhile, regressing the 6-month refinancing propensity (from January-June 2009) on $E_{j, \text { Nov2008 }}^{\text {med }}$ yields a coefficient of +0.147 (s.e. $=0.028$ ). 
Figure A-16: Accounting for Ex-Ante Heterogeneity

(a): Match ARM-Share
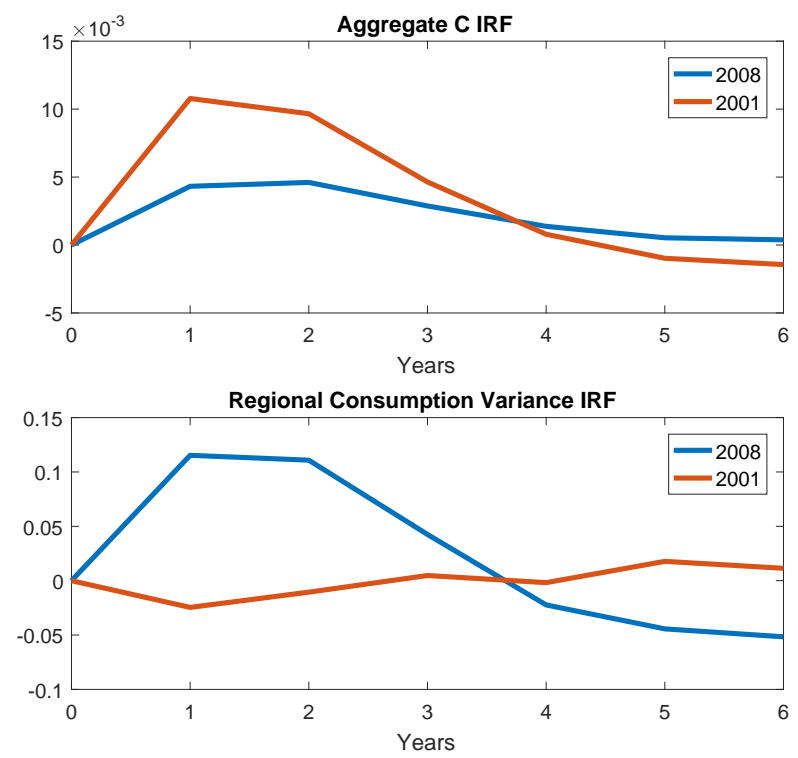

(c): Reduce Equity-Refi Elasticity
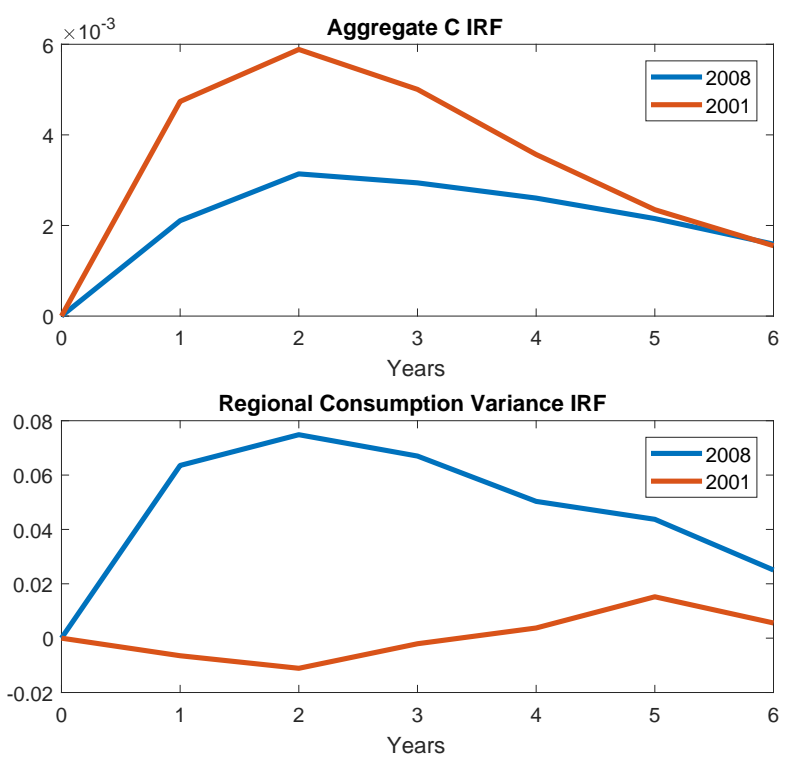

(b): Spending responses of ARM vs. FRM borrowers
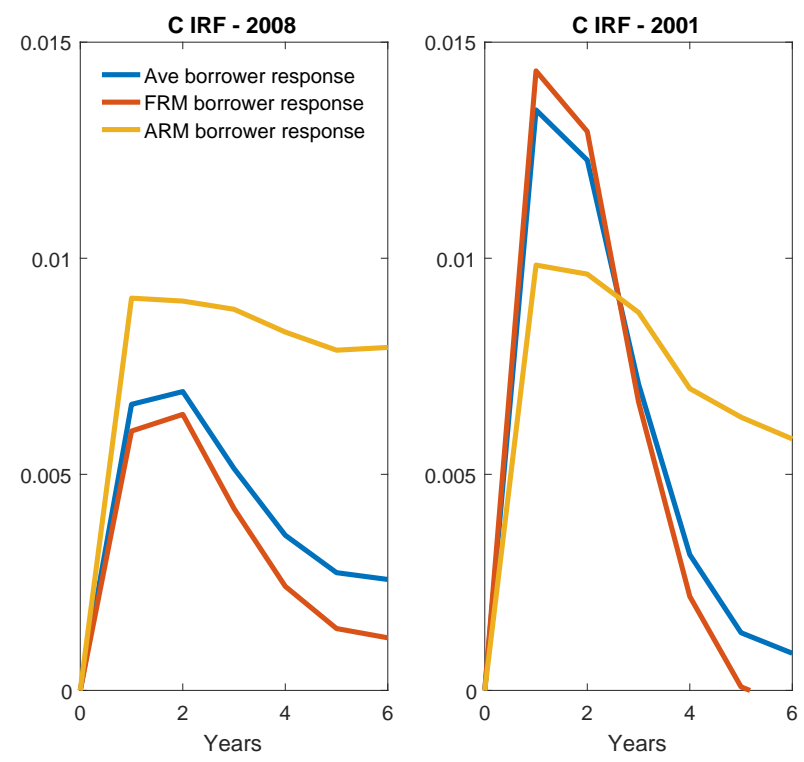

(d): Boom-Bust
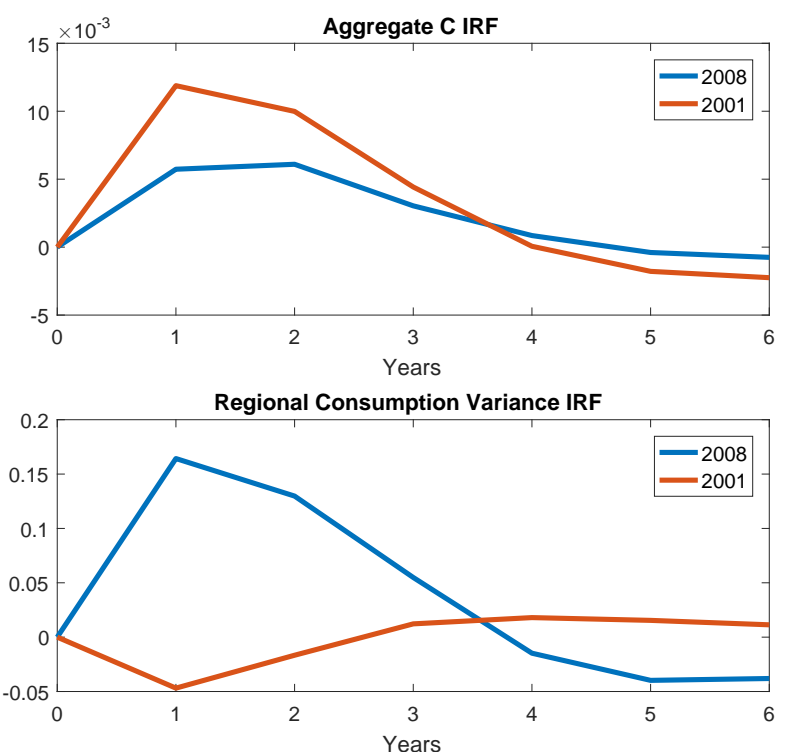

Panel (a) repeats Figure 11 in a model with both FRM and ARMs calibrated to match the regional differences with house prices in the data. Panel (b) shows the average spending response of ARM borrowers, FRM borrowers and their shareweighted averages in 2008 compared to 2001. Note that the share-weighted average borrower average is not identical to the aggregate spending response since it includes no lender responses. Panel (c) repeats Figure 11 in a model where fixed costs are doubled. This roughly halves the relationship between regional equity and refinancing. Panel (d) repeats Figure 11 in a model where regions with the largest house price declines experience a prior house price boom. 


\section{Figure A-17: Robustness Results}

(a): Relaxing Full Cash-out Assumption
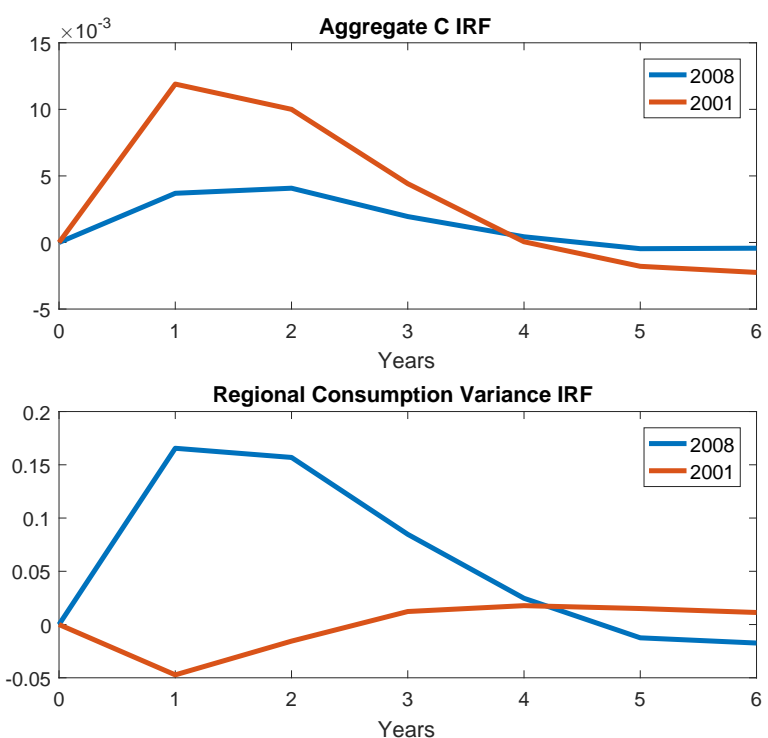

(c): Reduce $r$ and $r^{m}$
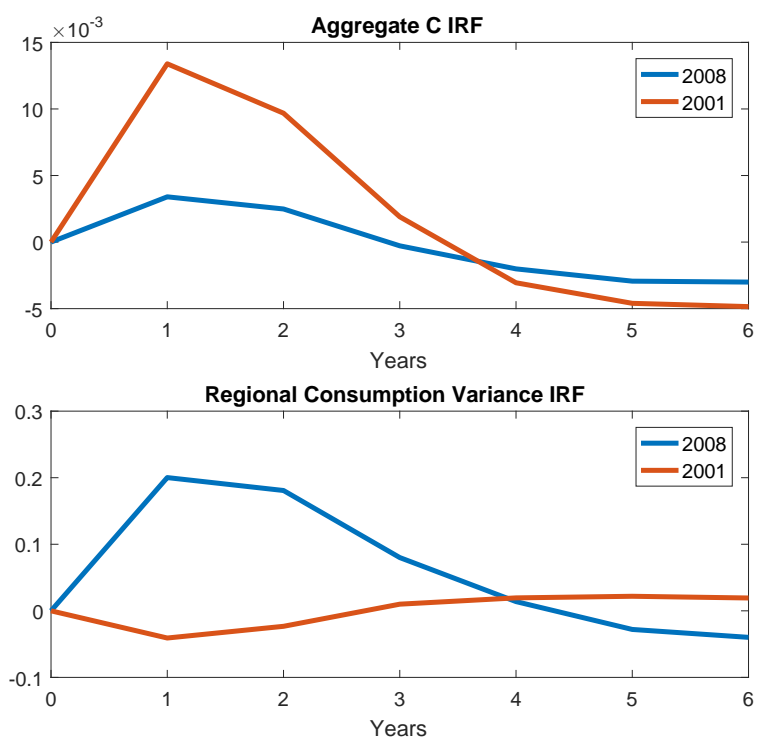

(b): Stochastic Mortgage Rate
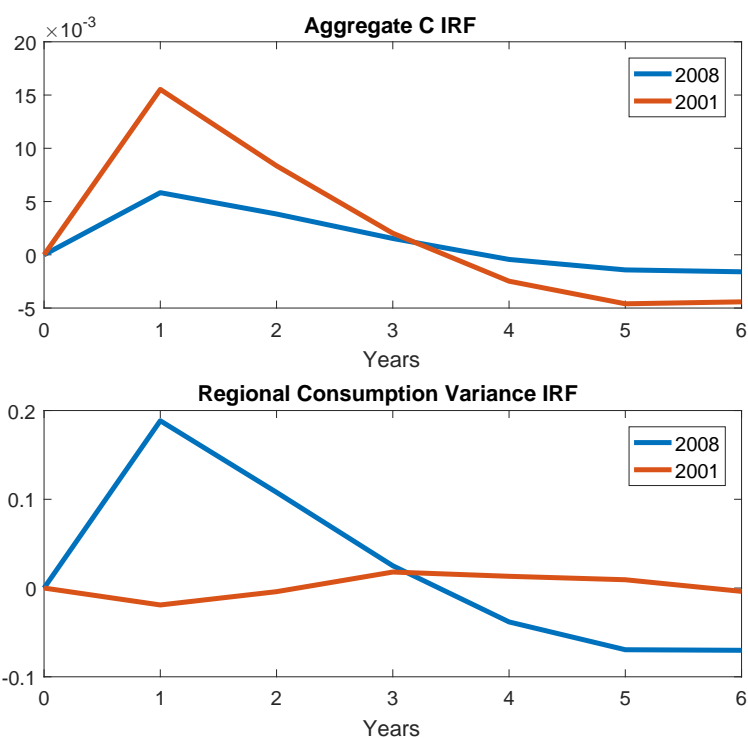

(d): Reduce only $r$
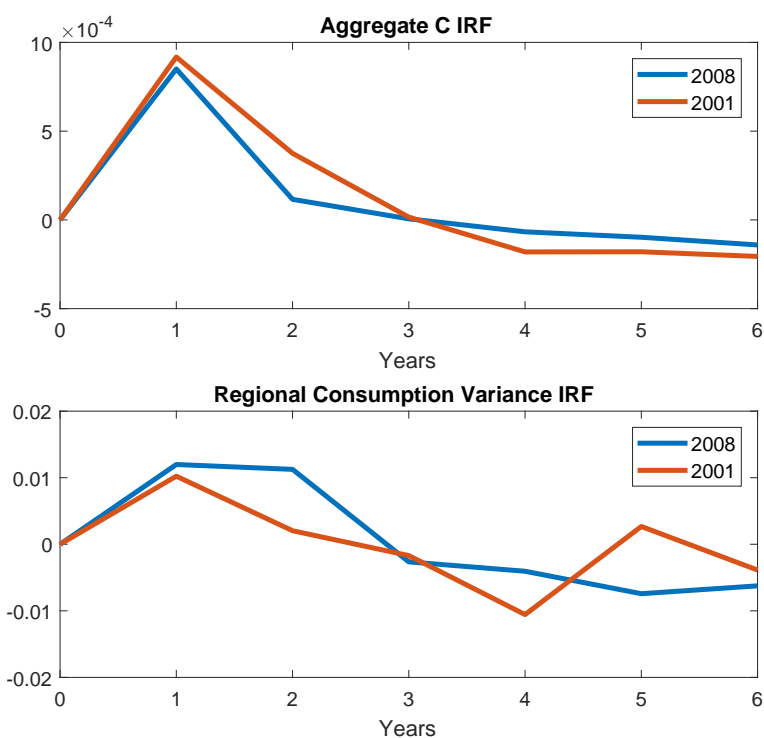

This figure repeats Figure 11 in several alternative models. In panel (a) households can choose between full cash-out and no cash-out refinancing. In panel b) interest rate movements are stochastic instead of a one-time shock. In panel (c) $r$ and $r^{m}$ both decline, with a constant spread. In panel (d), only $r$ declines. 
Figure A-18: More Robustness Results

(a): Include temporary income shocks
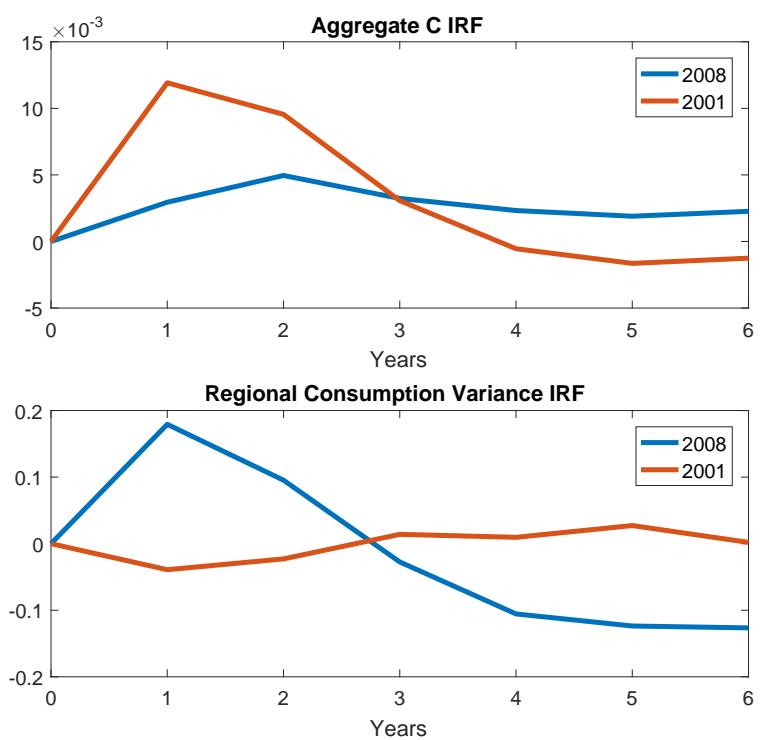

(b): Correlated income and hp shocks
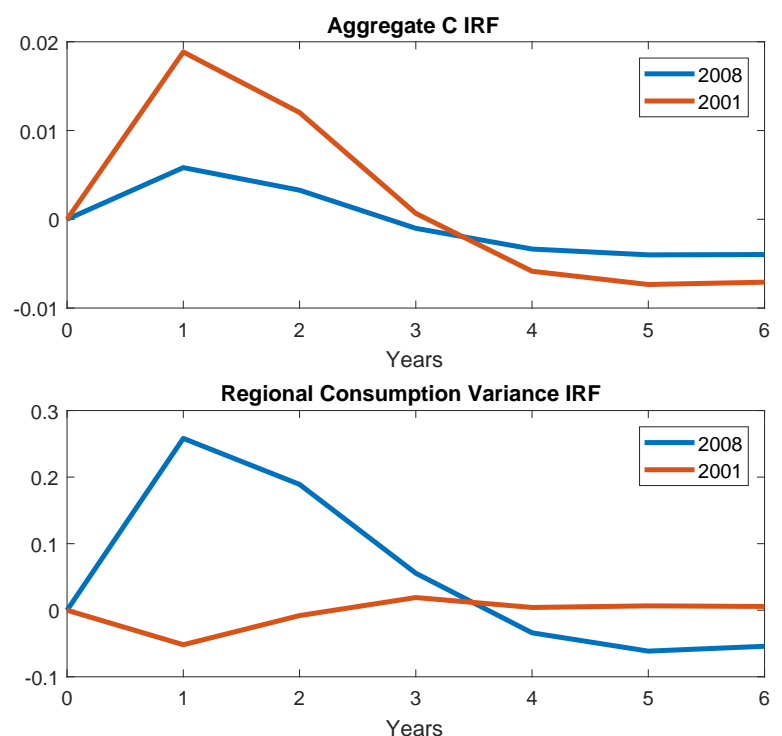

(c): Double House Price Growth
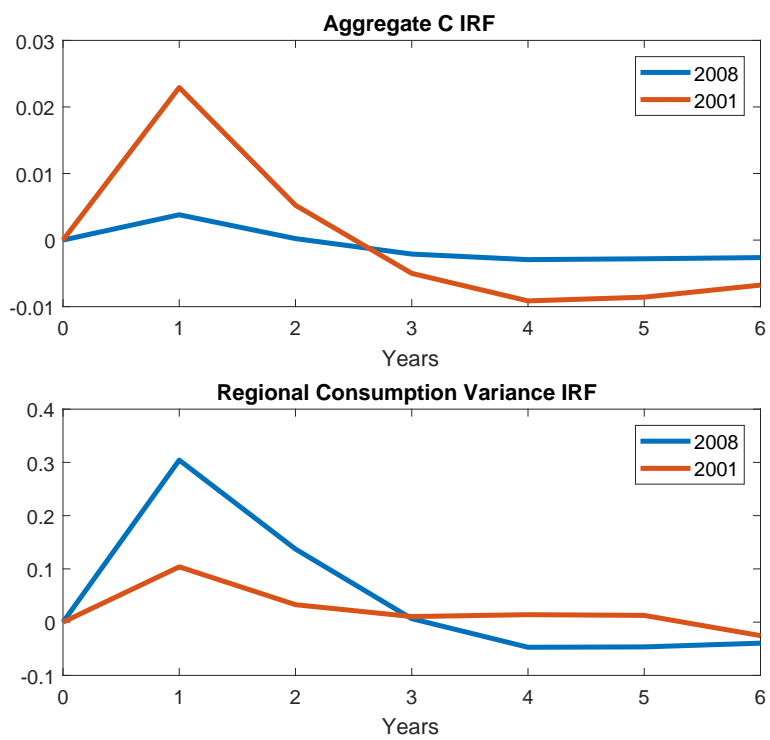

This figure repeats Figure 11 in several alternative models. In panel (a) households experience i.i.d. transitory income shocks. In panel (b), regional house price and income shocks are perfectly correlated instead of uncorrelated. In panel (c) trend house price growth is doubled. 